\title{
Administrative Obstacles to Technology Use in West Virginia Public Schools: A Survey of West Virginia Principals
}

David W. Agnew

West Virginia University

Follow this and additional works at: https://researchrepository.wvu.edu/etd

\section{Recommended Citation}

Agnew, David W., "Administrative Obstacles to Technology Use in West Virginia Public Schools: A Survey of West Virginia Principals" (2011). Graduate Theses, Dissertations, and Problem Reports. 3538.

https://researchrepository.wvu.edu/etd/3538

This Dissertation is protected by copyright and/or related rights. It has been brought to you by the The Research Repository @ WVU with permission from the rights-holder(s). You are free to use this Dissertation in any way that is permitted by the copyright and related rights legislation that applies to your use. For other uses you must obtain permission from the rights-holder(s) directly, unless additional rights are indicated by a Creative Commons license in the record and/ or on the work itself. This Dissertation has been accepted for inclusion in WVU Graduate Theses, Dissertations, and Problem Reports collection by an authorized administrator of The Research Repository @ WVU.

For more information, please contact researchrepository@mail.wvu.edu. 
Administrative Obstacles to Technology Use in West Virginia Public Schools:

A Survey of West Virginia Principals

David W. Agnew

Dissertation submitted to the

College of Human Resources and Education

at West Virginia University

in partial fulfillment of the requirements

for the degree of

Doctor of Education

in

Educational Leadership Studies

Paul Chapman, Ph.D., Chair

Richard Walls, Ph.D.

Mark Manchin, Ed.D.

Neal Shambaugh, Ph.D.

Ted Price, Ph.D.

Department of Educational Leadership Studies

Morgantown, West Virginia

2011

Keywords: Technology; Administration; Education; Computers; Obstacles;

Perceptions; West Virginia; Staff Development; Technology Trends;

Technology Integration Specialist

Copyright 2011 David W. Agnew 


\begin{abstract}
Administrative Obstacles to Technology Use in West Virginia Public Schools: A Survey of West Virginia Principals
\end{abstract}

David W. Agnew

Public school principals must meet many challenges and make decisions concerning financial obligations while providing the best learning environment for students. A major challenge to principals is implementing technological components successfully while providing teachers the 21st century instructional skills needed to enhance students ' utilization of technology. For this study, technology consisted of areas related to infrastructure (facilities, hardware, software, funding), social issues (staffing, staff development, principals' motivation, teacher and student perceptions), and policy affecting how principals implement technology in elementary, middle, and high school environments. These areas of technology are greatly impacted through the administrative decision making process. School systems across the United States spend millions of dollars on technology (Monk, Pijanowski, \& Hussain, 1997). Research shows there is little assistance to principals on how to implement and maintain this technology.

Four research questions will be answered:

1. What technology support do West Virginia principals provide to teachers?

2. Who do West Virginia principals rely on to provide technology support when unable to do so themselves?

3. What facilitates principals‘ implementation of technology in West Virginia public schools?

4. What impedes principals' implementation of technology in West Virginia public schools?

This quantitative study measured perceptions of principals implementing technology in West Virginia public schools. Six hundred and thirty-five emails delivered through Survey Monkey returned an overall response rate of $38.4 \%$ from the three groups of principals, elementary, middle, and high school. Representation from all fifty-five West Virginia counties existed for this study. A brief history of technology beginning in the early 1980s included in chapter two demonstrates West Virginia's successful implementation of technology into public schools. This background builds the context of technology use for principals attempting to establish 21 st century skills in West Virginia public schools through the implementation process of technology. A brief history of national technology trends in chapter two also suggests that the obstacles for West Virginia principals exist across the country.

Approximately $76 \%$ of West Virginia principals responding to this study had less than fifteen years experience as a principal. Over $95 \%$ had been involved in some type of technology training. The data support the importance of a strong technological principal to enhance the implementation process of technology in West Virginia public schools.

Lack of technical support to maintain existing technology in public schools is one of the biggest obstacles for West Virginia principals according to this study. The Technology Integration Specialist (TIS) plays a very positive role in successfully implementing technology; however, only $20.8 \%$ of the principals responding have access to a TIS. Over $79 \%$ of the principals agreed that lack of technical support is an obstacle. 
According to West Virginia principals, obstacles exist that impede the technology implementation process. The research also provides several areas that facilitate the implementation process of technology and recommendations that may provide support to West Virginia public school principals. 


\section{Acknowledgements}

No work is accomplished alone, no matter how great or how trivial. I wish to acknowledge the support and patience of several personal and professional individuals that have been by my side throughout this entire process.

First, I would like to thank God for giving me the ability to complete this process. Many prayers for patience, knowledge, and time have been answered. My wife, Kristine, has been my motivation and best friend throughout this process. I appreciate the support of my family, their patient consideration while I was working at home, and their understanding of my absences.

A deeply felt thank you goes to Dr. Paul Chapman, my chair, for the guidance, support, and true friendship that developed throughout the dissertation process. He appreciates life and the importance of focusing on the challenge, but without sacrificing life's treasures granted by God during the process. Thanks also to my committee members and their support during this process.

This process has been a true experience, endeavor, and challenge to enhance my personal ability to provide a better education to children and adults. One more thank you goes to the individuals that started this process along side of me: those who completed the process as well as those who are still moving along. Many of our conversations focused on issues in education. I have learned that many minds working together are much stronger than a solitary scholar. 


\section{Table of Contents}

\section{Abstract}

Acknowledgements

Table of Contents

\section{Chapter One: Introduction}

Research Justification

Statement of Purpose

Research Questions

Research Design

Definition of terms

Organization of Document

Chapter Two: Review of Literature 11

History of Technology in West Virginia Public Education 12

The Principal's Role $\quad 26$

$\begin{array}{ll}\text { Leadership and Vision } & 27\end{array}$

$\begin{array}{ll}\text { Learning and Teaching } & 27\end{array}$

$\begin{array}{ll}\text { Productivity and Professional Practice } & 28\end{array}$

Support, Management and Operations 28

Assessment and Evaluation $\quad 29$

Social, Legal and Ethical issues $\quad 29$

Obstacles Principals Encounter Implementing Technology 30

$\begin{array}{ll}\text { Infrastructure } & 30\end{array}$

Facilities 31

Hardware 33

Software $\quad 35$

$\begin{array}{ll}\text { Funding } & 38\end{array}$

Social Issues $\quad 39$

Staffing of Technology Positions 41

$\begin{array}{ll}\text { Professional Development } & 44\end{array}$ 
$\begin{array}{ll}\text { Principals‘ Technological Motivation } & 48\end{array}$

Teacher and Student Perspectives 53

Technology Policy 56

21st Century Skills in West Virginia and Technology 57

West Virginia Governor's Council for Technology in Education $\quad 60$

Results of Basic Skills Program $\quad 63$

West Virginia Technology Integration Specialist 63

West Virginia Policies Relating to Educational Technology $\quad 70$

$\begin{array}{ll}\text { National Technology Trends in Education } & 74\end{array}$

Research Findings: Bakia, Mitchell, and Yang 83

$\begin{array}{ll}\text { Chapter Three: Method } & 85\end{array}$

Research Design $\quad 86$

$\begin{array}{ll}\text { Research Participants } & 87\end{array}$

Table 1: Representation of West Virginia Principals 88

$\begin{array}{ll}\text { Survey Development } & 90\end{array}$

Web Surveys 93

$\begin{array}{ll}\text { Reliability and Validity } & 94\end{array}$

$\begin{array}{ll}\text { Panel of Experts } & 95\end{array}$

$\begin{array}{ll}\text { Pilot Study } & 98\end{array}$

$\begin{array}{ll}\text { Data Collection } & 99\end{array}$

$\begin{array}{ll}\text { Data Analysis } & 100\end{array}$

$\begin{array}{ll}\text { Summary } & 104\end{array}$

$\begin{array}{ll}\text { Chapter Four: Research } & 106\end{array}$

$\begin{array}{ll}\text { Research Findings } & 106\end{array}$

Table 2: Nine Significant Items 107

$\begin{array}{ll}\text { Organization of Data Analysis } & 108\end{array}$

Presentation of Descriptive Characteristics of Respondents 109

Table 3: Survey Response by Group $\quad 110$

Table 4: Representation of West Virginia Counties 110 
Table 5: WV Principals‘ Experience

Table 6: WV Principals` Technology Training

Table 7: Types of Training

Table 8: Research Question 1, Survey Question 9, Item 5

Table 9: Research Question 2, Survey Question 10, Item 5

Table 10: Research Question 2, Survey Question 10, Item 8

Table 11: Research Question 2, Survey Question 10, Item 10

Table 12: Research Question 3, Survey Question 16, Item 3

Table 13: Research Question 4, Survey Question 18, Item 9

Table 14: Research Question 4, Survey Question 18, Item 11

Table 15: Research Question 4, Survey Question 19, Item 2

Table 16: Research Question 4, Survey Question 20, Item 5

Summary

\section{Chapter Five: Conclusions}

Introduction

Summary of Study

Discussions of Findings and Recommendations

Years Experience

Training

Technology Support

Staff Development

Funding

Attitude

Policy

Facilities

Hardware/Software

Time

Access

Additional Research Questions

Summary at a Quick Glance

Table 17: Years Experience as a Principal

Table 18: Percent of Principals with Technology Training

Table 19: Types of Training 
Table 21: Summary of Strongly Agree and Agree Items 147

Summary of Important Findings from the Study 148

$\begin{array}{lr}\text { References } & 149\end{array}$

$\begin{array}{ll}\text { Appendices } & 162\end{array}$

Appendix A: Sample Technology Integration Specialist Job Description 162

Appendix B: Sample Job Posting for Nicholas County in West Virginia 164

Appendix C: EETT Grant Technology Integration Specialist Job Description 165

Appendix D: Letter to Panel of Experts 167

Appendix E: Letter to Pilot Study Participants 168

Appendix F: Letter Requesting Support 169

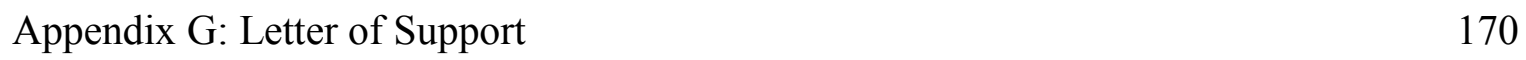

Appendix H: Letter to All West Virginia Superintendents 171

Appendix I: Email to Principals $\quad 172$

Appendix I (2): Email Sent to All West Virginia Principals 173

Appendix I (3): Follow-up Email Sent to Non-Respondents 174

Appendix I (4): Final Email Request to Non-Respondents 175

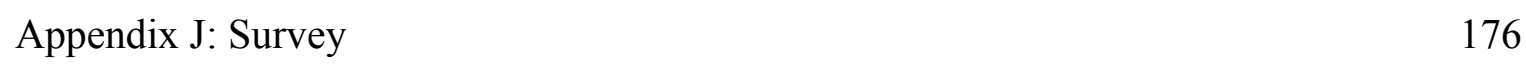

Appendix K (1): Organization of Data Analysis, Research Question One 185

Appendix K (2): Organization of Data Analysis, Research Question Two 186

Appendix K (3): Organization of Data Analysis, Research Question Three 187

Appendix K (4): Organization of Data Analysis, Research Question Four 188

$\begin{array}{ll}\text { Author Note } & 189\end{array}$ 


\section{Chapter One: Obstacles to Technology Use in West Virginia Public Schools}

Principals face many obstacles implementing technology into public schools. Technology includes information and communication technologies such as computers, networking, and other technologies (e.g. probes, sensors and accelerometers, IPods, interactive whiteboards, etc.); audio, video, multimedia and other digital tools; access to online learning communities and resources; aligned digital content software; and adequate hardware for all students and educators with appropriate technology support systems (West Virginia Board of Education Policy 2520.14).

Technology is now present in all West Virginia public schools; however, principals must connect this educational tool to current curriculum through the implementation process of technology, the development of teaching methods, and planning. West Virginia public school principals have many challenges relating to the implementation of technology. Integrating and employing technological innovations seamlessly into the curriculum is an ongoing problem.

According to the literature, the role of the principal is extremely important for the success of technology. Fechnology has the potential to change how we work, teach, and learn in our school districts, and this potential will only be realized if leaders assume the lead role in realizing this potential" (Costello, 1997, p. 1). Bosco states, In order for teachers and students to fully use technology to achieve academic goals, they need the support and vision of tech-savvy principals" (as cited in Hopkins, 2002, p. 1). The principal's responsibilities include implementing the curriculum, maintaining the facility, implementing technology, developing staff, evaluating classroom teachers, budgeting, and maintaining a safe environment for all students. This study focuses on the administrator's responsibility of implementing technology and the obstacles to this process as seen by building-level principals. 
Stansbury (2008), Ronnkvist, Dexter, and Anderson (2000), Monk, Pijanowski, and Hussain (1997), Kearsley and Lynch (1992), Hasselbring (1991), and Bozeman and Spuck (1991) present many obstacles that principals face implementing technology. These include

- providing staff development,

- monitoring student achievement,

- providing technical support,

- retiring teachers,

- welcoming and orienting new teachers and monitoring the training they receive during their certification process,

- overseeing funding,

- measuring student knowledge and ability,

- scrutinizing student access to technology outside of the school system,

- maintaining infrastructure,

- monitoring and maintaining Internet availability, and

- $\quad$ assessing moral issues concerning the use of technology.

A survey of West Virginia public school principals will provide evidence that these same obstacles impede the successful implementation of technology in West Virginia public schools.

This study examines the role of the principal in providing technological leadership at the elementary, middle, and high school levels in West Virginia public schools. An online survey tool will examine the perceptions of these principals, and the data collected will provide a better understanding of these obstacles.

\section{Research Justification}

The purpose of this research is to examine what impedes and facilitates the implementation of technology according to the principals' perceptions at the elementary, middle, and high school 
level. Obstacles inhibiting technology exist at all levels of education due to our technology-rich world and public education's lack of access to this resource. In The World Is Flat by Thomas Friedman (2005), he stated that the playing field has become level, and new communication technologies have erased obstacles in the realm of knowledge. According to Friedman, the flat world creates worldwide competition and an equal playing field for students with access to $21 \mathrm{st}$ century technology. This places even greater responsibility on principals to maintain a fast-paced technological implementation process to keep their students competitive in the vast world of increasing knowledge. Public schools must undertake the challenge of implementing innovative technology to prepare students for the 21 st century.

\section{Statement of Purpose}

The purpose of this study is to determine if the obstacles that exist during the implementation of technology (according to the literature) agree with the perceived obstacles of West Virginia public school principals. This study collects data with an online survey from three groups of principals in West Virginia: elementary school principals, middle school principals, and high school principals. The study will then compare the data to determine if the obstacles are consistent among the three groups.

The data from this study also determines what obstacles in West Virginia public schools impede technology in order of the most critical to the least critical (according to the perceptions of principals). Documented research supports the existence of many barriers concerning the implementation of technology; however, only minimal research studies exist to determine how the principals' perceptions of these barriers affect technology. Findings from this study will enhance principals‘ ability to facilitate technology use and overcome determined impediments. 


\section{Research Questions}

The research will answer these four questions:

1. What technology support do West Virginia principals provide to teachers?

2. Who do West Virginia principals rely on to provide technology support when unable to do so themselves?

3. What facilitates principals' implementation of technology in West Virginia public schools?

4. What impedes principals' implementation of technology in West Virginia public schools?

\section{Research Design}

Principals from all fifty-five counties in West Virginia received an electronic survey. The information collected pertains to infrastructure including facilities, hardware, software, and funding. Other areas addressed by this study are social issues including staffing, staffing of technology positions, staff development, principals ‘ motivation, and teacher and student perspectives. Technology policy is the last area addressed by this study.

An online survey conducted with Survey Monkey, an online survey tool, collected data from three groups of West Virginia principals: elementary, middle, and high school. The elementary principals are the largest group with 425, 124 middle school principals, and 109 high school principals $(\mathrm{N}=658)$. Random drawings for prizes to individuals completing the survey were used to increase the participation rate. 


\section{Definition of Terms.}

- RESA: Regional Education Service Agency

Eight area RESAs serve all fifty-five West Virginia counties. They provide computer repair services, staff development, public service training, and several other services.

- Educational technology as defined by Edtech (2009), also known variously as e-learning, instructional technology, and learning technology, is the use of technology to support the learning process. The term —ducational technology" is big; a Google search returned more than 52 million hits. The term - Fearning" returned more than 94 million hits and tearning technology," returned over 78 million hits. For the purpose of this study technology will consist of areas related to infrastructure (hardware, software, facilities), social (staff development, acceptable use, training), and policy affecting how principals implement technology in elementary, middle, and high school environments.

- Enhancing Education Through Technology (EETT) provides funding for school technology from the No Child Left Behind Act of 2001 used in classrooms to improve student academic achievement. Formulas and competitive grants determine the distribution of funds (http://www.cde.ca.gov/ls/et/ft/eett.asp).

- In order to provide discounted, affordable access to the Internet by schools and libraries down to the -elassroom" level, the Telecommunication Act of 1996, co-authored by Senator Jay Rockefeller (D-WV) developed E-rate. Discounts based on the Free and Reduced Lunch program and the federal designation for a school (either Urban or Rural) provides discounts on Internet access, web hosting, and email along with basic telephone services. E-rate does not provide hardware such as personal computers or other end-user equipment. E-rate requires technology plans, including budgets. 
- International Society for Technology in Education (ISTE) is a nonprofit membership organization; ISTE provides leadership and service to improve teaching, learning and school leadership by advancing the effective use of technology in Pre-K through grade 12 and teacher education. Home of the National Educational Technology Standards (NETS), the Center for Applied Research in Educational Technology (CARET), and the National Educational Computing Conference (NECC), ISTE represents more than 85,000 professionals worldwide.

(http://www.iste.org/am/template.cfm?section=about_iste)

- Technology: West Virginia has three standards for technology: Information and Communication Skills, Thinking and Reasoning Skills, and Personal Workplace Skills, which reflect the content, found in six national standards published by the International Society for Technology in Education (ISTE). These are:

(a) Basic operations and concepts,

(b) Social, ethical and human issues,

(c) Technology productivity tools,

(d) Technology communication tools,

(e) Technology research tools, and

(f) Decision making tools that solve technological problems listed last.

Technology tools include:

Information and communication technologies such as computers, networking, and other technologies (e.g. probes/sensors and accelerometers, IPods, interactive whiteboards, etc.); 
- Audio, video, multimedia and other digital tools; access to online learning communities and resources; aligned digital content software and adequate hardware for all students; and educators with appropriate technology support systems (West Virginia Board of Education Policy 2520.14).

Dr. Greg Davis uses Fitzpatrick and Pershing's (1996) definition of technology in his dissertation entitled The Development and Field Test of the Education Technology Leadership Assessment Survey" as an application of modern communications and computer technologies to the creation, management, and use of knowledge. Dr. Davis's definition of technology generally refers to personal computers, networking devices, and other computing devices (e.g., electronic whiteboards and personal digital assistants (PDAs), also includes software, digital media, and communication tools such as the Internet, email, CD-ROMs, and video conferencing.

- A two million dollar grant from IBM to the West Virginia Department of Education established The Reinventing Education project (Taylor and Landin, 1999). This project's purpose is to define and validate criteria for creating instructional plans that use the power of the Internet to address the West Virginia Instructional Goals and Objectives and improve student achievement and learning. A Criteria for Excellence was created, and then employed by a group of pilot teachers to develop lesson plans that would be peer reviewed, validated by field-testing, and observed during classroom implementation and repeatedly revised. These lesson plans resulted in significant learning improvement and placed in the Best Practices database to share with teachers across the state. The original pilot teachers represented sixth through twelfth grade mathematics. However, during the summer of 1998 , additional teams representing reading language arts, social studies and science began similar work 
- Survey Monkey is a private American company that enables users to create their own Web-based surveys. More than $80 \%$ of the Fortune 100 companies have used Survey Monkey (Wikipedia, n.d.).

- West Virginia Education Information System (WVEIS) is a computerized data system that includes:

○ A comprehensive Student Management System that manages student records including demographics, attendance, scheduling and grading for all active, inactive and graduated students.

- An Employee Management System administering active and substitute employees.

- A Financial Management System maintains the accounts payable and purchasing for each county.

- The Human Resources Management System maintains personnel and seniority information.

O Other related programs including the Point of Service Lunch-Room Program and the PEIA financial reconciliation program (West Virginia Educational Information System, n.d.).

\section{Organization of Document}

This dissertation includes five chapters beginning with the study`s introduction and research justification in chapter one. Chapter One also includes the four research questions and the research design for this study. Terms included in this study that may need additional explanation are included in the definitions of terms section of chapter one. 
Chapter Two presents a review of literature of administrative obstacles related to the implementation of technology. This section begins with a history of technology. This history is in chronological order, and covers the early 1980s through 2009 in West Virginia public schools. This background information provides the framework of technology use in West Virginia public schools.

Chapter Two presents the role of the principal in public schools and describes the many responsibilities of the principal. Listed next, are the obstacles to technology, categorized by infrastructure, including facilities, hardware, software, and funding. The next category includes social issues pertaining to staffing and technology positions, staff development, principals technological motivation, and teacher/student perspectives. The last category discussed as an obstacle is policy.

Included next are three programs initiated in West Virginia to enhance technology; 21st Century Skills in West Virginia, West Virginia‘s Governor Council for Technology in Education and Technology, and the Basic Skills Program. The impact of The Technology Integration Specialist (TIS) position in West Virginia public schools is included next. In addition, specific West Virginia policy related to technology is detailed.

A study of national trends in technology is included providing national perspectives on technology obstacles, funding, and staffing issues. An examination of a study conducted by Bakia, Mitchell and Yang for the U.S. Department of Education Office of Planning, 2007 follows. This report examines the role of Enhancing Education Through Technology (EETT), a program authorized by Title II, Part D, of the Elementary and Secondary Education Act of 1965 (ESEA). The No Child Left Behind Act of 2001 (NCLB) reauthorized the ESEA as the No Child Left Behind Act of 2001 (NCLB). This study provides national and individual state data indicating 
possible obstacles principals encounter during the implementation process of technology in public education. The data provides information and national trends that may impede the technology planning and development process.

Chapter Three describes the research process and methodology of the survey instrument used to gather the data for this study. A table is included in the research participants section illustrating the number of schools at each level. Furthermore, a description of the panel of experts for this study follows, as well as a report on how the study maintains reliability and validity. An explanation of the data collection process and data analysis concludes this chapter.

Chapter Four presents an analysis of the data collected through Survey Monkey. Representation of the data using tables describes the outcomes related to each of the four research questions. Chapter Five contains a summary of the study, conclusions from the study, and recommendations for practice during the implementation process of technology. 


\section{Chapter Two: Review of Literature}

This chapter reviews the literature on theories and research related to obstacles principals must surmount to successfully implement and maintain technology. The first section of this chapter summarizes a history of technology in West Virginia public schools demonstrating the involvement of the West Virginia Department of Education and the technological advancements in the last 25 years. It provides the history and background for the context of technology use in West Virginia Public schools. This includes participation in programs developed to increase funding and support for technology.

The next section of this chapter reviews the role of the principal in the technology implementation process based on the literature and research examined for this study. The next section reviews the evidence, which documents the most encountered technological obstacles. Technological obstacles organized into three sections: infrastructure, social and policy follow. Infrastructure encompasses the physical structure of a building, hardware, software, and funding. The social section consists of staffing, implementing technological education into staff development, teacher and student perceptions of technology, and principals ${ }^{6}$ technological motivation. Policy and its impact is the final type of obstacle principals must consider during technological implementation. These obstacles present a rationale for the design of the survey.

Also included are brief descriptions of the 21 st Century Skills initiative and the West Virginia Governor's Council for Technology in Education concluding with a brief description of the results of the Basic Skills Program. West Virginia's Basic Skills/Computer Education program has had a powerfully positive impact on student achievement, as detailed in a study released by researchers from Columbia University and Hofstra University. The study noted that educational 
gains through technology were cost-effective and increased socio-economic and gender equity for West Virginia students.

The next section of this chapter summarizes the Technology Integration Specialist (TIS) position utilized by West Virginia public schools. This is followed by reviews of West Virginia technology policy and the impact of policy on principals and the decision making process in West Virginia public schools.

The final section of this chapter summarizes research pertaining to national trends in technology and public education. This includes a National Educational Technology Trends Study (NETTS) based on the collaborative work of SRI International, The Urban Institute and the American Institutes for Research (AIR) completed for the U.S. Department of Education.

\section{History of Technology in West Virginia Public Education}

This section describes the history of technology in the educational system in the state of West Virginia. Presented in chronological order, it emphasizes changes since 1989, when technology began to reach the classrooms. It provides the history and background for technology use in West Virginia Public schools.

The early 1980s saw the creation of the West Virginia Microcomputer Educational Network (WVMEN) as a statewide project that was the first step of educational technology for West Virginia public education. The project provided the first local area networks in vocational technical centers and comprehensive high schools. To provide access to one computer containing information by many computers within the system, the state developed networks. This enabled toll-free dial-up access to electronic bulletin systems with more than 9,000 educational and community users averaging more than 5,000 calls a month. These bulletin boards allowed users to place information on a centrally located computer to which identified users could connect via 
telephone and retrieve the information. Educational software evaluated by teachers, and licensed for local area network use and staff development, provided the educational use of telecommunications. This software, created to be more user friendly allowed progress toward a more graphical environment. In 1986, WVMEN won a national award from Association for Educational Communication and Technology (AECT) for advancements in instructional technology. This provided for best practices for the statewide technology implementations that began in 1989-1990 (WVDE, 2005).

The mid 1980s provided rapid growth in technology for education through 1989. However, most of this growth grew through electronic bulletin boards and the development of small internal networks or local area networks. In 1989 West Virginia made a statewide commitment to technology with the creation of Basic Skills/Computer Education Program that provided funding for a comprehensive kindergarten through Grade 6 solution that included hardware and software purchases, installation and maintenance, and initial and ongoing staff development for every school (WV Code 18-2E-7) (WVDE, n.d.). Legislators allocated approximately $\$ 7$ million a year in the early 1990s; however, legislators significantly reduced the allocations in the early 2000s (K. Boone, personal communication, June 30,2008). This was the beginning of utilizing technology in the classroom to expand learning beyond the boundaries of the traditional classroom.

The West Virginia Department of Education (WVDE) organized a committee of educators to develop a request for proposals to vendors of educational technology in 1989. This would utilize the bid process for technology vendors providing technological equipment to schools. In June 1990, the WVDE signed contracts with the IBM Corporation and Jostens Learning Corporation to provide educational technology solutions for basic skills development for kindergarten through grade 6 students, launching the highly successful Basic Skills/Computer Education program. Two 
providers: IBM for hardware standardized throughout the state, and Jostens Learning for the software allowed teachers the choice to select packages that best fit their local needs and philosophy. Students utilized the software and hardware packages to reinforce basic skill concepts related to the core curriculum used in the classrooms. The original contracts with IBM and Jostens expired on June 30, 2000. During this time, the purchase of two complete network systems allowed servers to manage student accounts. The software packages ran through -dummy" workstations or computers requiring very little hardware that were connected to the file server, which was the brain and storage system of the entire network. Currently the WVDE has a contract with IBM serving as prime vendor and Compass Learning as a subcontractor. This contract continues to provide for hardware, software, cabling and professional development for the implementation of the Basic Skills program (WVDE, 2008).

Early phases of the implementation included IBM Model 25 workstations and base band networks. Base band was the network cabling connecting the workstations to the file servers. It was very similar to a single strand of coax cable. Software included Jostens' Basic Learning System and several software titles from IBM, including Writing to Read; Measurement, Time, and Money; and Exploring Math Concepts. Implementation began in kindergarten and moved upward through the grades. The West Virginia Legislature appropriates funding annually (WVDE, 2008).

The contract permitted upgrades to the software and hardware component of technology but only through IBM and Jostens Learning. To illustrate, the 2002-2003 contract provided Pentium IV, $1.8 \mathrm{GHz}$ machines, the latest versions of software, and structured Category 5 infrastructure. Intermediate phases from 1990 to 1999 included 10Base2 networking and computers of the 486 and earlier Pentium varieties. Workstation operating system software included DOS, Windows 3.1, Windows 95 (including several versions) through Windows XP . Network operating system 
software ranged from Novell NetWare 2.2 through Netware 6.0 and Microsoft NT Server 4.0 through Server 2000. While the most recent purchases include modern technology, some of the original hardware, software, and networking infrastructure still exists and is operational in schools today (WVDE, 2008).

The West Virginia Education Information System (WVEIS) project began in 1990. This project insured standardized data collection and reporting to the WVDE (WVDE, 2005). It provided computer access for administrators at county and local school levels to maintain and retrieve student records such as schedules, grades and personal information. This allowed quick accessibility by individuals connected to the system including personnel at the state department.

Also in 1990, Curriculum Technology Resource Centers (CTRC) provided educational videotapes with unlimited statewide duplication rights (WVDE, 2005). This material enhanced the classroom by providing teachers faster access to current teaching materials. Curriculum Technology Resources Center (CTRC) offered staff development on a variety of technology use. It also provided current training materials for teachers to enhance their personal skills to increase the successful implementation of technology in the classroom. This provided an increase in county consistency for staff development and increased the ability for the state department to provide consistency statewide in staff development. Local Regional Education Service Agencies (RESA) became involved in the process of distributing these materials. This provided a faster access for teachers to current materials.

Schools sought grants to enhance technology in the classrooms through the U.S. Department of Education. West Virginia received Technology Demonstration Grants in 1992 for nineteen schools. The schools receiving the grants received financial assistance to enhance their 
technology equipment and increase their access through the Internet to the world. In 1993, WV schools received eleven more Technology Demonstration Grants (WVDE, 2005).

Policy 2460 (Use of the Internet by Students and Educators) was adopted by the West Virginia State Board of Education in 1994. This includes regulations for the safety and use of the Internet. It addresses acceptable use, privileges, accountability and responsibility, web publishing, network etiquette, reliability, security, safety and vandalism. Policy 2460, revised in 2001, included the new federal regulations regarding issues of child safety: Children's Online Privacy Protection Act (COPPA), the Children's Internet Protection Act (CIPA) and acceptable use of the Internet to comply with the Universal Service Fund for Schools and Libraries (E-rate) guidelines.

In addition, the World School program began to provide connections to the Internet with a goal of providing Internet to every school in the state. Local phone companies provided materials and volunteers to wire schools for Internet access. Bell Atlantic-West Virginia (BA-WV) offered Internet connections to nearly 700 schools in 1994 (WVDE, 2005) while working with local boards of education. The World School Program initially focused on schools within the BA-WV territory. In 1996, Citizens Communications offered an Internet connection to all the schools in their service territory. Other smaller West Virginia Telephone companies such as Hardy Telephone, Armstrong Telephone, Spruce Knob Telephone, War Telephone and West Side Telephone offered to implement a similar program to schools they served (WVDE, 2005). The Infomine Grant in 1996 and E-rate discounts have helped with the purchase of routers and other equipment needed in these schools to provide Internet access.

The Federal E-rate program provided funding which assisted placing Internet into classrooms (WVDE, 2005). E-rate, established through an amendment to the Telecommunications Act of 1996; co-authored by Senator Jay Rockefeller (D-WV), based funding on school social 
economic status and provided assistance in many areas of need. West Virginia state average discount from E-rate is approximately $74 \%$ with counties ranging from 20\%-90\% (WVDE, 2005).

A Technology Task Force created in 1994 to assist the West Virginia public educational system with connection of our schools to the world. This task force, organized by the Governor Gaston Caperton and State Superintendent of Schools David Stewart, created the state's first educational technology plan. Technology requires integrations with educational improvements and reform to accomplish educational goals, increase student achievement and provide increased opportunities for lifelong learning (WVDE, n.d.). Technologies, especially computers, enhance both the academic achievement and the workplace readiness of all students based on $21 \mathrm{st}$ Century Learning Skill requirements. An additional eleven schools received Technology Demonstration Grants in 1995 (WVDE, 2005).

Additional Telecommunication/Technology grants, announced in 1995, assisted with the implementation of the Internet into remote schools outside of the Bell Atlantic-West Virginia (BAWV) territory. These grants received by counties, served as part of the match for federal telecommunication funds. The WVDE received a 3-5 year, \$2 million grant from IBM for Reinventing Education to develop Internet based lessons designed to improve student achievement and impact teaching strategies and classroom organization (WVDE, 2005). The Reinventing Education grant program provides the centerpiece for IBM's commitment to education. IBM works with school partners to develop and implement innovative technology programs.

The process of selecting teachers for the Reinventing Education Pilot Project Team began in 1997, and assisted with attracting funds from IBM and the Reinventing Education grant. Funds awarded to schools to tackle critical problems with school reform with the assistance of technology, resulted. 
In 1996-1997, the state updated instructional goals and objectives in technology and integrated them into each area of the curriculum. Professional development design followed this same model just a few years later. The 1996 West Virginia Legislature amended West Virginia Code $§ 18-2 \mathrm{E}-7$ to provide for the utilization of technology in middle, junior high and high schools.

West Virginia Legislature funded the WV SUCCESS Initiative in 1997. SUCCESS, Student Utilization of Computers in Curriculum for the Enhancement of Scholastic Skills, provided technology tools to prepare students, grades $7-12$, to be successful in college or gainful employment. The actual implementation of this program began in 1997 (WVDE, 2005). Eleven more schools received Technology Demonstration Grants in 1996 and 13 more in 1997.

Policy 2470 (Use of Internet by Students and Educators) was adopted in 1997 by the West Virginia Board of Education. This states that students of all ages and citizens as lifelong learners require both the necessary skills and access to technology tools to take responsibility for their own learning, to be actively involved in critical thinking and problem solving, to collaborate and cooperate, and to develop as productive citizens.

The Curriculum Technology Resource Center (CTRC) provided staff development and laptops for teachers with productivity software to enhance classroom technology implementation. Policy 2520 (Technology Instructional Goals and Objectives) was adopted by the West Virginia Board of Education. This policy addressed concerns about providing goals and objectives students must achieve in technology.

The state established Cisco Academies in Spring Valley High School and Marshall Community College, and an additional five local academies in Nicholas, Wetzel, Mineral, and Wayne Counties in 1998. These academies provided highly technical training for high school students in the area of networking. Challenge grants helped schools put computers in classrooms 
and provided more training for teachers to use technology to improve lesson plans. The World School Program won a 1998 Recognition Award for Outstanding Achievement in the Field of Information Technology from the National Association of State Information Resource Executives (NASIRE) in the category of Internet Use for Service to Citizens. Laptops, given to 36 Reinventing Education teachers through CTRC enhanced staff development. These same teachers received desktop computers for their respective classrooms in Social Studies, Math and Science. West Virginia received Federal Technology Literacy Challenge Funds (TLCF) providing $\$ 2,768,517$ in Round 1 awards. Later in 1998 , round two of these same awards totaled $\$ 3,108,801$. Five West Virginia schools received Technology Demonstration Grants totaling \$150,000 (WVDE, 2005).

Reinventing Education teachers received additional laptops in 1999 through CRTC. The Milken Family Foundation released the findings compiled by researchers from Columbia and Hofstra University. The West Virginia Story" reported that students in West Virginia who participated in the Basic Skills/Computer Education technology program saw improved student achievement. West Virginia schools received additional TLCF awards totaling \$3,500,000 in 1999. West Virginia K-12 schools received Technology Demonstration grants totaling \$149,000 (WVDE, 2005). The Office of Technology received a United States Department of Education Preparing Tomorrow‘s Teachers to Use Technology Capacity Building Grant to expand Reinventing Education Grants to elementary teachers and to four West Virginia teacher education programs.

The WVDE entered a pilot program established by NivoNet, a sub-contractor for Microsoft. This provided free Microsoft Office User Specialist (MOUS) testing for West Virginia public school teachers at 10 sites across the state. 
The year 2000 brought additional expectations for West Virginia schools in the realm of technology. The Pre-K through sixth grade Basic Skills/Computer Education Program received the contract. CTRC provided staff development with laptops to 48 Reinventing Education teachers. Thirteen West Virginia teacher programs received The Reinventing Education Grant, expanded by the United States Department of Education Preparing Tomorrow`s Teachers to Use Technology Implementation Grant. WV schools received TLCF awards totaling \$3,500,000 (WVDE, 2005), and the State of West Virginia established the Virtual School. West Virginia schools received additional Technology Demonstration grants of $\$ 150,000$.

In addition, West Virginia received a \$1.2 million State Challenge Grant for Leadership Development from the Bill and Melinda Gates Foundation. The grant launched the Learning Educational Administration from a Distance (LEAD) project. County superintendents and school principals are provided staff development to meet the ISTE NETS-A standards for administrators (WVDE, 2005). Staff development included digital camera use, Palm Pilot training and implementing them for observations and evaluations supporting principals using technology for implementing West Virginia State Policy 5310.

The MarcoPolo educational partnership with WorldCom Foundation, announced by the Office of Technology early 2001, provided staff development for train the trainers and for teachers. CTRC provided Internet integration for elementary classrooms with data projectors. Policy 2460 (Safety and Acceptable Use of the Internet by Students and Educators) is revised to meet federal mandates from the E-rate program so West Virginia could continue receiving this funding. West Virginal Schools received an additional \$3.6 million from TLCF grants. Training began for West Virginia Virtual school contacts. West Virginia's Reinventing Education program resulted in middle and high school students making substantial gains in all curriculum areas, according to the 
research report released in Washington D.C. at the Hudson Institute Achieving Large-Scale Education Reform Round Table Discussion (WVDE, 2005).

Technology plans at the county level are beginning to take form with individual schools participating in creating local technology plans. Technology teams from 97 West Virginia schools received training in writing comprehensive school technology plans. Policy 6200 (Planning for School Facilities) revised to include technology infrastructure. Additional Technology

Demonstration Grants awarded to Kanawha, Lincoln, Grant, and Hardy Counties to enable schoolto-school collaboration. The SUCCESS contracts provided many West Virginia schools with Compaq computers. A large component of this process was the RESA Office becoming warranty providers through WVDE training programs. Local RESA technology departments, trained to assist with warranty work through IBM and Compaq assisted with the increased number of computers in the classroom that required technical repairs. Fourteen counties received federal funds totaling \$654,529 from the Federal Repair and Renovation grant program (WVDE, 2005). The state established Cisco local and regional academies in 42 different locations throughout the state.

West Virginia Virtual School received a federal AP incentive grant to develop courses for middle school Spanish and to pay AP tuition for online courses in 2002. An additional fourteen counties received grants totaling $\$ 565,598$ from the federal Repair and Renovation Grant. Several students and teachers were the first recipients of the Caperton Educational Technology Awards of $\$ 5000$ each. A special Caperton Educational Technology Award, given to Brenda Williams, Executive Director of Technology with the WVDE, rewarded her dedication to countless technology initiatives in West Virginia schools (WVDE, 2005). OTIS (Office of Technology and Information Systems) received IBM Reinventing Education Grant 3. West Virginia received the 
MarcoPolo Award for Internet staff development sessions. NASIRE 2002 Award arrived for the telecommunications and E-rate programs (WVDE, 2005).

IBM`s \$1.5 million commitment to West Virginia is part of a \$15 million Reinventing Education grant program that paves the way for teachers at more than 20 leading schools of education in nine states to receive new levels of quality training and professional development to assist with meeting the requirements of the President's No Child Left Behind Act. West Virginia Board of Education approves new Content Standards and Objectives including Technology Standards and Objectives across each grade level. These content standards, objectives and performance indicators evolved from the International Society for Technology in Education (ISTE) Standards for Students (NETS-S) (WVDE, 2005).

A National Virtual School Town Hall Meeting highlighted West Virginia's Virtual School in 2003. Capitol Hill presented West Virginia‘s Reinventing Education Program. The Office of Technology received two of the United States Department of Education Technology Evaluation Grants. Fifteen West Virginia counties received Enhancing Education through Technology (EETT) Round 1 competitive grants. Policy 5310, Evaluation of School Personnel, revised with Technology Standards added (WVDE, 2005). This provided principals the opportunity to evaluate the use of technology in the classroom.

Eighteen West Virginia counties received Enhancing Education Through Technology (EETT) Round 2 competitive grants in 2004. A grant made by the Wellman Family Foundation provided teachers and their students across West Virginia access to curriculum (SAS inSchool) through the 2006-2007 school year. Making It Happen Awards, presented to three individuals along with the Gates Foundation Leadership Awards arrived in nine counties. Governor Caperton and the Greater Kanawha Valley Foundation recognized outstanding educators for utilizing and 
providing leadership or service to make a significant contribution to K-12 public educational technology (WVDE, 2005).

The West Virginia Board of Education encouraged more state schools to take advantage of SAS inSchool, an award winning, and web-based educational curriculum during 2005. The United States Department of Education recognized the West Virginia Instructional Technology program. The latest National Education Technology Plan (NETP) featured West Virginia‘s technology plan. This plan for 2005 builds on the 1996 and 2000 plan and incorporates response to the No Child Left Behind Act (NCLB).

West Virginia Department of Education‘s current technology plan (2007-2010) core beliefs are:

1. The knowledge and skills needed to succeed in the 21 st century are changing dramatically and that West Virginia students must develop proficiency in 21 st century content, technology tools, and learning skills to succeed and prosper in life, in school and on the job.

2. Students must be equipped to live in a multitasking, multifaceted, technology-driven world.

3. The provision of 21 st century technologies and software resources in grades Pre-K through 12 is necessary to prepare high school graduates for college, other postsecondary education, or gainful employment.

This goal reflects a fundamental belief that the youth of the state exit the system equipped with the skills, competencies and attributes necessary to succeed, to continue learning throughout their lifetimes and to attain self-sufficiency. 
4. To promote 21 st century learning, teachers must be competent in 21 st century content and learning skills and must be equipped to integrate technology to transform instructional practice and to support 21 st century tools and resources.

5. For students to learn 21 st century skills, students and teachers must have equitable access to high quality, 21 st century tools, and resources.

6. When aligned with standards and curriculum, technology-based assessments can be a powerful tool for teachers.

7. Teachers must understand how to use technology to create classroom assessments for accurate timely measurements of student proficiency in attainment of academic content and 21st century skills (WVDE, 2007).

Such policy, grants and practices have brought West Virginia into the forefront nationally in the use of technology for both administrative and instructional purposes. These core beliefs provide a guide for principals and teachers to focus their technology visions.

Information provided by Vicki Allen (personal communication, April 7, 2008) from the West Virginia Department of Technology, shows the extensive utilization of email as a tremendous part of West Virginia's educational success. There are currently 41,768 Access email accounts. Total number of student accounts is 9,644 , teacher accounts 25,159 , and administrator accounts 6,903 (V. Allen, personal communication, April 7, 2008). This information only takes into account state provided email accounts as counties have taken their own initiatives and created their own email servers providing their teachers, principals, and students separate email accounts.

The Technology Counts 2007, A Digital Decade, report gave West Virginia:

- A in Access to Technology,

- $\quad A$ in the Use of Technology, 
- $\mathrm{C}$ in Capacity to Use Technology, and

- $\quad$ B as an overall grade

For the Technology Counts 2007 report, the EPE Research Center awarded grades for technology leadership to the 50 states and the District of Columbia. The EPE Research Center based grading on 14 individual indicators spanning three core areas of state policy and practice: access to instructional technology, use of technology, and capacity to use educational technology effectively. The data shows West Virginia is very competitive nationally, and maintains access to computers in the classroom at $68.5 \%$. This is significantly higher than the national average of 49.5\%. The data also shows that 86.5 percent of West Virginia schools have labs or media centers. Again, this is higher than the national rate of $77 \%$ (Editorial Projects in Education, 2008).

West Virginia currently has student standards including technology. Students receive testing in technology, and virtual schools exist. West Virginia also offers computer-based assessment along with 22 other states (Editorial Projects in Education, 2008).

West Virginia's school technology policies and implementation strategies are among the best in the nation according to Technology Counts 2008: STEM, The Push to Improve Science, Technology, Engineering and Mathematics. The state received an overall score of 95.3 on the report, which ranks West Virginia at the top of the class for its use of technology (WVDE, 2008). In an effort to prepare all students to be competitive in the global marketplace, the West Virginia Department of Education (WVDE) joined the Partnership for 21st Century Skills, and launched the 21 st Century Learning Initiative. West Virginia has adopted elements of the 21 st century including a foundation built with technology tools. These initiatives are included in the 21 st Century Skills in West Virginia and Technology section of this document and are in their entirety from the WVDE (2008). 


\section{The Principal's Role}

Over the past 50 years, the role of the principal has evolved from a building manager to an instructional leader and through this systematic change process; principals must become great visionaries to overcome obstacles to technology. They move from managerial roles to instructional facilitators as technology moves to the forefront of education, working collaboratively with all to create a shared vision (National School Boards Association, 2001).

The principal as a technology leader, noted as one of the most important factors affecting the effective integration of educational technology by (Byrom \& Bingham, 2001). According to research, the principal and the expectations of the principal determine the success of technology implementation. Analysis of the effectiveness of technology in education (e.g., Cuban, 1986; Office of Technology Assessment, 1988; Saettler, 1990) as cited by Kearsley and Lynch (1992) suggests that the manner in which technology is implemented is more important than any intrinsic characteristics of the technology. In other words, leadership of one kind or another plays a very critical role in the success of instructional technology" (Kearsley \& Lynch, 1992, p. 1).

To assist in defining the role of the principal as a technology leader, Education World's Fechnology Standards for School Leaders Released" published six standards from the Technology Standards for School Administrators (TSSA Collaborative) in 2001. The principal's roles included are Leadership and Vision; Learning and Teaching; Productivity and Professional Practice; Support, Management, and Operations; Assessment and Evaluation; and Social, Legal, and Ethical Issues. The standards builders wrote, An underlying assumption to these standards is that administrators should be competent users of information and technology tools common to information-age professionals" (TSSA Collaborative, 2001, p. 4). 
Leadership and vision. Educational leaders inspire a shared vision for comprehensive integration of technology and foster an environment and culture conducive to the realization of that vision” (TSSA Collaborative, 2001, p. 6). Bosco (as cited in Hopkins, 2002) states the importance of a vision for principals supporting technology use. Schools following the leadership and vision of technology perceptive and hands-on principals are more likely to thrive in the area of technology. Much of the benefit of technology is lost for principals who rely on an intermediary to do their email, manipulate critical data or handle other technology tasks for them" (TSSA Collaborative, 2001, p. 4).

A study by Wilburg (1991) in three schools identified as successful integrators of technology provided data supporting the principal as a strong advocate and user of computer technology. Anderson and Dexter (2000) present that the role of a strong technological leader is linked to the decision-making process regarding the role of technology in education. The results show that leadership of the principal has great impact on the outcomes and success of technology programs.

Learning and teaching. The second role of the principal as a technology leader: Educational leaders ensure that curricular design, instructional strategies and learning environments integrate appropriate technologies to maximize learning and teaching" (TSSA Collaborative, 2001, p. 6). This includes assisting teachers in using technology to access and analyze student data for modification of instruction to meet the students' specific need (TSSA Collaborative, 2001). Principals play a central role in determining the use of technology in classrooms. Bosco speaks of the role of the principal in effectively using technology: In order for teachers and students to fully use technology to achieve academic goals, they need the support of tech-savvy administrators" (as cited in Hopkins, 2002, p. 1). 
As part of the teaching process, the principal implements, supports, and participates in professional development designed to improve student learning. The principal assumes the role of facilitator for technology use to enhance the instructional methods (TSSA Collaborative, 2001).

Productivity and professional practice. The third role of the principal as a technology facilitator: Educational leaders apply technology to enhance their professional practice and to increase their own productivity and that of others" (TSSA Collaborative, 2001, p. 6). TSSA Collaborative (2001) presents that the principal models routine and effective use of technology and is responsible for keeping apprised of emerging technologies and their potential in education. The principal uses a variety of media including email, web sites and Blogs to interact with peers (TSSA Collaborative, 2001).

Principals as technology leaders exhibit skills instrumental in modeling the use of technology. When principals model use of technology and they lead staff through sound daily practice, the program is much more likely to prosper (McKinzie, 2002). Principals must set aside time for teachers to share their successful teaching with technology strategies.

Support, management, and operations. The fourth role: Educational leaders ensure the integration of technology to support productive systems for learning and administration" (TSSA Collaborative, 2001, p. 7). MacNeil and Delafield (1998) present the need for principals to accept the challenge to create supportive conditions, which will foster innovative use of computers. Technology savvy principals ensure the integration of technology to support productive systems for learning and administration. Kincaid and Feldner (2002) who stated that principals making technology a priority and provide technology support, observed that other concerns decreased such as insufficient time for staff development, lack of technical support, and limited access to technology. 
According to TSSA Collaborative (2001), the role of the principal is to allocate funds and other resources including human resources to expand technology. Providing staff development and staff development opportunities is also an important role of the principal. Principals must ensure guidelines and policies are monitored to provide consistent implementation practices (TSSA Collaborative, 2001). Other important roles of the principal are to reward teachers for using technology and encourage teachers who are not using technology (Starr, 2009).

The role of the principal is to provide sufficient up-to-date and workable computer equipment. Funding for computer improvements requires substantial allocations. Time and resources for troubleshooting programs and technical issues as well as Internet access are also very important to the role of a technological administrator (Starr, 2009).

Assessment and evaluation. The fifth role: - Edcational leaders use technology to plan and implement comprehensive systems of effective assessment and evaluation" (TSSA Collaborative, 2001, p. 7). The principal must focus data collection efforts on technology to enhance the learning environment for all students and promote the data collection process using technology (TSSA Collaborative, 2001).

The principal's role consists of utilizing technology for data collection of teacher quality and interpreting results. The principal compiles the data to assist with the evaluation process of the teacher (TSSA Collaborative, 2001).

Social, legal, and ethical issues. The sixth role of the principal includes identifying, communicating and enforcing social, legal and ethical issues related to technology (TSSA Collaborative, 2001). This includes enforcing the acceptable use policy and other policies related to security, copyright issues and technology use. The principal's role also includes ensuring equity of access to technology for everyone (TSSA Collaborative, 2001). 
A study conducted by Sandholtz, Ringstaff, and Dwyer (as cited in Kincaid and Feldner, 2002) established that principals offered their teachers much needed emotional and moral support by showing interest in changes teachers were instituting in their classroom to accommodate new technology concepts. According to this study, the effective principals also eased tension among teachers and fostered collaboration rather than competition (Kincaid \& Feldner, 2002).

\section{Obstacles Principals Encounter Implementing Technology}

In 1991, there was a small amount of empirical evidence with respect to how existing and emerging technologies enhance or influence the principal's role in public education (Hasselbring, 1991). As the role of the principal has changed over time and nearly $\$ 17$ billion spent in 2008 on K-12 technology (Nagel, 2008), many obstacles exist for principals during the technology implementation process that may facilitate or impede technology use affecting public education.

MacNeil and Delafield (1998) conducted a study in the southeast school district of Texas, the main inhibitors to implementing technology for principals are: (a) lack of financial resources for infrastructure, hardware, and software, and: (b) lack of time for professional development which are also obstacles discussed in this paper. Principals must use their existing resources wisely and creatively to overcome these barriers by thinking - outside the box" (MacNeil \& Delafield, 1998).

Infrastructure. SearchDataCenter (2009) defines infrastructure as the physical hardware used to interconnect computers and technology users. For technology users, a solid infrastructure must exist to support the flow and processing of information. According to Dictionary.com (2009), an infrastructure is an underlying base or foundation" (para. 1). Therefore, a school's infrastructure includes the physical requirements needed to support a strong technological network. 
According to Ronnkvist et al. (2000) dimensions of technology concerns the methods, or types of resources, used to deliver technology support services. These services include facilities, hardware, software, Internet access, support staff and professional development. Developing a technology support environment that encompasses all these resources requires considerable effort and expense. For the purpose of this study, infrastructure" includes facilities, hardware, software and funding.

Facilities. Most infrastructure barriers that challenge principals consist of factors beyond the principal's immediate control. The facilities component of infrastructure pertains to the building including electricity, lighting, temperature control, asbestos, and fire stopping. Barriers impeding technology implementation stated by Chin and Horton (as cited by Stegall, 1998) are the deficiencies in the facilities. These deficiencies include outdated electricity and inadequate Internet services that are difficult to update especially in older buildings. Asher (2002) also contends that the existing physical and electronic infrastructure of many rural schools contain a variety of challenges. Many buildings are old and don't have walls, ceilings, and wiring pathways that accommodate the necessary electrical and network cables required to build robust infrastructures.

According to R.T. Chiero (1997), an essential barrier is the lack of electricity, including electrical outlets. New York State Education Department's Guidelines and Standards for the Technology Infrastructure of 21st Century Education prevents issues with new construction and problems meeting technology requirements, and recommends the use of these guidelines by other states. The guidelines include specifics such as a $20 \mathrm{amp}, 120$-volt circuit that should be available for each general circuit per classroom for task lighting, and other miscellaneous plug in devices including one circuit designated for printers and scanners (New York State Education Department, 1998). There should also be a designated circuit for every three to four computers (New York State 
Education Department, 1998). These are standards for new building construction according to the Guidelines and Standards for Technology Infrastructure of 21st Century Educational Facilities (New York State Education Department, 1998). However, this becomes very difficult in older school buildings containing outdated electrical wiring and circuitry that is already overloaded.

Outdated lighting in existing buildings is another issue according to the Guidelines and Standards for Technology Infrastructure of 21st Century Educational Facilities (New York State Education Department, 1998). Inappropriate lighting creates excessive glare or even two images on the computer screens. New schools are using indirect lighting to eliminate the glare on computer screens. An example of this would be reflecting light from the ceiling back into the work area of the classrooms or lab (New York State Education Department, 1998).

Another concern is temperature control. According to Asher (2002) existing heating and cooling systems in older schools are not conducive to installing quality technology networks. High heat and humidity causes extensive damage to hardware and the equipment in the telecommunications closets (Asher, 2002). The equipment rooms consisting of the wiring racks, servers, and other telecommunication equipment must also maintain a temperature of 64 to 75 degrees year round (Asher, 2002).

A fifth infrastructure obstacle is asbestos. The Guidelines and Standards for Technology Infrastructure of 21st Century Educational Facilities (New York State Education Department, 1998) stresses the importance of identifying areas of the facility that may contain asbestos in old buildings before restructuring begins. This may prevent upgrading of Internet access due to alternative locations when the network lines require replacement. Older buildings containing large areas of asbestos may prevent any reconstruction projects of major capacity such as new labs or even create an unsafe environment when disturbing a single wall to mount a new data projector. 
Fire stopping is another critical issue when running new data lines throughout the building.

— Wen a cable tray, conduit, or cable assembly passes through a fire or smoke rated barrier, it must have its integrity re-established" (New York State Education Department, 1998, p. 9). Many situations do not allow for new cabling in the ceilings, increasing the cost of improving the data communication system of the school.

Many of these obstacles concerning facilities are not in the forefront of your average principal's technology plan due to possible lack of technological knowledge or lack of training. The more aware principals are of infrastructure obstacles, the more successful the plan for implementing and maintaining technology in public schools.

Hardware. The term hardware originated to distinguish the box," electronic circuitry, and components of a computer from the program that operates it. This includes not only the computer but also the cables, connectors, power supply units, and peripheral devices such as the keyboard, mouse, speakers and printers. Sometimes the term hardware describes the physical aspects of the telecommunications network infrastructure. For the purpose of this study, hardware obstacles consist of limited hardware (computers), spending and purchase challenges to maintain hardware consistency, and determining the most beneficial learning environment for the hardware.

Earle (2002) stated that limited access to operational hardware creates obstacles for principals implementing technology. According to Hasselbring (1991), the number of schools, using computers for instruction grew from $18 \%$ to $95 \%$ in six years beginning in 1981 . In 1991 , the number of computers in U.S. schools translated to about one computer per thirty students with students averaging little more than one hour per week use (Hasselbring, 1991). However, Hasselbring (1991) states that many of the computers found in the schools are old technology, outdated, and lack the power necessary to implement sophisticated instructional programs. Current 
research shows many schools at a ratio of one computer per three students with no evidence pertaining to the functionality of the existing hardware.

Hardware issues remain obstacles, even as spending increased on educational technology in 1995 from \$21 million (O`Dwyer, Russell, \& Bebell, 2003) to nearly \$17 billion in 2008 (Nagel, 2008). Approximately $36 \%$ of the $\$ 46.5$ billion spent on technology for K-12 education provided funding for telecommunications. The increased spending trends, geared toward IT services such as learning content and video applications, excludes new hardware (Nagel, 2008). A survey from the National School Board Foundation (2002) reported that thirty-three percent of the respondents stated that lack of funding for hardware is a major obstacle for technology implementation.

County and state contracts predetermine much of the hardware purchased for classrooms or labs. Counties attempt to provide consistency in products for every school and abide by requirements of the state contract; this does not allow much flexibility. Providing consistency in hardware decreases technical concerns (WVDE, 2005).

Availability of computers and necessary hardware in individual classrooms is another condition required for meaningful computer technology integration (Riedel, Smith, Ware, Wark, \& Yount, 1998). Maddox (as cited by Riedel et al. 1998) describes current views of computer integration as merely dispersing computers from school computer labs into individual classrooms. Schools must view computer labs as an important and necessary component of school-wide computer integration (Riedel et al. 1998).

The results of a survey of American teachers on technology in public schools conducted by the National Education Association (NEA, 2008) also demonstrated findings of hardware inadequacies. - The number of computers in public school classrooms was not adequate to use computers effectively for classroom instruction, and the classroom was not the main location in 
school where most students used computers" (NEA, 2008). More than half of the public school educators had no more than two computers in their classrooms for instruction. Educators in elementary schools had more computers in the classrooms for students whereas secondary schools had more computers located in technology labs (NEA, 2008).

Software. SearchDataCenter (2009) defines software as a general term for the various kinds of programs used to operate computers. Software, viewed as the variable part of the computer, includes application software (programs that provide direct information to the user for a specific function such as accounting). However, software also encompasses, system software, which is the operating system, and any program supporting application software. Software obstacles for the purpose of this study include under-utilizing software packages due to outdated hardware, lack of built in student data collection, types and availability of software, expense of training to utilize and maintain the software, limited administrative knowledge of software, and slow Internet access to utilize online software packages.

The majority of educational software focuses on lower-level skill development with drill and practice software programs, which operate with few technical issues on low-end hardware systems. The older hardware is more prevalent in schools so software companies are still designing software packages that do not fully utilize new hardware capabilities (Riedel et al. 1998). Much of the current software, specifically designed to operate under the minimum system requirements imposed by earlier hardware, limit the software's functionality. Software packages designed to operate on a specific system make it difficult to sustain reliability, and often schools have a hodgepodge of hardware and operating systems. Riedel et al. (1998) also states this also often leads to difficult technical concerns. 
Hasselbring (1991) raises the issue of current software packages lacking the ability to collect and maintain longitudinal student performance data. As our schools move toward an assessment" based practice, software companies are beginning to look at software designed to track student progress. Newer hardware configurations are required for implementation of more powerful software titles to enhance student performance data and assist teachers with instructional decisions based on the student's learning profile.

In 1991, there were more than 10,000 software titles available for educational purposes (Hasselbring, 1991). Locating appropriate software is a challenge for schools. According to Riedel et al. (1998), the Office of Technology Assessment reports that the quality of educational software has improved but quality issues remain. The tremendous variety and availability of software creates additional obstacles for principals. The principal may face decisions concerning software packaging. Will it fit the students' needs? Will it accommodate each child? How difficult will it be for teachers to comprehend and who can provide staff development on the new software?

There are many types of software available. Staff members may download freeware and shareware. This type of software is available free of charge to download but can be time consuming to download and install especially if hardware configurations are not consistent. The trial version of software may have functional limitations with fully functioning upgrades available for a fee. Software titles are available in most department stores in the most common media form of a CD-ROM. General types of application software titles are also available consisting of word processors, presentation software; graphics design software, specialized scientific software and educational software. With such a variety of - - ver the counter" software titles, principals often are overwhelmed with the decision of which to purchase. The National Education Association (2008) reported that access to instructional software was now adequate. However, urban schools still 
demonstrate lack of adequate software and are troubled with hardware configurations that do not support advanced software titles.

According to West Virginia Department of Education (2005), software purchased through state contracts provides consistency among the schools. Some flexibility provided with these contracts allows principals the opportunity to purchase software packages to meet the needs of their students. One of the focuses for the WVDE and purchasing software from state contracts is the availability of technical support for software titles purchased as bundles from state contracts.

Software tends to be the least expensive component of technology implementations; however, training on operating the new software becomes extremely expensive according to SearchDataCenter (2009). Sandholtz, Ringstaff, and Dwyer (1997) found when teachers were provided training they were still unable to share their knowledge due to insufficient software in the school. The National Education Association (2008) conducted a study that showed lack of technical assistance to support new software also created obstacles for principals.

One of the most important facets of effective use of technology is the principals competence in using available programs and applications (Bozeman \& Spuck, 1991). Sawtelle (2008) proposed nine essential concepts for successful computer software implementation by building level administrator: objectives in place before obtaining software, proper planning before implementation, positive stakeholder involvement, evaluation criteria, effective leadership and adequate technology in the facility, user knowledge, usage monitoring and evaluation of usage from each of the previous stages. Limited understanding in these areas can create additional unnecessary obstacles for principals.

The National Education Association (2008) reported inadequate Internet speeds for accessing online software resources create yet another obstacle for principals. The infrastructure 
and bandwidth (Internet speed) required for operating systems such as the Software as a Service" (SaaS) programs may be inadequate. SaaS is a cost effective software delivery model in which a software vendor develops a web-based software application and hosts the application for use by its customers over the Internet (Stansbury, 2008). Customers pay only for using the software, which is usually cheaper than purchasing hard copies for each computer. According to Stansbury (2008), a survey conducted by eSchool News, stated that fifty-three percent of the respondents utilize SaaS applications in areas that have high-speed access.

Funding. A major barrier impeding technology implementation stated by Chin and Horton (as cited by Stegall, 1998) is the deficiency in the area of funding. Harvey Barnett (2001) states that the overall cost to implement technology create a major obstacle for principals. Kearsley and Lynch (1992) suggest that the major obstacle of insufficient funding is one of the many reasons cited for the relative failure of technology in education. Lack of funding for technology, increased financial responsibility in other educational areas, and lack of approval for increased public taxes create obstacles to technology funding.

Limited funding is a key obstacle to supporting effective school Information Technology (IT) according to an eSchool News survey as reported by Stansbury (2008). Sixty-four percent of those surveyed said their technology support budget is not enough to support technology assets they have already purchased, and nearly seventy percent said it is not enough to meet their district's IT expectations.

Certain mandates such as special education spending are required before allocating funds for technology. The School Technology Report (1998) stated that one district had an increase in student enrollment, which would require hiring new teachers, and re-allocations from other funding 
sources. Maintenance needs requiring a tremendous amount of funds remains a major concern according to this report.

Another district spent more than $26 \%$ of the entire budget on the special education operating budget for fiscal year 1997. Many districts also compete for public funding with other organizations such as transit systems, parks and sports facilities limiting the amount each year available for technology (School Technology Report, 1998).

In addition, principals encounter community tax resistance as another obstacle to overcome when attempting to implement more technology, according to the School Technology Report (1998). Neither local bonds nor special levies (district property tax initiatives) specifically target technology. The public frequently declines higher taxes as an option. An unwilling public refuses to pass special levies or bonds, which could provide additional technology funds. According to the School Technology Report, some state school finance systems limit the amount of funds districts can raise locally to prevent inequity.

The availability of so many funding options to principals does not guarantee funds for technology. The competition for these resources is tremendous and many projects remain partially funded leaving the principal once again looking for additional funds from other sources. Federal, state and county governments provide millions of dollars for technology, but other areas of education have also increased demands for additional funding to maintain sustainability (School Technology Report, 1998). The tremendous expense to maintain technology and provide updated technology equally to all students is an area many principals have difficulty overcoming. This creates more inequality and additional technological obstacles.

Social Issues. For the purpose of this study, social issues include staffing of technological positions, staff development, the motives of principals, and teacher and student perceptions of 
technology. This introductory section includes concerns of attitudes, anxieties, equality and the social impact of technology in education.

Attitudes toward technology and the impact of technology on society are important not just in education but to society. Obstacles that may impede the movement forward of technology as stated by Chin and Horton (1993) include negative attitudes, anxieties, and inequality. Attitudes of principals, teachers and students play a role in the technology implementation process and its success or failure. Anxieties also can slow the advancements of technology by inhibiting the process of change.

Society and the educational systems do not equitably share advances in technology. School districts with money have more opportunity to acquire technology than those without money. Some may say that this is leading to a greater social economic division. Providing equality for all is an important component of the implementation process of technology for principals.

Technology is changing the way we live today and the social impact can be tremendous. Studies conducted on how technology is creating students that isolate themselves from live" interaction with other students continue. Colleges and universities are now offering classes discussing the implications and impact of technology. Georgetown University is offering a class called Social Implications of Personal Technology" during the 2009-2010 academic year. This course will explore the social impact of the use of personal technologies and examine the concept of impact" through a variety of lenses - how it affects our personal and cultural values, how it transforms decision-making abilities and how it empowers and challenges our communication skills. The more technological knowledge future principals have, the more prepared their students will be as they move into tomorrow's world. Understanding the relationship of technology to society is necessary for principals, teachers and students. In addition, its relationship to society as 
they prepare the classrooms of tomorrow, the more prepared their students will be as they move into tomorrow's world.

An important area for technology leadership is the ability to evaluate existing and new technology environments. For example, there are many social and philosophical implications of technology in schools (e.g., Bowers, 1988; Lynch, 1990) as cited by Kearsley and Lynch (1992) that are not addressed in the usual technology courses. Educators must be able to think about the possible side effects and human impact of technology and weigh these consequences in their decision making process (Kearsley \& Lynch, 1992).

Staffing of technology positions. Staffing of technology positions include several obstacles for principals. This section will address the obstacles created by limited technical support, recruiting and hiring issues, the variety of technology support needed, limited funding of technological staff, and the responsibility of the principal as a technology support person.

In addition to having access to hardware and software, principals also need people ware" to support technology resources (Ronnkvist et al. 2000). Sandholtz et al. (1997) suggests that principals invest in technology support rather than additional hardware and software. Sandholtz et al. (1997) suggests a key component of successfully implementing technology is technical support. Teachers need immediate access to individuals that can support the technology both technically and with the integration process into the curriculum and often become a task of the principal.

Stegall‘s (1998) survey analyzed indicators of successful technology programs. Eighty-one percent of the schools surveyed utilized a computer teacher for technological support. Beth Ferguson Coghlan's dissertation, Addressing the Barriers to Technology Integration: A Case Study of a Rural School" (2004) addresses four barriers to technology infusion by teachers, stating limited technology support as a major obstacle. Coghlan's study, conducted over a three-year 
period, collected data to assess technology integration through interviews, observations, and document analysis.

Forrester Research, an independent market research firm, published a recent report titled Staffing for Technology Support: The Need May Be Far Greater Than You Think,” which concluded that large corporations typically employ one support person for every $50 \mathrm{PCs}$, at a cost of $\$ 1420$ per computer, per year (Stansbury, 2008). According to this model, a school district with 1,000 PCs would need a staff of 20 and an annual tech-support budget of $\$ 1.4$ million. Currently some school districts are approaching one technology support person for every 1500 computers (Stansbury, 2008).

The biggest obstacle according to an eSchool News survey is recruiting and retaining Information Technology (IT) staff members. The salaries offered are not competitive enough when measured against similar positions outside of the public schools (Stansbury, 2008).

An additional obstacle to hiring technology staff is limited technology descriptors and certifications in advertised positions especially at the elementary level. This makes it difficult for principals to hire technological trained teachers. Teaching positions remain advertised according to grade level or curriculum area. In the state of West Virginia, positions are filled based on seniority and teacher certification. Specific qualifications such as technological background have little or no emphasis on the individual selected for the position.

According to Ronnkvist et al. (2000), technology coordinators indicated they performed a wide variety of duties within the school and many were unrelated to technology. Forty-five percent of the technology coordinators were also classroom instructors and sixteen percent were media specialists. The study also shows that technology coordinators spend an average of three hours per week troubleshooting, two hours supporting and training teachers, one hour for staff development, 
and less than an hour assisting teachers in integrating technology. This data shows that technology coordinators spend less than 3-5 minutes per week assisting teachers with integrating technology into the curriculum.

A grant writer is one staffing position that may provide support for technology; however, overlooked and ignored there are few hired. By aggressively seeking out grants, principals can offset to some extent the high cost of introducing and sustaining technology in public schools. According to Slowinski (2000b), the culture of schooling affords little time for such endeavors as grant writing. In addition, few school staff members possess the necessary skills and knowledge to engage in the formal preparation of grants.

The School Technology Report (1998) found that technical support staff is more difficult to fund than other components of technology. Stipulations on funding often prevent principals from utilizing funds for hiring staff. According to this report, grant opportunities are often limited to one-year payoffs and would not provide stability in technological staffing. Technical support is often less visible to the public and not deemed as feasible as a new computer lab in the building. The report states that most technology staff, funded primarily from district operating budgets, demand funding for many other competing needs.

Another finding from the literature is that teachers lack the necessary support from principals resulting in teachers who are reluctant to use technology. Additional research of the literature reported that the focus of school principals should be on how teachers are using technology, not just getting the technology into the classroom. Stegall's study from 1998 demonstrated the importance of principals being involved in the hiring of technology literate teachers to increase the success of technology in their building. 
Principals must design technical support with instructional needs of the teacher in mind. They must create convenient access to necessary resources, provide individualized support, train teachers to integrate technology into the classroom, and provide resources as incentives (Ronnkvist et al. 2000). This underscores the need for a systematic approach to creating technology support in our public schools and technological literate principals as leaders. The technologically literate principal will model the way for professional development for the teaching and learning technologies.

Professional development. Through professional development, principals and teachers can become more aware of the role technology plays in learning (Hasselbring, 1991). High quality technology support is comprehensive; it includes a variety of elements that are not simply technical" support such as undertaking routine maintenance and resolving software and hardware issues (Ronnkvist et al. 2000). In addition —instuctional” support includes individualized training, professional development activities and professional development content that focuses on instruction and integration (Ronnkvist et al. 2000). This section discusses professional development obstacles including experience as a teacher, limited availability and method, limited time, amount of principal involvement, and teacher perceptions. The final component of this section briefly summarizes two major professional development initiatives by the United States Department of Education.

Chin and Horton (1993) include deficiencies for technology professional development opportunities for the principal as a major obstacle. However, most of the literature reviewed for this study did not distinguish between teachers and principals‘ professional development. According to CareerinfoNet (2010) the majority of elementary and high school principals (73.9\%) hold a bachelor's degree or higher, most with significant experience in the teaching profession. 
The assumption is that professional development occurs during the role as a teacher. It becomes the role of the principal to initiate professional development.

Professional development and years experience are important factors in how well teachers are prepared to use computers and Internet in the classroom for instruction according to a study conducted by Rowand (2000). Teachers with fewer than three years of service were more likely to feel well prepared to use computers and the Internet in the classroom compared to teachers with 20 years of experience. Teachers with more than 32 hours of professional development in use of computers and the Internet within the last 3 years were more likely to report feeling very well prepared than teachers receiving 0 to 32 hours of formal professional development (Rowand, 2000).

Prensky (2006, p. 20) states that —ducators have slid into the 21 st century--and into the digital age...still doing a great many things the old way." Prensky coined the phrases -digital natives" and -digital immigrants" to describe individuals who have cognitively developed through a time of technological use opposed to those who have had to learn technical techniques for the purpose of work or recreation. According to Horne, Coffman, Campbell, Heller, and Slater (2010) most individuals thirty or older grew up without knowing technology as it is today, hence the word immigrant. Individuals less than thirty years old, referred to as -digital natives," suggests that these individuals have a grasp of the fundamentals of technology (Horne et al. 2010).

Limited availability of professional development according to Hasselbring (1991) is an obstacle. Only one third of all teachers in grades K-12 have had as much as 10 hours of computer training based on a study conducted by Office of Technology Assessment in 1988. Much of this training was learning how to use the computer, not on integrating technology into the classroom. Hasselbring also states that training requires years, not days, with ongoing front-line technical 
support provided, while giving teachers the opportunity to practice what they have learned. Hoffman (1997) suggests teachers' limited time to practice using technology they have learned is an obstacle preventing successful implementation.

A study conducted in 1999 by the National Center for Educational Statistics stated that ninety-three percent of the teachers surveyed cited independent learning as their most frequent method of professional development. Eighty-eight percent of these same teachers cited professional development activities as their second most frequent means of gaining technological expertise. This same study stated that most teachers (77\%) over a three-year period participated in professional development activities in the area of computers or Internet.

Kersley and Lynch as cited by Beth Ferguson Coghlan s (2004) review of literature stated school principals often underestimate the time needed by teachers to learn to use technology effectively in their classrooms and principals do not realize how important hands-on practice is for most people to learn to use new software and hardware. The literature reviewed for this study also cited $82 \%$ of the teachers stated lack of time to learn and plan how to use technology as their greatest barrier to using technology in the classroom.

The National Center for Education Statistics (1999) stated even with professional development opportunities, the amount of time was equivalent to four days or less providing only 12 hours per year. Sandholtz, et al. (1997) stated that principals supporting technology use by teachers provided teachers the time to learn technology skills. The most positive results came from training provided throughout the year and not one-time workshops. Technological barriers according to Harvey Barnett (2001) are lack of time teachers are allocated to incorporate technology into the curriculum and lack of appropriate professional development to reform practices to be more engaging for students. 
According to studies like the Bank Street College of Education's (Cummings, 1995), efforts to integrate technology into classroom practices indicate the most effective mode for assisting teachers in the integration process is professional development. This study states that it takes an average of five years of involvement in professional development for staff to feel comfortable with technology integration.

The principal's involvement in professional development creates trust between teachers and their principals (MacNeil, Spuck, \& Ceyanes, 1998). Their research also states that teachers' job satisfaction is related to how principals ' instructional management focuses on teachers professional development.

MacNeil and Delafield's study conducted in 1998 states that professional development is essential for technology implementation in the schools. Principals need to solve the dilemma of how to provide appropriate technology training for the faculty. Guhlin, (1996) according to MacNeil and Delafield, stated that principals need to be aware of focusing technology training on teachers' needs or technology will fail.

Many teachers perceive technology as being another burden of responsibility added to the already overwhelming load of a teacher (MacNeil and Delafield, 1998). Sandholtz, et al. (1997) found that teachers are more likely to seek help from their peers than principals and technicians. Many times technicians may be new to the building or someone with limited involvement that just visits occasionally and teachers have not built the level of trust with them as they may have with the teacher across the hall they have taught with for many years.

In reaction to the proliferation of technology in schools in the mid-1990s, the United States Department of Education (USDOE) formulated the Technology Literacy Challenge Fund (TLCF). The purpose of this five year, $\$ 2$ billion program was to see that all teachers were technology 
literate by the year 2000 (USDOE, 1996). One of the four major goals of this program was to prepare teachers to teach with technology by providing professional development (USDOE, 1999a).

A second initiative by the USDOE was the E-rate program. E-rate, established through an amendment to the Telecommunications Act of 1996, and co-authored by Senator Jay Rockefeller (D-WV) based funding on school social economic status and provided assistance in many areas of need. West Virginia's average discount from E-rate is approximately $74 \%$ with counties ranging from 20\%-90\%. According to a study conducted by the National School Board Foundation, sixteen percent of E-rate funds pay for professional development (Stansbury, 2008). No matter how planned or funded they are, isolated federal initiatives yield little change in practice.

Stegall's (1998) survey included indicators of successful technology programs examining professional development as a key barrier to the successful implementation of technology. Stegall also demonstrated in her study the importance of professional development and remembering that technology must serve the curriculum, not the other way around."

Principals’technological motivation. Dictionary.com defines technological as -of or pertaining to technology". It defines technology as — thøranch of knowledge that deals with the creation and use of technical means and their interrelation with life, society, and the environment, drawing upon such subjects as industrial arts, engineering, applied science, and pure science”. Motivation is defined as - thact or an instance of motivating, something that motivates; inducement; incentive." Combining these three definitions, defines principals ‘ technological motivation as the principal's perception and actions pertaining to implementing, improving, and maintaining all aspects of technology while inspiring others to meet the technological challenges with a positive approach and attitude for the enhancement of public education. 
Principals must be adept in the area of technology to support technology and motivate others to utilize technology. This section discusses a program and objectives designed by Kearsley and Lynch to improve the abilities of a technological principal. The technical support of the principal, principal's interest in technology, enthusiasm of the principal, benefits of technology from a technological principal, issues associated with technology created by a poor technological principal, ethical and legal issues, and the curriculum and environment will be included in this section.

There is a critical need to establish formal training programs for teachers and school principals in technology leadership. Kearsley and Lynch (1992) developed an outline for a Technology Leadership Training Program with the goal of developing individuals capable of improving our educational system through the wise use of instructional technology. The objectives of this program are:

- Conceptualize and design technology based solutions to educational problems,

- Know and employ strategies resulting in the successful implementation of technological educational solutions.

- Explain and predict the changes that adopting a new technology will entail,

- Understand the strengths and limitations of current and emerging technologies,

- Conduct evaluations of technology, including formative and cost/benefit studies,

- Understand the conceptual and theoretical issues underlying the application of instructional technology.

These objectives assist the principal with focusing on their goals during the technological process. They create a pathway for principals to follow which may assist with overcoming obstacles to technology. 
Stegall (1998) found previously conducted research that the support and leadership of the principal was the key to the successful implementation of technology. According to Harvey Barnett (2001), the lack of leadership is the single biggest obstacle to the use of technology in the classroom. Fullan states in his book, Leading in a Culture of Change, five key components for school capacity. The fifth component and the key to the success of the other four is quality leadership.

Support for teachers is essential for successful use of technology by teachers. Sandholtz, et al. (1997) found that one of the most critical factors in determining technology integration by teachers is the level of support by the principals. Principals send strong messages about their attitudes toward technology and these attitudes greatly affect the level of changes in their schools often based on the level of support they provide.

Sandholtz, et al. (1997) found that teachers who showed the most improvement in technology integration were teachers with support including support from the project coordinators, peers and principals. Teachers easily become discouraged when adequate support is not immediately available. Sandholtz, et al. (1997) found that one of the most critical factors in determining technology integration by teachers is the level of support by principals. Sandholtz, et al. (1997) stated that principals who supported technology use by teachers provided teachers with time for learning technology skills, showed an interest in what the teachers have learned and what they use, arranged technical support, and shared a vision of change with teachers.

Weiss (as cited by Stegall, 1998) found that the amount of money designated for technology has not necessarily correlated to effective use. A more important question is did the principal spend money to create a supportive environment? 
It is very difficult to measure higher-level outcomes generated by the use of technology. Therefore, if there is no evidence of rising test scores," individuals may quickly investigate other methods to support student learning. Principals must continue to focus on the positive results of technology and the benefits of moving our students into a 21 st century environment while providing technological support.

Research by Anderson and Dexter (2005) demonstrates an important and positive relation between the principal's interests in technology and the teachers and students' use of technology in the classroom. This study, conducted utilizing an informational poll, practiced on approximately 400 teachers, 800 technology coordinators and 867 principals in 1150 schools. Other research supports the principal's interest being much more important than the substructure of technology, and it shows that technology leadership is much more effective than the substructure and the expenses of technology in public schools (Birinci \& Kabakci, 2007).

Patricia Stegall (1998) explains why principals' enthusiastic technological leadership is essential for success in her paper, The Principal-Key to Technology Implementation. Stegall conducted a survey of 54 elementary schools and all the principals agreed that technology was an important component of their school. The seven schools with the highest technology scores based on the survey shared one characteristic_-strong, enthusiastic principal leadership.

Stegall's survey included indicators of successful technology programs from her literature review examining the principal's attitude toward technology. Ninety-six percent of principals either agreed or strongly agreed that they had a strong interest in computer technology, and eightyseven percent agreed or strongly agreed that they had a great deal of knowledge concerning computers" (Stegall, 1998, p. 7). Stegall took the study a step further by visiting seven schools and one factor mentioned by all seven was the importance of the enthusiastic leadership of the 
principal. Stegall's studies have demonstrated that when teachers see principals using technology effectively they also felt the need to utilize technology.

According to Kearsley and Lynch (1992), the potential benefits of good technological leadership can include:

- improved academic achievement by students,

- improved student attendance and reduced attrition,

- better vocational preparation of students,

- more efficient administrative operations

- reduce burnout, and turnover among teachers and staff members.

Issues and concerns associated with technology use in education attributed to poor administration according to (Becker, 1997; Dwyer, Ringstaff, \& Sandholtz, 1990; Sheingold \& Hadley, 1990) as cited by Kearsley and Lynch (1992) include:

- lack of knowledge about how to use technology (resulting in ineffectual usage),

- lack of adequate time or funds to properly implement technology,

- use of technology for its own sake rather than genuine need,

- unequal access creating have" and have-not" groups,

- poorly designed facilities resulting in limited access,

- poor instructional results resulting in negative attitudes about technology, over resistance on the part of potential users.

Research by Schoeny, Heaton and Washington (1999) demonstrates that comprehending ethical and legal issues related to technology use is an important function of the principal. This study provides data supporting principals making changes to instructional methods whereby encouraging teachers to become facilitators of learning and providing ways to encourage students 
to take a more active role in their own learning with technology. Principals must also model the successful use of technology and stay abreast of current literature in instructional technology and legal issues concerning technology use, while analyzing and organizing data to make informed technological decisions.

Pellicer, Anderson, Keefe, and McLeary (as cited by MacNeil \& Delafield, 1998) stated that instructional leadership is likely the most important function in a school for creating a productive and satisfying environment” (p. 41). Lou Gerstner, CEO of IBM (as cited by MacNeil \& Delafield, 1998) claims that nothing matters more to America's schools than finding competent principals to lead them.

As the research suggests, the involvement of the principal is consistently relevant to the success of the program. A motivated administrator willing to be part of the implementation process proves to provide a much more successful technological environment. Being a successful technological principal not only requires good general leadership skills but sufficient technology knowledge must also be present.

A key to ensuring the success of technology in schools is the way the principal integrates technology into the school's curriculum (MacNeil \& Delafield, 1998). School principals must understand the importance of technology for improving school management as well as its implication for improved instruction. Instruction is the driving force for the enhancement of overall student achievement and the principal must demonstrate the mastery of the art of instruction.

Teacher and student perceptions. According to a study conducted by MacNeil and Delafield in southeast Texas, teacher resistance does not appear as a high inhibitor, possibly due to technology use becoming more common in the classroom. The National Education Association 
(NEA) Report (2008) also states that most educators have positive perceptions about the value of technology for teaching and learning. According to one finding from NEA (2008), most educators surveyed were highly optimistic about the impact of technology on their jobs and on their students, and they considered technology essential to teaching and learning. Most believed that technology had improved students' motivation for learning.

A study conducted on teacher quality by the National Center for Educational Statistics (NCES) found only $20 \%$ of all teachers felt very well prepared to integrate technology into their classroom (U.S. Department of Education, 1999c). According to a second study by NCES in 2000, nearly $70 \%$ of teachers do not feel well prepared to use computers and Internet in their teaching.

Kearsley and Lynch (1992) cited a study by Wiske, Zodhiates, Wilson, Gordon, Harvey, Krensky, Lord, Watt, and Williams on How Technology Affects Teaching.” This study involved a national sample of teachers and their perspective of what they need to utilize technology successfully. They reported the following needs: easy access and availability of suitable hardware and software; guidance in how to use computers effectively in their classrooms; adequate training and follow-up assistance; layers of support, including aides, computer coordinators, colleagues, and sympathetic principals; more influence on technology policy; and more research of effective strategies of computer use.

A report conducted by the National Center for Education Statistics (NCES) in 1999 showed that administrative support as an obstacle varied by years of teaching experience. Teachers with 10-19 years experience cited lack of administrative support in the area of technology was a great barrier. Teachers with 20 or more years did not cite the administrator's technology expertise as a barrier within their school. However, over fifty percent of all the teachers surveyed cited lack of general support in ways to integrate technology as being a major obstacle. 
According to the NEA Report (2008) even with a positive perception of technology, it is difficult for teachers to participate in required technology training. One of the biggest inhibitors is still that teachers do not feel prepared to use technology for instructional purposes. Some advocates strongly argue that schools of education should place more emphasis on technology in their teacher preparation programs. Even so, only 19 states have requirements in place to ensure technology competency before issuing an initial teaching license (Bausell \& Klemick, 2007). Of the 48 states with technology standards, only four test students on their knowledge of technology (Bausell \& Klemick, 2007). The full integration of technology into teaching and learning will require a systematic and balanced approach that goes beyond just acquiring computer hardware and using limited technology skills (NEA, 2008).

Enthusiasm for technology has led many school districts to alter not only the curriculum but also the delivery of the curriculum. For example, at least 23 states have virtual school programs that permit students to receive instruction online according to Robelen (as cited by the 2008 NEA Report). Moreover, whereas the vast majority of educators in the NEA (2008) study agreed that technology is essential to teaching and learning, educators in urban schools were more likely to believe technology had increased the motivation of their students.

The NEA Report (2008) findings supported the vast majority (86.4\%) of educators agreed that technology saved time in helping them do their job, and a similar majority $(87.5 \%)$ agreed that technology had improved their overall effectiveness in their job. Nearly $89 \%$ of the educators surveyed considered technology as essential to teaching and learning.

There are inequities among the availability of technical support, training, and equipment for teachers but awareness of these inequities could suggest teachers may actually be using technology. Some teachers are more inclined to take advantage of opportunities when they are aware of these 
opportunities and perceive them as beneficial. A study conducted by National Center for Educational Statistics (1999) concluded that students did not have the same equal access to computers at school. Teachers in schools with low minority enrollments were more likely to have the Internet classroom availability than the teachers in schools with high minority enrollments (higher than 50\%) do. This same study showed that eighty-two percent of public school teachers have a computer available in their home. Sixty-three percent of those teachers had Internet access and twenty-seven percent stated they could access their school networks from home.

According to Kearsley and Lynch (1992), users of technology need to believe that their technological requirements will be successful. They must also believe that the implementation of technology is the best solution to an identifiable educational problem. Teachers must receive the technical expertise and support required to maintain the technology in a form consistent with the technology's appropriate use (Kearsley \& Lynch, 1992).

Technology Policy. From fiscal year 1995 to fiscal 1999, the 50 state legislatures appropriated nearly $\$ 4$ billion to instructional technology (Milken Exchange on Education Technology, 1999). In an effort to guarantee a return on their investments, forty-five states have created or are in the process of creating standards for state technology competencies" (Slowinski, 2000a, p 3). According to Slowinski, nine of these states also require teachers to pass a technology related exit exam before graduation. Beginning in 2001 the state of Idaho required $90 \%$ of all district staff members to demonstrate technology proficiency. Faculty members uninterested in acquiring technological skills can rely on an antiquated response of resisting change" (Slowinski, 2000a, p 4). However, the passage of policy often acts as an operational catalyst and impetus (driving force) for change. 
Technology raises many challenges for school leaders, including copyright issues and appropriate use of the Internet. This creates yet another obstacle, as school principals must become aware of at least the fundamentals of technology related school law. The Council of School Attorneys and Technology Leadership Network (CSATLN), a subgroup of the National School Boards Association, states that -apid development of new technologies has outpaced the development of related law, leaving educators in doubt as to how to manage issues of copyright, privacy, liability and security" (Slowinski, 2000b p 3).

Future policies must address computer usage and student involvement of inappropriate actions via the Internet involving other students or staff. However, this requires consideration to our First Amendment and freedom of speech. An example of this could be cyber-bullying or harassment of teachers through the Internet. While addressing these obstacles, principals must create policies that are consistent, fair, and communicated to all involved.

\section{1st Century Skills in West Virginia and Technology}

In an effort to prepare all students to be competitive in the global marketplace, the West Virginia Department of Education joined the Partnership for 21st Century Skills and launched the 21st Century Learning Initiatives. These initiatives include:

1. Frameworks for High Performing 21st Century Classrooms, Schools, and School Systems:

Systematic change requires a common vision at each level of the education enterprise. Thus, West Virginia has developed a series of Framework documents to describe the culture, practices, and processes that characterize high performing $21 \mathrm{st}$ century school districts, schools, and classrooms. These Framework documents, used together, help align the local system toward 21 st century learning. Furthermore, they 
serve as a guide to local improvement efforts as superintendents, principals and classroom teachers make decisions about how to serve the needs of 21 st century students.

2. Rigorous Content Standards:

To educate students who will be internationally competitive, state education agencies must develop curriculum standards that meet the highest level of international rigor.

The WVDE completed a total audit of its Content Standards and Objectives to determine rigor and relevance for the 21 st century. With guidance from international experts, state business and educational leaders and members of the P21 Partnership, West Virginia revised its curriculum standards to meet the rigor of national and international measures such as National Assessment of Educational Progress (NAEP), American College Testing (ACT), Trends in International Mathematics and Science Study (TIMSS) and Program for International Student Assessment (PISA). 3. Instructional Guides for integrating 21 st Century Content, Skills, and Technology Tools:

Successfully preparing students for the 21 st century requires changes in the instructional process. The WVDE believes that teachers need support in this effort by providing exemplars of quality instructional models and user-friendly instructional resources. Using the new curriculum standards as a basis, nearly 120 Pre-k through grade 12 teachers (representing reading, English/language arts, science, social studies and mathematics) met to develop quality lessons that focus on the use of quality formative classroom assessments built upon performance, products and clearly defined 
rubrics. Because of this yearlong effort, classroom teachers will receive support, with at least four 21 st century instruction guides per grade level.

4. Curriculum Standards for 21st Century Learning Skills and Technology Tools:

The WVDE determined that the goals of 21 st century learning required the establishment of statewide curriculum standards, not only for content but also for teaching learning skills and using 21 st century technology tools. Classroom teachers, higher education representatives and WVDE staff, wrote programmatic standards, and formulated policy to define the various categories of learning and technology skills that must be part of the instructional focus in every West Virginia classroom.

5. Technology Integration Specialist:

To support the integration of technology into the instructional process, the WVDE designed an intensive professional development process to certify Technology Integration Specialists. After completing 40 hours of training, participants receive certification that allows them to work cooperatively with classroom teachers in the design of instructional processes.

6. West Virginia Institute for 21st Century Leadership:

To implement a systemic focus on 21 st century learning, strong leadership is essential. Thus, the WVDE convened a statewide planning committee of regional agency staff, superintendents, and principals to design a 21st Century Leadership Institute. The work of this committee resulted in a yearlong professional development process designed to build leadership knowledge and skills related to the Frameworks for High Performing 21st Century elementary schools, middle schools and high Schools. The professional development process includes a 12-day residential experience 
(summer, spring and fall) and a series of interim electronic and face-to-face professional development sessions. The Institute experience culminates with participants presenting an ePortfolio to their local superintendent as part of their annual evaluation process.

7. Professional Development for WVDE Staff and Key Stakeholders:

To develop knowledgeable statewide leaders and serve as a catalyst for change, the WVDE designed nine days of professional development focused on the urgency for change and the six components of 21 st century learning. Convened over a three month period, all WVDE staff, Regional Agency staff, representatives from all institutions of higher education and other key stakeholders met, learned about key 21 st century concepts, discussed implications for their respective roles and determined personal and organization changes that should be made to lead 21 st century learning in West Virginia (WVDE, n.d., 21st Century).

The implementation of 21st century skills emphasizes the support of the WVDE for technology in education. West Virginia public education focuses on technology as a tool to improve student performance and to increase the teaching skills of teachers.

\section{West Virginia Governor's Council for Technology in Education}

The Governor's Advisory Council on Education Technology, formed with the passage of Senate Bill No. 248 in 2005 received the task of developing a strategic plan to improve West Virginia's integration of technology and education. The Advisory Council identified six major areas to focus their efforts; professional development, infrastructure/hardware/software, economic development, 21st century learning/curriculum, higher education/research, and state agency support (West Virginia Governor‘s Advisory Council for Technology in Education, 2005). As mentioned 
previously, the funding mechanism to provide technological opportunities is a major barrier in all categories.

The vision statement of this council concerning infrastructure/hardware/software is $\mathrm{In}$ order to actively participate in a growing global environment, West Virginia will embrace, value and utilize technology to stimulate a robust educational economic and community climate that enhances the lives of all its citizens." Many of the goals developed by this council are current issues principals must devote effort and time such as eliminating obsolete hardware and software, ensure adequate bandwidth (Internet connection speed), establish a technology support structure and manage costs of technology. This council demonstrates the commitment West Virginia has made to the successful implementation of technology into public education.

Many of the same obstacles discussed throughout this document are also concerns of the Governor's Advisory Council. Some of the barriers addressed by the council in 2005 are:

- available funding to support new initiatives,

- flexible purchasing options for local schools,

- providing efficient and effective technical support,

- maintaining E-rate funds,

- adequate communication between higher education and state agencies to promote essential 21 st century skills, and

- equity in distribution of funds based on student enrollment continues to decline creating less capacity to meet the technological needs.

One key to maintaining equality was placing the purchasing cycle on a four-year plan to ensure equitable distribution of new equipment, and to reduce the age of current equipment in the classrooms (West Virginia Governor's Advisory Council for Technology in Education, 2005). 
This council developed components to measure the success of technology implementation; a checks and balance system of groups of students, teachers and principals who measure each group's perception of success on an annual basis. West Virginia technology implementations have also been studied and researched via outside evaluators and researchers. These include such research organizations as Columbia and Hofstra University researchers, Hezel Group, MGT of America, Education Development Center (EDC), and SRI to study the integration of technology into the classroom.

Providing time to teachers for professional development is another obstacle addressed by the Governor's Council. The council deemed it very important to identify current staff development programs and address their relevancy to technology integration. The council determined the importance of providing teachers more time for learning technology and developing a process to integrate more technology into the classroom. The council also identified technological needs of future teachers and communicated these to higher education establishments.

One of the major goals of the council in 2005 was to address the need of staffing schools with Technology Integration Specialist (TIS) to assist with technical and staff development issues. Addressed somewhat with the special requirements of becoming a Technology Integration Specialist (TIS), but still a concern in the hiring of teachers, is the slow change in the certification requirements to include technology. The need for permanent and sustainable TIS positions is truly the missing piece to the puzzle to making technology integration happen successfully at all levels according to individuals surveyed by the Governor's Council.

The Governor's Council is just one resource West Virginia has utilized to assist with removing technology barriers faced by principals each day. Many of the goals set forth by this council began successfully. However, by evaluating each step of the process, the council can 
provide pertinent information to principals to assist with technology implementation and provide opportunities to eliminate some of the technological obstacles.

\section{Results of Basic Skills Program}

West Virginia‘s Basic Skills/Computer Education program has had a powerfully positive impact on student achievement, as detailed in a study released by researchers from Columbia University and Hofstra University. Commissioned by the Milken Exchange on Education Technology, an independent research team studied the effectiveness of the state's 10-year learning technology program (The West Virginia Story: Achievement Gains From a Statewide Comprehensive Instructional Technology Program, Dale Mann, Ph.D., Charol Shakeshaft, Ph.D., Jonathan Becker, J.D., Robert Kottkamp, Ph.D., n.d.). The report cited the West Virginia program for its effective use of technology that led directly to significant gains in math, reading and language arts skills. The study noted that educational gains through technology were cost-effective and increased socio-economic and gender equity. West Virginia received recognition as a national leader in recent years by Education Week's —

The Basic Skills/Computer Education program receives consideration as the nation's most comprehensive statewide approach to computers in education (WVDE, 2008). Since implementation, student scores have consistently raised on both the state standardized testing instrument and the National Assessment of Education Progress (NAEP) (WVDE, 2008).

\section{West Virginia Technology Integration Specialist}

West Virginia has begun a new initiative moving teachers toward 21 st century teaching skills to enhance the technology curriculum in the schools. At the forefront of this initiative is the placement of educators in an integral position as a Technology Integration Specialist. Beginning in 2006 twenty-six counties in West Virginia funded the placement of a Technology Integration 
Specialists (TIS). Over the years, there have been many technology position titles in the public school system. These include, but are not limited to,

- technology coordinator,

- technology support specialist,

- instruction technology coordinators,

- technology mentor teachers,

- curriculum technology partners,

- educational technologists and

- technology support coordinator.

Unlike the above titles," this new position is a paid staffed position defined by the West Virginia Department of Education. The role of a Technology Integration Specialist (TIS) is to empower teachers to harness the power of technology integration for student learning (Hofer, Chamberlin \& Scot, 2004). The position is designed to do more than just help advance technology use; these teachers become global leaders in schools and change agents for curricular and pedagogical renewal" (Hofer et al. p. 3).

West Virginia has developed the TIS position to assist teachers with implementing technology into the classroom. The number of computers and Internet access dramatically increased in the mid-to late 1990s. However, documentation indicates that computer usage by students in classrooms shows only a modest increase (Williams, 2000). Even when technology is frequently used, it often provides skill-and-drill work. Documentation supports the idea that this type of application provides the most benefits for lower performing students (Becker, 2001; Mann, 1999; Reeves, 1998). Utilizing technology for this type of teaching misses a powerful opportunity 
to support higher level thinking skills through constructive activities. Teachers need both technical and pedagogical support to use technology effectively. The design of the TIS does both.

Many teachers in West Virginia who were implementing technology in addition to their regular teaching responsibility have completed the required training to be a Technology Integration Specialists (TIS). Each TIS must be a certified teacher who is able to attend all professional development programs, has a working knowledge of technology integration, and meets the qualifications set by the district and the WVDE. The required training conducted by the WVDE begins with a week of intense technology education. The training for the 2007 and 2008 beginning sessions took place in Charleston, West Virginia. The training continues throughout the year with hands-on and online sessions for a total of 320 hours (WVDE, 2008).

Thus far, as part of this training, the teachers have received laptops; data projectors and whiteboards; interactive resources such as SAS inSchool, ThinkFinity, Think.com, TechSteps, Intel Tech tools; and the related professional development that will give them tools to bring 21 st century instruction to their schools. For example, whiteboards, used to project the image of a computer (laptop) onto a larger screen, allows the entire class to see an image. These boards allow for interaction from the student or teacher directly. The touch sensitive display allows interaction with documents, photos, and other items displayed on the computer screen. It allows manipulation of the material by the student, and instant interaction allows for immediate assessment of the material covered. In addition, TechSteps is an interactive website providing lessons that the instructor can manage and monitor. This also provides immediate assessment results and corresponds directly with the curriculum.

According to the West Virginia Department of Education's Office of Technology, as of August 2008, approximately 400 West Virginia educators have completed the 320 hours to become 
a credentialed technology integration specialist. Once the teachers have completed the required training, they are adequately prepared to implement usable technology skills in their schools. This shared knowledge enables other teachers to integrate technology into their teaching plans to improve student achievement.

Fechnology is at the core of 21st century learning," said West Virginia State Superintendent of Schools Steve Paine. He continued,

In a digital world, the 21 st century learner must learn to use technology to master the core subjects and other important skills. Teachers play a critical role in how students learn the skills required to succeed in the 21 st century. (WVDE, 2008, p. 1)

One model WVDE would like to see implemented with the TIS position is schools with 20 or fewer teachers have at least one half-time TIS for the entire school year and schools with more than 20 teachers have one full time TIS on staff (WVDE, 2008, p. 1).

According to the Enhancing Education Through Technology (EETT) job description, the TIS position developed to provide training and support to staff on technology integration. The EETT competitive grants established by the No Child Left Behind Act of 2001 provide partial funding for the TIS positions in WV. The major functions of the TIS fall into three categories. Planning and facilitating teaching and learning includes modeling technology use, providing staff development, and instructing students. Planning and facilitating information access and delivery would be function two including introducing best practices for safety, collaboration with the principal and county technology team members, and planning for technology infrastructure upgrades. The third major function would be planning and facilitating program administration by providing leadership, collaboration with teachers, evaluation of current technology plan, and addressing curricular needs. 
Appendix A includes a sample copy of a TIS job description taken from a national posting. It does not require a separate credential for the TIS but lists teacher certification and preferred technological skills. Included in Appendix B is a sample job posting for a TIS position in an elementary school in Nicholas County, West Virginia. As stated in the job description it prefers a credentialed TIS or agreement to work toward this credentialed training. This demonstrates the movement in West Virginia public schools toward implementing a TIS position for the role of supporting teachers. Included in Appendix $\mathrm{C}$ is the current EETT grant application for a job description (Appendix D of Grant) that counties must follow if applying for state funding for the TIS positions.

The Enhancing Education Through Technology (EETT) grant program funds many of the TIS positions. The EETT grant has three main goals. The first is to improve student academic achievement using technology in schools. The second is to assist every student in crossing the digital divide by ensuring that every student is technologically literate by the end of eighth grade. The third is to encourage the effective integration of technology with teacher training and curriculum development to establish successful research-based methods. Some building level principals have elected to fund these additional positions by relinquishing a teaching position, an obstacle faced by many principals attempting to determine what positions would most benefit their students.

Angie Urling (personal communication, November 10, 2008), a TIS for three years at Lincoln County High School, is filling one of these Technology Integration Specialist (TIS) positions in West Virginia. She considers this position essential for the success of technology integration into the classroom. Some of her most important responsibilities consist of assisting students in the media center or computer lab, co-teaching with other teachers utilizing technology, 
and scheduled times to assist teachers with technology such as mobile labs and SMART Boards. She carries a PDA (handheld device) with her at all times to track questions and create an accessible database providing answers to many questions (A. Urling, personal communication, November 10, 2008)).

Angie's position, funded for the first year with the EETT grant, also provides funds to assist with providing equipment and professional development. Currently there is no funding for professional development so she has to be creative and utilizes teachers' lunchtime for Eunch and Learn" sessions. The teachers receive lunch, and Angie provides them with technological information for twenty minutes. The information includes items such as, appropriate websites for the classroom, upcoming training and allows time for teachers to share successful ideas with each other. She supports 75 teachers in a 21 st century environment that is rich with technology.

Traci Monachello (personal communication, January 6, 2009), currently a TIS in Lewis County, had been teaching English since 1995 and is now a TIS after completing the training in 2005 required by the state of West Virginia. Not only is Traci responsible for assisting with the integration of technology with the teachers but also provides limited technical support school-wide. One of her main responsibilities is creating lesson plans for teachers and models successful use of technology in the classroom. Her plan of action when implementing new ideas consists of creating the lesson plans, sharing with the teacher, lead the lesson on day 1, work with the teacher on day 2 and perhaps leaving the room some, and on day 3 just provide assistance if needed. This allows the teacher to become independent and feel confident if he or she requires assistance.

One of her struggles is balancing academics" with technology." Traci is responsible for the Aquity Bench Mark testing with all students. She also assists with the Online Writing Assessment and preparing students for the Westest (a custom designed assessment for West 
Virginia students to measure defined standards and skills). She has to be cautious not to encompass too much of her time with teachers demonstrating simple websites that are for test prep or skill improvement. There is still a level of frustration according to Traci that teachers are not meeting the technology CSOs (Content Standard and Objectives) even when using certain levels of technology in the classroom. Traci states technology has to become seamlessly integrated into the curriculum, not a separate entity used to showcase one item."

Traci works ten additional days compared to a regular classroom teacher's contract. This provides her some flexibility with scheduling and working after school or during the summer with teachers. Traci states, "my favorite part of the position is teaching teachers project based technology assignments and then watching the kids learn the new cool technology skills."

For many West Virginia teachers, the technology integration specialist is their first and only contact with technology. Across the state, they help the reluctant and eager teacher alike to build on their vast subject knowledge and incorporate technology into their lesson plans. $\mathrm{It}^{\text {‘ }} \mathrm{s}$ always exciting when we see once hesitant teachers work with a technology integration specialist and gain the confidence and incorporate technology into their lesson plans," said Vicki Allen, assistant director of West Virginia Department of Education's Office of Technology (WVDE, 2008, p. 1).

As the demand continues to grow for technological support in our public schools, West Virginia continues to address these needs as a leader of 21 st century skills. The Technology Integration Specialist position provides a means to support technology and assist with integrating technology components into the classroom. Teachers receive individual support and the opportunity to utilize technology successfully in their classrooms with the assistance of a Technology Integration Specialist. 


\section{West Virginia Policies Relating to Educational Technology}

Although there are many federal, state and county policies that principals must comprehend, three specific state policies govern the operation and use of technology. West Virginia policies that pertain to technology implementation and Internet use are WVDE Policy 2470, WVDE Policy 2460 and WVDE Policy 2450. Three additional policies that relate to technology use and implementation are Policy 2520, Policy 5310 and Policy 5100.

West Virginia Policy 2470 establishes regulations for educational technology for West Virginia public schools. This policy was one of the first pertaining to technology enacted on July 1, 1997. The policy focuses on students as lifelong learners acquiring both the necessary skills and access to technology tools enabling them to take responsibility for their own learning, to be actively involved in critical thinking and problem solving, to collaborate and cooperate, and to develop as productive citizens (WVDE, 2470). Technology requires integration with educational improvements and reform through policy to accomplish educational goals, increase student achievement and provide increased opportunities for lifelong learning.

Policy 2470 establishes guidelines for local school improvement councils to assist with fostering the growth and use of technology. This policy required all county boards to have a county technology team and comprehensive technology plan by December 31,1997 . It is the responsibility of the county boards to ensure computer technology skills are included in all programs of study (WVDE, 2470).

West Virginia Policy 2460 enacted on September 9, 2001, Safety and Acceptable Use of Internet by Students, -establishes criteria for the safety and acceptable use of the Internet by students, educators, school personnel, and West Virginia Department of Education Employees" 
(WVDE, 2460, 1.1). This policy has been revised to include the new federal regulations regarding issues of child safety and acceptable use of the Internet" (WVDE, 2460, Purpose).

The Internet provides millions instant access to electronic email, information, news, software, discussion groups, connection to libraries, virtual courses, businesses, online staff development, and many electronic educational tools that must be regulated by WVDE policy. WVDE Policy 2460 specifically describes acceptable and non-acceptable use of the Internet by students and staff. With connections to computers and people all over the world, comes the availability of materials that may not be considered appropriate or have educational value. Policy restricts Internet use by staff and students from public school computers to educational purposes only. Principals must enforce this policy by monitoring staff usage of the Internet and addressing concerns of inappropriate use. Lesson plans and classroom visitations by building level principals ‘ monitor student use. Other means such as software packages are also available to principals allowing them to monitor Internet use and track students through user login names.

Distance learning and the West Virginia Virtual School is regulated by Policy 2450 enacted September 11, 2002. This policy establishes requirements for distance, online, and technology delivered learning programs, including student needs, course content, teacher/facilitator guidelines, virtual classes, funding and management at the state, county and school levels. - Thqurpose of this policy is to assure consistent high quality education for the students of West Virginia while utilizing technology-delivered courses" (WVDE, 2450, 2.1).

A policy also providing requirements for technology in West Virginia public schools is West Virginia Policy 2520, which determines the instructional goals and objectives for all areas of the curriculum. Section 2520.14 defines the content standards (or instructional goals) and 
objectives specifically for technology. The West Virginia Standards for 21 st Century Learning integrate 21 st century learning skills and 21 st century technology tools into three standards:

- Standard I: Information and Communication Skills, states the student will access, analyze, manage, integrate, evaluate, and create information in a variety of forms using appropriate technology skills and communicate that information in an appropriate oral, written, and multimedia format;

- Standard II: Thinking and Reasoning Skills, states the student will demonstrate the ability to explore and develop new ideas, to intentionally apply sound reasoning processes and to frame, analyze and solve complex problems using appropriate technology tools; and

- Standard III: Describes Personal and Workplace Skills (WVDE, 2520.14).

These three standards from WVDE Policy 2520.14 reflect the content found in the six national standards published by the International Society for Technology in Education (ISTE). The six national standards are basic operations and concepts, social ethical and human issues, and technology productivity tools, and technology communication tools, and technology research tools, and technology problem solving and decision making tools (WVDE, 2520). The performance descriptors for the area of technology described in Policy 2520 are:

- distinguished,

- above mastery,

- mastery,

- partial mastery and

- $\quad$ novice.

An example of a fourth grade objective is TEC.4.1.1 stating the student will demonstrate with some proficiency proper finger placement for all keys on the keyboard. Another standard 
TEC.4.5.1 states the student will select and use appropriate software and/or other technologies to locate and acquire information from electronic resources (WVDE, 2520).

Policy 5310 enacted on September 11, 2002 has two major purposes: - -t甲romote professional growth and development and assure quality performance in West Virginia Schools and to provide evaluation data as one basis for sound personnel decisions" (WVDE, 5310, 2.1). Technology standards became a part of this evaluation process on July 1, 2003. The standards require teachers to demonstrate competency and knowledge in the implementation of technology standards identified by the West Virginia Board of Education policies, based on the ISTE standards. These items reflect instructional leadership competencies from WVDE Policy 5310: (a) Demonstrates a sound understanding of technology operations and concepts; (b) applies technology to facilitate a variety of effective assessment and evaluation strategies; (c) uses technology to enhance productivity and professional practice, and; (d) understands the social, ethical, legal and human issues surrounding the use of technology in PreK-12 schools and applies that understanding in practice. (14.8)

West Virginia Policy 5100 establishes the process for developing, implementing and receiving West Virginia Board of Education approval to operate an educational personnel preparation program leading to West Virginia licensure. The purposes of WVDE Policy 5100 are

a. Establish a collaborative process for program approval;

b. Improve educational personnel preparation programs and potential educational personnel by incorporating program guidelines based on research and best practices;

c. Ensure that those who are prepared for employment in the public schools have the knowledge, skills and dispositions necessary to function as entry-level members of the profession; and (d) Ensure that higher education institutions work collaboratively with the 
public schools in designing and delivering professional educator preparation experiences to increase student achievement through written agreements with public schools.

This policy is important because it establishes requirements for public schools and higher education pertaining to the implementation of 21 st century skills and the ever-changing needs of our workforce. Section 9.3.1 of the Instructional Technology Content in Administrator Preparation states, All administrator preparation programs must contain a minimum of three semester hours of preparation in instructional technology" (WVDE 5100).

These policies became an integral part of the educational system as technology arrived in the educational system. The West Virginia Department of Education addresses many issues and concerns with utilizing technology in the classroom. As technology continues its incorporation into the educational process, West Virginia policies must provide guidelines for teachers, principals and students addressing the successful utilization of technology.

\section{National Technology Trends in Education}

This section discusses the national trends of technology in education. Principals in West Virginia have successfully utilized technology since the early 1980s and followed a process that has placed West Virginia public schools among the top states for technology utilization. A major concern in education today focuses on funding a variety of programs while the amount of funding continues to decrease annually. Approximately $\$ 265$ billion is spent a year on education with 63.1\% going directly to teachers' salaries and benefits (Monk, Pijanowski, \& Hussain, 1997). Many school districts are choosing to utilize available funding to implement large amounts of technology such as laptops, computer labs and Internet access for students, thereby enhancing the educational system. 
Research continues to concentrate on the successes and failures of our educational system as we utilize expensive technology to enhance our students` educational process. Over time, the perception developed that technology was going to change education. Technology arrived in the classroom as early as the 1960s with television, and continued through the 1980s with the use of videodisc players.

Technology implementation remained relatively unchanged through the late 1990s. Nevertheless, studies of instructional uses of technology over the past decade have taken a new turn. Technology utilized as a teaching tool compared to conventional instruction supports the assertion of technology and increased implementation levels. The effects technology has on learning in the classroom, and how the teaching process through technology use has changed the learning role of the student is still a difficult area to examine (United States Dept. of Education, 1993).

One of the barriers principals face with technology relates to funding. Technology funding continues to decrease after peaking in 2003. As funding decreases, it increases the difficulty for principals to maintain a successful level of implementation of technology. Spending trends according to Bakia, Mitchell and Yang show that 1998 Federal spending on technology was just over 1.6 billion dollars increasing steadily through 2003 reaching 2.7 billion dollars. As of 2006, the estimated spending had dropped to 2.3 billion dollars.

Computers and the Internet play an obvious role in Pre-K through 12 education. Technical feasibility drives the hardware, software and curricula of today, instead of the benefits teachers and students can gain in the actual classroom. Schools are spending millions on computers, wiring and applications software, a windfall for vendors who insist the money spent will result in improved accountability and alignment to standards. In 1994, approximately thirty-five percent of public 
schools connected to the Internet. By the year 2000, nearly ninety-eight percent of schools accessed the Internet (The CEO Forum, 2001).

Teacher use of computers for daily planning and/or teaching jumped from forty-seven percent in 1998 to seventy-six percent in 2000. The number of teachers with email addresses has gone from thirty-nine percent in 1998 to seventy-seven percent in 2000 (The CEO Forum, 2001). This educational equivalent of the automated battlefield is attractive to decision makers who know little about either computers or instruction and are suspicious of the classroom as an arena of human interactions that are difficult to quantify (Warhaftig, 2005).

According to a study conducted in 2001 by The CEO Forum, Year 4 Star Report, only nine percent of fourth grade students use computers for schoolwork almost every day. This study also shows that nearly $55 \%$ of fourth grade students never or hardly ever use computers for schoolwork. Technology in the elementary classroom has increased drastically over the past ten years at a tremendous expense to school systems. Research supports that the use of computers is beneficial in the classroom and the administrator's role is vital for the success.

In 1998, American Schools spent \$5.2 billion in technology, outpacing the year before by nearly \$1 billion. In 1988, there was one computer for every 37 students (Ravitch, 1998); now many schools average one computer for every three students. According to The CEO Forum School Technology and Readiness Report, the ratio of students to computers has gone from 10:1 in 1995 to 5.4:1 in 2000. More than ninety-eight percent of American schools are now online. At this pace and expense, technology must be proven to enhance education or the funding needs to be redirected.

Current differences in computer use among students are smaller than those differences found among adults in previous analyses (e.g., U.S. Department of Commerce 1999). This reflects 
the fact that most students now use computers. For example: in 2001, adults with graduate education were four times more likely than adults with less than a high school credential to use computers. Adults living in families making over $\$ 75,000$ per year were three times as likely as those in families making less than $\$ 20,000$ per year to use computers, reflecting differences of 66 and 58 percentage points, respectively (DeBell \& Chapman, 2003). In contrast, students with a parent with some graduate education were about 1.2 times more likely to use computers than students whose parents have not completed high school, reflecting a difference of thirteen percent. The weighted sample represents approximately 58.3 million non-institutionalized children age 3 and older in nursery school through 12 th grade in October 2003. These estimates exclude children in long-term medical care facilities and juvenile detention facilities, as well as those who have dropped out of school. The Current Population Survey defines nursery school as a group or class organized to provide education for children before kindergarten. It includes preschool and prekindergarten. Reported usage may involve the cooperation or assistance of an adult or older child, but the report did not include that information. All differences cited in this report are significant at the .05 level using the Student's $t$ statistic. When analyzing data from large samples, many differences (no matter how substantively minor) can be statistically significant. The discussion is limited to differences of at least 5 percentage points.

Most of the 88 million offspring of baby-boomer adults find using digital technologies (such as computers and video games) no more intimidating than using a VCR or a toaster (Kimble, 1999). Tapscott (1998) calls these children the Aet Generation" in his book, Growing Up Digital. He cites a 1997 survey by Teenage Research Unlimited in which more than eighty percent of teenagers polled said it is "in" to be online, a rating that puts being online par with dating and 
partying. The job market tends to dictate the skills students must have when graduating and today's society has become intensely dependent upon technology.

In 1948, the General Assembly of the United Nations made a declaration that has the potential to remake civilization (Bennett, n.d.). The declaration stated simply, everyone has a right to education" (p. 1). According to this study conducted by the General Assembly, more than 100 million children, including at least 60 million girls, have no access to primary schooling. More than 960 million adults, two-thirds of whom are women, are illiterate. Millions of children who begin primary education do not acquire essential knowledge and skills. Their goals were to decrease the 1990 adult illiteracy rate by half with emphasis on female literacy, universal completion of primary education, and provide basic education for all by the year 2000. In 2000 their study proved to be dismal, there were still 113 million children with no access to primary education. In addition, 880 million adults remained illiterate. The study concluded that by the year 2015, - countries accounting for twenty-six percent of the world's population might not meet any of the three measurable goals" (p. 3).

Bennett (n.d.) argued that one solution to this problem might be the use of technology. However, he stated that during the years when American schools added millions of computers, national test scores did not improve. There was no significant change in test scores on the National Assessment of Educational Progress test for reading, mathematics or science. This study included three age groups; nine year olds, thirteen year olds, and seventeen year olds, from 1994 through 1999 (Bennett, n.d.). Obviously, the method of implementing technology in schools in the United States did not improve education.

Teachers training on technological integration with curriculum utilize technology about thirty-two percent of the time (The CEO Forum, 2001). Only ten percent of teachers will admit to 
being *ery well prepared" in the use of technology in their classroom (p. 27). All of these factors are non-existent if school districts do not have the technical support of individuals to train teachers, upgrade computers, repair computers, and this support system is not without great expense. An additional component to include is the ever-changing field of technology, what is pertinent today will be obsolete by the end of the year. Once again, returning to the amount of funding school systems have for technology and comparing the actual results teaching with technology provide. Are schools investing in the correct area?

Although many aspects of education tend to look at long-range goals, e.g., the Five Year Strategic Plan, technological implementation by many school districts does not consider the longrange costs. The goal is immediate, how many computers can we purchase for the school? Many businesses look at a concept known as — total ost of ownership," or TCO (Hurst, 2005). The Appalachia Educational Laboratory, a nonprofit organization in Charleston, WV, researches school improvement and began developing online tools designed to help districts gather and analyze their own TCO data. This concept is just beginning to filter into the educational system. This system helps organizations measure and manage the direct and indirect costs of acquiring, maintaining and using technology. The collection of key information such as salaries, hardware and software costs, repair expenses, staff training and equipment supply costs plugged into a software program calculates the long-term costs of technology. This gives school districts the opportunity to see what areas of technology may fall short of funding, a tremendously beneficial tool for principals to utilize for maximizing implementation of technology.

One of the first school districts to utilize this TCO system was in Texas. The school district felt they were doing well with technology but the financial analysis revealed that a majority of the district's computers was less than three years old and nearly sixty percent of its 192 network 
servers, which supported these newer machines, were outdated. It reported a waste of more than $\$ 200,000$ a year on ink cartridges for their 3,300 ink jet printers because the system could have used money-saving laser printers (Hurst, 1999). A levy or tax based funding is another method considered by many districts to fund technology. However, voters do not approve many levies.

Not surprisingly, teachers and researchers found that an array of tools for acquiring information and for thinking and communicating allows more children more ways to become successful learners. However, they also found that technology itself is a catalyst for changeencouraging fundamentally different forms of interactions among students and between students and teachers, engaging students systematically in higher-order cognitive tasks, and prompting teachers to question old assumptions about instruction and learning (ACOT, 1995).

Kulik (1994) summarizes a large number of meta-analyses of computer-based instruction from the 1980s. He finds an average effect size of .32 standard deviation units for all computer uses. Effects vary with the type of research design, source of the study (dissertation or professional evaluation), duration of the study, type of computer use (tutorial, enhancement, management, simulations, programming), and the educational level of the intervention. Kulik (1994) noted that the average effect size of computer-based instruction compares favorably with a number of other innovations implemented in schools.

Most critics do not refute positive research results but instead criticize technology use in the classrooms, the technical expertise and preparedness of the teachers, and the relative costs of acquiring technology (Kimble, 1999). Technology is making a significant, positive impact on education. Important findings are included in these studies.

(a) Educational technology has demonstrated a significant positive effect on achievement. Research suggests that positive effects result in all major subject areas, 
in preschool through higher education, for both regular students and special needs students. Evidence suggests that interactive video is especially effective when the skills and concepts taught have a visual component and the software incorporates a research-based instructional design. The use of online telecommunications for collaboration across classrooms, in different geographic locations, leads to improved academic skills.

(b) Educational technology leads to positive effects on student attitudes toward learning, in addition to improving students self-concepts. Students felt more successful in school, were more motivated to learn and have increased self-confidence and selfesteem when using computer-based instruction. This was particularly true when the technology allowed learners to control their own learning.

(c) The level of effectiveness of educational technology is influenced by the specific student population, the software design, the teacher's role, student groupings and the level of student access to the technology.

(d) Students trained in collaborative learning, had higher self-esteem and student achievement.

(e) Introducing technology into the learning environment makes learning more studentcentered, encourages cooperative learning, and stimulates increased teacher/student interaction.

(f) Positive changes in the learning environment brought about by technology are more evolutionary than revolutionary. These changes occur over a period of years, as teachers become more experienced with technology. 
(g) Courses for which computer-based networks were use increased student-student and student-teacher interaction, increased student-teacher interaction with lowerperforming students, and did not decrease the traditional forms of communication used. Many students who seldom participate in face-to-face class discussion become participants that are more active online.

(h) Greater student cooperation and sharing and helping behaviors occurred when students used computer-based learning that had students compete against the computer rather than against each other; and

(i) Small group collaboration on computer is especially effective when student have received training in the collaborative process (Institute for the Transfer of Technology Education, 1995).

Technology can provide teachers a method of enhancing the classroom environment and provide students the opportunity to use computers as a tool for success. The literature reviewed supports technology as a tremendous influence in our society and students must have the opportunity to use technology, as these will be skills required by our ever-changing world. Some of the studies also provide many reasons that technology may be successful in education such as teacher expertise in the field of technology, time spent using technology in the classroom (ACOT, 1995), students' willing participation when using technology, and providing a comfort zone for many students to be successful. Administration must address all of these areas, and thereby influence the success or failure of technology.

This brief introduction to the trends of technology in America's public schools, the benefits and concerns, provide research to principals that may assist them when creating plans to implement technology successfully and remove many barriers within the process. 


\section{Research Findings: Bakia, Mitchell and Yang}

The National Educational Technology Trends Study (NETTS) is the result of collaborative work by SRI International, The Urban Institute and the American Institutes for Research (AIR) completed for the U.S. Department of Education. Marianne Bakia, Karen Mitchell and Edith Yang were the contributing authors of the project. - - The recent proliferation of information and communication technologies, including desktop and laptop computers, handheld devices, cell phones, portable video players, and the Internet, has transformed the world in which we live. In just a decade or two, the ways in which people shop, bank, work and communicate have changed sufficiently to suggest to many that children growing up today will require a new and more demanding intellectual skill set to thrive in adulthood. As a result, many experts recommend that students' ${ }^{6}$ educational experiences be reformed to better prepare students for their future" (Bakia et al. 2007).

Key findings from this report established that forty-two states had technology standards in place by fall of 2004. Of these forty-two states, eighteen reported having -stand-alone" standards, and sixteen reported embedding technology standards with other academic content standards. The remaining eight states reported having both stand-alone and integrated technology standards.

Two states reported that they used statewide assessment of students' proficiency with technology. Eleven more states reported plans to begin assessment of technology skills. Assessments required and collected at the state level allow a common framework for evaluation of state standards across a state and increase the probability that districts can compare results.

More than half of the states (27) reported on the survey that they had technology standards for teachers in order to specify the knowledge and skills that teachers need to use technology for 
administrative and instructional purposes. Five states formally assessed teachers ${ }^{`}$ technology skills at the state level.

Just over half of the states reported the provision of activities related to online education, with twenty-six states reporting that they provided online courses, tutorials, software, and other academic content and resources in core subject areas. Sixteen states reported offering Internet or computer based assessments of students ${ }^{\varsigma}$ academic achievement. Five states made electronic networks and other distance learning a priority for Enhancing Education Through Technology (EETT) competitive grants in 2003.

According to this study, technology is increasing in our schools at a tremendous rate. States are addressing issues concerning technology as they arise, reactive not proactive with a movement to -pla" better and establish guidelines for success with an evaluative tool for assessment. Student assessment has become a much larger part of technology and teacher expectations are continuing to increase. This will result in the need for additional professional development, technical support and technological literate principals leading our schools. 


\section{Chapter Three: Method}

This study examined the principals ' perception of barriers to implementing technology at the elementary, middle, and high school level. The purpose of this chapter is to explain the methods used in this study, and the collection and analysis of data. The method of obtaining data directly affects the result of the study (Suskie, 1996). This chapter includes

○ Research Design

- Research Participants,

- Table 1: Representation of Schools for Sample

o Survey Development

- Web Surveys,

○ Reliability and Validity,

- Panel of Experts,

- Pilot Study,

- Data Collection,

- Data Analysis, and

○ Summary.

This quantitative study utilizes a survey for data collection, which involves administering questions to individuals. Quantitative research uses methods adopted from the physical sciences. The design ensures objectivity, generalizability, and reliability (Weinreich, 1996). According to WordIQ (2009), objectivity is the conclusion drawn through interpretation of the results of data analysis and should be based on facts of the findings derived from actual data and not from our own subjective or emotional values. Generalizability is the ability to make inferences (the 
reasoning involved in drawing a conclusion) from a sample to the population (WordIQ, 2009).

Reliability is the extent to which a measure will produce consistent results (Weinreich, 1996).

A quantitative survey, designed to collect and utilize data, measured perceptions of principals implementing technology in West Virginia public schools. Actual research considers the researcher as external to the actual research, and replicable results expected. The quantitative data should be applicable to a larger population with similar characteristics.

\section{Research Design}

The researcher answered four main questions:

1. What technology support do West Virginia principals provide to teachers?

2. Who do West Virginia principals rely on to provide technology support when unable to do so themselves?

3. What facilitates principals` implementation of technology in West Virginia public schools?

4. What impedes principals` implementation of technology in West Virginia public schools?

Six hundred and fifty-eight West Virginia principals were selected to participate in an online survey utilizing Survey Monkey. Survey Monkey is a private American company that enables users to create their own web-based surveys. This survey included content based on the review of literature using a five-point Likert Rating Scale and a questionnaire to determine background demographics of the principals.

Incentives offered to a randomly selected number of participants that complete the online survey increased participation. These incentives were offered through a tiered model providing 
more opportunities for those submitting the completed survey as the first fifty participants. This incentive program was utilized increase the response rate.

A participation rate of $70 \%$ is ideal according to Suskie (1996) with a minimum of 50\%. A goal of not less than $43 \%$ represented from each level of principals includes 283 principals responding out of 658 . This would include 183 elementary, 53 middle school, and 47 high school principals responding to maintain equal representation. To reach a $70 \%$ response rate, 464 of the 658 principals must respond. This would include 300 elementary, 87 middle school, and 77 high school principals for equal representation of each group.

Research participants. Principals in West Virginia received the opportunity to participate in this online survey through Survey Monkey. WVDE webpage maintains a list of information pertaining to principals in West Virginia, including school addresses and grade configuration. Using the principal's name on http://access.k12.wv.us:1026, provided the email addresses for each principal, and this information was utilized to create the spreadsheet of contact information.

The number of principals participating in the survey affects the size of the study. There are a total of 658 schools with at least one principal currently in West Virginia public schools at the following levels: 425 elementary, 124 middle, and 109 high schools according to a 2008 West Virginia Department of Education (WVDE) database. This survey did not include the five West Virginia Pre K-Twelfth Grade configured schools, Career Technical schools, and the individual Headstart programs in West Virginia. The Pre-K through Twelfth Grade configuration does not always include an elementary, middle school, and high school level principal. These schools may have one, two or three principals responsible for the entire building, and it would be difficult for the purpose of this study to divide their responsibilities and may skew survey results. The Career Technical schools focus on specific job related skills and the focus of technology within this type 
of configuration may skew the results of the survey. The individual Headstart programs generally operate under the supervision of a county level director, not a principal.

The elementary schools include configurations listed as PK-2, PK-3, PK-4, PK-5, PK-6, PK-8, 3-5, and 4-6." The elementary configuration for this study relies on administrative certification of K-8 in West Virginia public schools. The middle school configuration consists of sixth through eighth grade only. The high school configuration includes ninth through twelfth and sixth through twelfth. The sixth through twelfth grade configuration participated in the high school configuration based upon administrative certification of 5-12 in West Virginia public schools as shown in Table 1.

Table 1

WV Public Schools: Representation of West Virginia Principals

\begin{tabular}{ccccc} 
& $\begin{array}{c}\text { Principals } \\
\text { Surveyed }\end{array}$ & $\begin{array}{c}\text { Percent of } \\
\text { Representation } \\
\text { By Group }\end{array}$ & $\begin{array}{c}\text { Participants to } \\
\text { Maintain a 70\% } \\
\text { Response Rate }\end{array}$ & $\begin{array}{c}\text { Minimum } \\
\text { Response Rate } \\
43 \%\end{array}$ \\
\hline Elementary Schools & 425 & $65 \%$ & 300 & 183 \\
Middle Schools & 124 & $18 \%$ & 87 & 53 \\
High Schools & 109 & $17 \%$ & 77 & 283 \\
\hline Total Schools & 658 & $100 \%$ & 464 &
\end{tabular}

According to Suskie (1996), a sample of participants will provide beneficial results for most surveys conducted. Example: a sample size of 217 from a population of 500 provides an approximate sample of $43 \%$ and according to Suskie (1996), $43 \%$ of population is an appropriate sample size. A population of 1,000 requires approximately $37 \%$ of the population for an appropriate sample. For this study, 283 principals from the 658 schools will provide a response rate of approximately $43 \%$. To maintain a 70\% response rate, approximately 464 of the 658 
principals will have to complete the survey. To maintain a $70 \%$ response rate per group, a minimum of 183 elementary principals, 53 middle school, and 47 high school principals must respond. This represents a proportional number at each level. A participation rate of $70 \%$ is ideal according to Suskie (1996) with a minimum of 50\%. E-mail and web-based surveys before the year 2000 received response rates of nearly $90 \%$ but the rates have steadily declined since then, with a response rate of $30 \%$ to $60 \%$ according to WordIQ (2009).

Simmons and Wilmot (n.d.) stated response rates to social surveys, where participation is voluntary, have fallen in recent years. Offering incentives will increase the response rate of the participants. Simmons and Wilmot (n.d.) review of literature stated that offering incentives shows an increase of $4.5 \%$ to $19.1 \%$ of response rates. According to Survey Monkey, the incentives require careful selection, so as not to skew the results. An example of skewing the results may be by providing an i-Pod as an incentive. A younger population of participants may be more likely to submit the survey to receive this item. For an older population of participants, this item may not be an incentive so they are not motivated to respond.

Randomly generated numbers through Survey Monkey matched the participants that have completed their surveys to participate in the incentive drawings. The first 50 respondents obtained eligibility in a drawing to win a $\$ 100$ cash card from a local gas station or grocery store. These first fifty participants received a second chance for eligibility in another drawing (minus the first winner). The second fifty respondents were eligible for a drawing for a $\$ 50$ cash card from a local gas station or grocery store. The third and final drawing consisted of four winners, all the participants that have submitted the survey, except for the first two winners, are eligible for one cash card at a local gas station or grocery store with a value of $\$ 25$. The winners received notice 
via telephone once the survey is completed and removed from online access. The USPS will deliver the incentives.

This study did not harm in any way the principals involved in completing the survey. Anonymous surveys collect the data. The information collected is in the form of numbers and responses contain no linkage back to the respondent. The researcher, an elementary principal, was not working with any other outside organizations that have influence or authority over individuals responding or not responding to the survey. The research will maintain anonymity and confidentiality at all times. All participant and researcher documents will receive a review by the Institutional Review Board (IRB).

Since the research will involve human subjects, the research will meet the four criteria required by federal regulations (specifically, 45 CFR 46, Subparts A-D). These include risks to minimal risk to subjects; reasonable risks to subjects, equitable selection of subjects, and receipt of appropriate informed consent (Suskie, 1996). The IRB of West Virginia University will ensure that this research meets these criteria.

\section{Survey Development}

The survey design collected data pertaining to four main questions:

1. What technology support do West Virginia principals provide to teachers?

2. Who do West Virginia principals rely on to provide technology support when unable to do so themselves?

3. What facilitates principals‘ implementation of technology in West Virginia public schools?

4. What impedes principals ${ }^{\star}$ implementation of technology in West Virginia public schools? 
The specific purpose of the survey instrument in this study is to measure the perceptions of principals implementing technology and the obstacles associated with this process at elementary, middle, and high school levels. The survey instrument design considers the most common obstacles documented in the current literature: keeping the survey as short as possible, and designing the survey to provide the data the researcher is attempting to collect. Questions carefully sequenced, will ensure that a question does not influence the response to subsequent questions (Suskie, 1996).

The categories of questions will include:

- infrastructure and facilities (RQ-3), (RQ-4),

- hardware (RQ-4),

- $\quad$ software (RQ-4),

- $\quad$ funding (RQ-4),

- $\quad$ social issues (RQ-3), (RQ-4),

- $\quad$ staffing/technology positions (RQ-1), (RQ-2), (RQ-3),

- $\quad$ staff development (RQ-1), (RQ-3),

- $\quad$ administrators' motivation (RQ-1)

- $\quad$ teacher and student perspectives (RQ-3), (RQ-4), and

- technological policy (RQ-3).

NOTE: Research Questions pertaining to each category are in parentheses.

For a complete list of questions, see School Principal Survey, Technology Use in West Virginia Public Schools: A Survey of West Virginia Principals 2010” (Appendix J).

The survey also contains a background section that will assist with providing general background information about the administrator. The demographics include: 
(a) school level,

(b) years experience as principal,

(c) technology training completed in last five years, and

(d) county of employment.

The five-point Likert Rating Scale addresses the questions pertaining directly to obstacles principals face during technology implementation. The categories are Strongly Agree, Agree, Neutral, Disagree and Strongly Disagree. This provides an opportunity for the respondent to maintain validity to the survey and to answer Neutral if not on one end or the other of the Likert Scale. This scale begins with a very positive response and continues to an extreme negative response. According to Suskie (1996), advantages of the Likert Scale are familiarity. It quickly collects a great deal of information, and easily compares answers within the scale. Vogt (2005) stated, Eikert scales, and Likert-like scales, are the most widely used attitude scale types in the social sciences" (p. 174). These scales tend to have high reliability and deal with attitudes. The researcher is looking for perceptions and attitudes; the Likert Scale succeeds in providing this type of data (Suskie, 1996).

If a question is difficult to understand, the respondent tends to read more into the question than specifically designed to answer. Suskie stated, The fundamental characteristic of a good questionnaire item is that it is clearly understood" (Suskie, 1996, p. 44). The questions are kept short, each question only asks one question and the questions are specific (Suskie, 1996). Questions attempting to lead principals to a specific answer will be avoided (Suskie, 1996).

A panel of experts, selected to assist with determining validity, reviewed the survey questions. The survey reflects a specific period, such as in the last five years for the administrator to use as a guide when answering the questions. 
Web surveys. Principals accessed the survey through an emailed hypertext link, placed online through Survey Monkey. Web-based surveys have advantages and disadvantages according to the literature. Advantages of web-based surveys are the following:

(1) generally inexpensive to conduct,

(2) they provide very fast results, and layouts of the surveys are easy to modify,

(3) online surveys streamline the data collection process formatting and entering responses directly into a database for analysis,

(4) response rates may be increased by the researcher through incentives for completing the survey (Solomon, 2001).

According to Solomon (2001), disadvantages of web surveys are the following:

(1) possible bias results based on individuals conducting the survey having access to the Internet,

(2) lack of response.

One hundred percent of West Virginia public school principals receive access to the Internet through the statewide Access system (WVDE, 2009) so lack of access to electronic email did not inhibit this study.

According to Solomon (2001), an email cover letter, including the hypertext link for the survey as a means of contacting the random sample of principals provides an especially effective and efficient approach to Internet surveying. Cook, Heath, and Thompson (as cited by Solomon, 2001) found that follow-up contacts with non-respondents, personalized contacts, and contacting sampled people prior to sending out the survey were the three dominant factors in higher response rates. All sampled individuals received letters introducing the survey before receiving the e-mail. Survey Monkey provides automatic responses to the individuals that have not completed the survey 
and provides a database of such information for the researcher. This information helps to increase the response rate.

Additionally, Dillman, Tortora, Conrad and Bowker (as cited by Solomon, 2001) found that relatively plain web surveys that load quickly resulted in higher response rates. They also found surveys asking for the respondent's email address decreased the number of respondents.

\section{Reliability and Validity}

Suskie (1996) states that a simple, straightforward -ne shot" study on a non-controversial subject creating results only for general information probably doesn't need much evidence of reliability or validity. The findings from this study are not a controversial subject, and do not concern sensitive issues. Suskie stated, A reliable questionnaire elicits consistent responses" (Suskie, p. 52). Surveys with reliability should produce very similar responses to similar questions (Suskie, 1996). The fundamental way to measure reliability is through correlations of individual items or overall questionnaire scores.

Researchers face difficulty in establishing validity, which relates closely to truth (Suskie, 1996). The closest synonym I can come up with is truthfulness: if a questionnaire is valid, you are finding out what respondents really, truthfully think about what you really and truthfully want to know" (p. 56). Therefore, a valid questionnaire measures accurately its goals. Suskie stated, The more, the better is therefore the rule in establishing evidence of validity" (p. 57). According to Suskie (1996), a basic method for survey researchers to develop evidence of validity is to pilot test the survey. This research includes a panel of experts and a pilot study.

To assist with ensuring construct validity, three percent of the items have reverse scoring which according to Suskie (1996) will provide additional validity. These reverse items will attract the respondent's attention using negative words in bold print (Suskie, 1996). Items changing the 
order of the question will result in a negative response instead of a positive response previously in the survey. According to Vogt (2005) construct validity is - thextent to which variables accurately measure the constructs of interest. Do the operations really get at the things you are trying to measure?" (p. 58). The researcher strived to conduct the survey in a manner that is free of potential bias, protect the rights of privacy and avoid misleading respondents.

Panel of experts. The Panel of Experts consists of three individuals. Marianne Bakia represents this panel from the national level, Dr. Greg Davis represents this panel from the national level and Becky Butler represents this panel from the county level. The alternate was Kathy Boone from WVDE and is a state level representative.

Marianne Bakia is a Senior Education Researcher, active in the educational technology research and development community for 10 years as a program evaluator, policy analyst and project director. Senior Education Researcher, SRI International, Washington, DC. Bakia was one of the authors for the State Strategies and Practices for Educational Technology: Volume 1Examining the Enhancing Education through Technology Program" with the U.S. Department of Education National Education Technology Trends Study. The teacher survey developed by Bakia was a tremendous part of this study and others have used it nationally.

Dr. Greg Davis is currently the Executive Director of Technology for Des Moines Public Schools. Dr. Davis has a Ph. D. in Education Leadership and Policy Studies. His dissertation focus was on the assessment of education technology leadership in Pre-K through 12 educations. He is currently co-chair of the Consortium for School Networking (CoSN) CTO Council. He also is chair of the State of Iowa's Educational Telecommunications Council (ETC). Dr. Davis is a member of the International Society for Technology in Education (ISTE). Dr. Davis has participated in special projects and grants related to enhancing technology in the Des Moines 
Public Schools. He also presented internationally in October 2007 to the International Association of School Business Officials, Value of Investment in Technology.

Becky Butler is currently the Director of Technology for Kanawha County Schools. Butler has a Masters in Educational Computing from the University of Charleston. She has taught computer literacy, computer history and computer science at the high school level. She was an Area Technology Teacher in Kanawha County Schools for four years. This job was very similar to the TIS position currently in West Virginia. She is an adjunct professor for Marshall Community and Technical College, Marshall University Graduate College, West Virginia University, and Southern West Virginia Community Technical College. She is also an instructor for West Virginia High Technology Consortium Foundation/EdVenture Group. She received recognition as Kanawha County Schools Educator of the Year. An alternate member for the panel of experts is Kathy Boone, Assistant Director, Office of Technology for WVDE.

The members of the expert panel received an e-mail to request their participation. Upon acceptance, they received a second email containing two attachments: the survey (Appendix J) and a letter of explanation (Appendix D). Included in the email were three questions pertaining to the survey design.

The panel of experts received three questions, as recommended by the Web Center for Social Research (2006):

(a) Does the question adequately address the four research questions guided by a comprehensive review of the literature?

(b) Do the questions contain sufficient information to enable an adequate response by the respondent based on his/her current position as principal?

(c) Is each question free from bias designed without guiding the respondent to a 
particular response?

The panel of experts received directions along with the survey via email; see Principal Survey: Directions for Panel of Experts (Appendix D). The three questions from the Web Center for Social Research pertain to the design of each survey item. The panel members provided feedback to the researcher via e-mail. The feedback provided information to the researcher and resulted in changes to the survey, before sending the survey to the pilot study participants.

The researcher documented and reviewed the suggestions and changes from the panel members. There were no considerable concerns with the original survey. The panel of experts had a couple of small suggestions about changing terminology and these suggestions were discussed via email. Small changes were made to the survey document to clarify wording.

Dr. Greg Davis provided feedback for the demographics section of the survey that I addressed based upon his suggestions. I rearranged the information pertaining to training and added data driven decision making as a choice for training. I added the words - inyour building to the implementation of technology" to the Obstacles Related to Infrastructure definition. I also reworded a couple of items throughout the domains to clarify terms based upon his suggestions.

Marianne Bakia also provided suggestions to clarify some terminology within the domains and domain headings. Bakia made a suggestion to change the title of the survey document slightly,

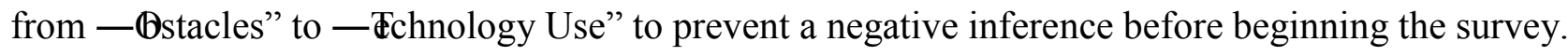
Bakia‘s suggestion for the demographics section on training was similar to Dr. Davis`s so the changes I made met both recommendations.

Becky Butler's suggestions were also to explain a couple of terms within the domain items and I made these changes based upon her suggestions. The suggestions from all three-panel members were consistent and addressed the same concerns with terminology. The corrections 
applied to the survey based on the panel's feedback increased the construct validity of the instrument.

These changes were reviewed during the redesign process before conducting the survey with the pilot study participants. The expert panel provided written feedback within ten days of receiving the documentation and the researcher discussed the feedback with Dr. Richard Walls, at West Virginia University (committee member).

Pilot study. Edwin R. van Teijlingen (2001) defines pilot study as a mini version of the full-scale study (also called a feasibility study). A pilot study can be the pre-testing or trying out" of a particular research instrument (Baker, 1994). One advantage of conducting a pilot study is that it might give advance warning concerning failure of the main research project, highlight the failure of research protocol or discover inappropriate or overly complicated methods or instruments (van Teijlingen, 2001). Suggestions by Peat, Mellis, Williams, and Xuan (as cited by van Teijlingen 2002) for pilot study procedures include administration of the questionnaire to pilot subjects in exactly the same way as administration of the main study. They further suggest, asking the subjects for feedback to identify ambiguities and difficult questions, recording the time taken to complete the questionnaire, assessing whether each question gives an adequate range of responses, and re-wording any questions that receive inadequate answers.

To establish reliability of this study, the researcher conducted a pilot study with five educational professionals from Kanawha County (Appendix E). Volunteers completed the pilot survey. This pilot study completed through Survey Monkey provided feedback on the survey document. The results were reviewed for consistency, reliability, clearly defined directions, and easy to follow format. The researcher randomly selected one of the pilot study participants to observe for active discussion during the completion of the survey. The other individuals discussed 
the survey with the researcher after completion. This feedback assisted with fine tuning areas of inconsistency before dissemination to the West Virginia principals. In addition, the researcher also timed the participants of the pilot study to determine the amount of time required to complete the survey. No more than ten minutes was required for any of the pilot study members to complete the survey.

Data collection. The researcher presented the survey to 425 elementary, 124 middle school, and 109 high school principals in West Virginia through Survey Monkey. The start to finish timeframe was approximately two months. This allowed adequate time for participants to complete the survey and did not allow much time for procrastination. The survey was sent out in June of 2010 and principals that did not respond were sent one reminder during the summer and one additional reminder at the beginning of the 2010-2011 school year.

The researcher sent a letter to 55 West Virginia county superintendents (Appendix H), notifying them of the survey process, contact information and a letter of support from Dr. Paine, WV State Superintendent (Appendix G). They received the courtesy notice approximately ten days before the principals received the emails.

An introductory email was sent to all West Virginia principals through to introduce this study and myself in June 2010. This introductory email (Appendix I) provided contact information for the researcher, time requirements to complete the survey, notice of voluntary participation, anonymity, confidentiality, incentive program and purpose of the survey.

An email with this same information and a link to an online questionnaire designed through Survey Monkey followed the first email, approximately three days later. Each principal received a third email, one week later to remind them to complete the survey if they have not. All participants received a final email at the beginning of the 2010-2011 school year to ask for everyone's 
participation and thank those that had completed the online survey. These automated emails were sent through a feature of Survey Monkey. This two-month period allowed for dissemination of the material, promoted participation, decreased procrastination and allowed time for collection of the data. The researcher will make the results of the research available within six months of completion.

- Week One (May, 2010): Letter sent to each county superintendent introducing the research (Appendix H) and a letter of support from Dr. Paine (Appendix G).

- Week Two (June 2010): An email sent to all West Virginia principals explaining the research project through Survey Monkey (Appendix I).

- Week Three (June, 2010): An email sent including a letter reviewing the purpose of the study containing a hypertext link for the principals to follow so they may complete the online survey through Survey Monkey.

- Week Four (June, 2010): A third email sent to remind each principal to complete the survey through Survey Monkey.

- Final Week (August 2010): Final email sent to ask for everyone`s participation and thank those that have completed the online survey through Survey Monkey.

- Final collection of data process completed (October 2010).

- Incentives sent in March of 2011 to the six randomly selected principals that participated.

Data analysis. Keeping the questions on a similar subject facilitates the internal consistency of the survey questions. According to Suskie (1996), a question at the beginning of a survey should have a similar response if that question appears again, later in the survey, in a similar format. The researcher designed the survey to address specific obstacles discussed in the literature review section. This maintains relevance to the study and increases the survey‘s validity. A valid 
question measures accurately what you want it to measure, and the inferences you make from this questionnaire will be accurate (Suskie, 1996). The survey results will provide information that can assist principals to make informed decisions about technology implementation.

Research Question 1: What technology support do West Virginia principals provide to teachers? The school principal survey addresses this question (Appendix J, pg. 2-3, 15 items). The 15 items of relevance are located in the domains of Staffing and Technology Support, Provision of Staff Development, Administrative Motivation, and Policy.

The means and standard deviations for each item in each domain for Research Question 1 are displayed in a table (Appendix K, p. 1). The column headings are Domain, Items, Elementary Principal Means and Standard Deviation, Middle School Principal Means and Standard Deviation, High School Principal Means and Standard Deviation, and Item Composite Means and Standard Deviation. The rows contain data from 15 items with a Range of 15 to 75, plus a row for Column Composite Means and Standard Deviations. This table allows reference to individual item means as well as overall descriptive statistics.

Research Question 2: Who do West Virginia principals rely on to provide technology support when unable to do so themselves? The school principal survey addresses this question (Appendix J, pg. 4, 10 items). Items of relevance are located in the Staffing and Technology Support domain. The means of these items are compared with the demographics from page one of the survey.

The means and standard deviations for each item in each domain for Research Question 2 are displayed in a table (Appendix K, p. 2). The column headings are Domain, Items, Elementary Principal Means and Standard Deviation, Middle School Principal Means and Standard Deviation, High School Principal Means and Standard Deviation, and Item Composite Means and Standard 
Deviation. The rows contain data from ten items with a Range of 10 to 50, plus a row for Column Composite Means and Standard Deviations. This table allows reference to individual item means as well as overall descriptive statistics.

Research Question 3: What facilitates principals‘ implementation of technology in West Virginia public schools? The school principal survey addresses this question (Appendix J, pg. 5-7, 21 items). Items of relevance are located in the domains of Obstacles Related to Infrastructure, Social Issues, Staffing and Technology Support, Provisions of Staff Development, Staff Development Concerns, and Teacher/Student Perceived Obstacles. The means of these items are compared with the demographics from page one of the survey.

The means and standard deviations for each item in each domain for Research Question 3 are displayed in a table (Appendix K, p. 3). The column headings are Domain, Items, Elementary Principal Means and Standard Deviation, Middle School Principal Means and Standard Deviation, High School Principal Means and Standard Deviation, and Item Composite Means and Standard Deviation. The rows contain data from 21 items with a Range of 21 to 105, plus a row for Column Composite Means and Standard Deviations. This table allows reference to individual item means as well as overall descriptive statistics.

Research Question 4: What impedes principals‘ implementation of technology in West Virginia public schools? The school principal survey addresses this question (Appendix J, pg. 8-9, 24 items). These items of relevance are located in the domains of Obstacles Related to Infrastructure, Social Issues and Teacher/Student Perceived Obstacles. The means of these items are compared with the demographics from page one of the survey.

The means and standard deviations for each item in each domain for Research Question 4 are displayed in a table (Appendix K, p. 4). The column headings will be Domain, Items, 
Elementary Principal Means and Standard Deviation, Middle School Principal Means and Standard Deviation, High School Principal Means and Standard Deviation, and Item Composite Means and Standard Deviation. The rows contain data from 24 items with a Range of 24 to 120, plus a row for Column Composite Means and Standard Deviations. This table allows reference to individual item means as well as overall descriptive statistics.

More extensive computation of statistical relationships takes the form of the following analysis strategy on each set of data pertaining to each research question. First, a Multivariate Analysis of Variance (MANOVA) is computed. MANOVA is The extension of Analysis of Variance (ANOVA) techniques to studies with multiple dependent variables. The MANOVA allows the simultaneous study of two or more related dependent variables while controlling for correlations among them" (Vogt, 1993, p. 147). This analysis included data for the 15 items for RQ-1, 10 items for RQ-2, 21 items for RQ-3, and 24 items for RQ-4. These items are divided by Elementary, Middle, and High School levels.

Computation of an initial MANOVA protects against a Type I error in the subsequent calculation of numerous Analyses Of Variance (ANOVAs). An ANOVA is - Atest of the statistical significance of the differences among the mean scores of two or more groups on one or more variables of factors" (Vogt, 1993, p. 7). Type I error occurs when multiple statistical tests are computed with the -statistical significance" level set at, for example, $\mathrm{p}<.05$, thereby allowing the appearance of statistical significance to occur by chance rather than an actual difference in the data. If this overall MANOVA yields a statistically significant finding (at least $p<.05$ ), then there is reason to compute the component ANOVAs to determine if each dependent variable (ratings on each set of items, the 8 Domains) indicates a significant result for the level of principal, Elementary vs Middle vs High School comparisons (independent variable in the MANOVA). 
Second, if the MANOVA is statistically significant, the ANOVAs are computed with each set of the eight Domains (dependent variable). As noted, the independent variable in each of these sets of item analyses will be the school level (Elementary, Middle, and High), and the dependent variable will be the item ratings ranging from 1 (Strongly Agree) to 5 (Strongly Disagree) for each item.

Third, if any ANOVA produces a statistically significant result (at least $\mathrm{p}<.05$ ), then multiple comparisons are calculated. One multiple comparisons test is a Tukey‘s Honestly Significant Difference Test, often abbreviated as Tukey HSD. After conducting an analysis of variance of the differences in group means, the researcher knows whether some group means are significantly different than the overall mean. To determine which means are significantly different, a Tukey‘s HSD Test can be used” (Vogt, 1993, p. 236). These multiple comparisons will test to determine if a statistically significant difference exists for Elementary vs Middle, or Elementary vs High, or Middle vs High. Thus, for each Research Question, these three levels of analytic examination will allow determination of general as well as specific effects.

Each survey item will demonstrate a correlation, how closely two or more items are related to each other, among elementary principals, middle school principals, and high school principals in the relationship of obstacles to implementing technology. A correlation among years experience should also provide a different set of obstacles especially in the domains of Obstacles Related to Infrastructure, Provision of Staff Development, and Staffing and Technology Support.

\section{Summary}

The research of this study explores the factors that impede and facilitate the implementation of technology according to the principals' perspective in West Virginia public schools. Three levels of principals: elementary, middle, and high school provided the data for the research. 
This chapter describes the process of creating the survey, testing the survey document and collecting data with Survey Monkey. A web-based survey distributed to 658 West Virginia principals provided the results for this study. This is represented by 425 elementary principals (65\%), 124 middle school principals (18\%), and 109 high school principals (17\%). A return rate of $70 \%$, not less than 50\%, will provide sufficient data for the study according to Suskie (1996).

The demographics compare the items from each domain to demonstrate a correlation between the demographics and each item on the survey. The demographics of the survey provide data for three levels of principals: years experience, relevant training and a county identifier. 


\section{Chapter Four: Research}

\section{Research Findings}

This study was designed to answer four research questions pertaining to obstacles administrators in West Virginia public schools encounter during the technology utilization process. Chapter four describes the research questions and how they are represented in the online survey distributed through Survey Monkey. The survey consisted of 70 items within eight domains to answer the four research questions.

MANOVA testing on the seventy survey items answered by three levels of principals; elementary, middle, and high school, provides data supporting that all seventy items are significant. Type I errors or false inferences were removed through the MANOVA testing. ANOVA testing on the seventy items determine that nine items, $12.8 \%$, are significant at $\mathrm{p}<.05$. The $\mathrm{F}$ scores from the ANOVA testing also demonstrate the means differ more than would be expected by chance alone. Since the effects are significant, the means must be examined in order to determine the nature of the effects. A continuation of testing utilizing a Tukey test on these nine items determines that $10 \%$ or 7 items remain significant at $p<.05$.

Table 2 presents a visual of the nine significant items from the ANOVA testing. It provides the research question number, the survey question number, the item number from the survey, the domain from Appendix K, the item number from Appendix K, and the significant value. 
Table 2: Nine Significant Items

\begin{tabular}{lccccc}
\hline $\begin{array}{l}\text { Research } \\
\text { Question }\end{array}$ & $\begin{array}{c}\text { Survey } \\
\text { Question }\end{array}$ & $\begin{array}{c}\text { Item \# } \\
\text { (Survey) }\end{array}$ & $\begin{array}{c}\text { Domain } \\
\text { (App. K) }\end{array}$ & $\begin{array}{c}\text { Item \# } \\
\text { (App. K) }\end{array}$ & Sig. \\
\hline RQ-1 & 9 & 5 & 6 & 12 & .049 \\
RQ-2 & 10 & 5 & 3 & 5 & .000 \\
RQ-2 & 10 & 8 & 3 & 8 & .022 \\
RQ-2 & 10 & 10 & 3 & 10 & .042 \\
RQ-3 & 16 & 3 & 7 & 15 & .003 \\
RQ-4 & 18 & 9 & 1 & 9 & .031 \\
RQ-4 & 18 & 11 & 1 & 11 & .041 \\
RQ-4 & 19 & 2 & 2 & 18 & .019 \\
RQ-4 & 20 & 5 & 7 & 23 & .010 \\
\hline
\end{tabular}

Research Question 1: What technology support do West Virginia principals provide to teachers? This question is addressed with 15 items from four of the eight domains (Staffing and Technology Support, Provision of Staff Development, Administrative Motivation, and Policy).

Research Question 2: Who do West Virginia principals rely on to provide technology support when unable to do so themselves? This question is addressed with 10 items from one domain (Staffing and Technology Support).

Research Question 3: What facilitates principals‘ implementation of technology in West Virginia public schools? This question is addressed with 21 items within six domains (Obstacles Related to Infrastructure, Social Issues, Staffing and Technology Support, Provisions of Staff Development, Staff Development Concerns, and Teacher/Student Perceived Obstacles).

Research Question 4: What impedes principals' implementation of technology in West Virginia public schools? This final question is addressed with 24 items from three domains (Obstacles Related to Infrastructure, Social Issues, and Teacher/Student Perceived Obstacles).

Also included in the online survey are four areas of demographics. The first demographic divides all the responses by elementary, middle school, and high school level principals. The second considers years experience as a principal. The third demographic section of the survey examines technology training completed by the principals. The final demographic determines the 
county each principal represents in West Virginia. All fifty-five counties are represented in this study.

\section{Organization of Data Analysis}

The data analysis is arranged by survey questions that indicate a statistically significant finding $(p<.05)$ from the research. Figures represent each response; see Appendix K, demonstrating the means and standard deviation of each item by level of principal. Each question is analyzed through a computation to determine statistical relationships, Multivariate Analysis of Variance (MANOVA). There are nine items yielding a statistically significant finding. An Analysis Of Variance (ANOVA) then determines if there is a relationship between the three levels of principals. The ANOVA determines if each dependent variable (ratings on each set of items, the 8 domains) indicates a significant result for the level of principal (independent variable). The item ratings are 1-strongly agree to 5-strongly disagree.

If any items from the ANOVA produced a statistical significant result $(\mathrm{p}<.05)$, then a multiple comparison (Tukey Test) was performed. These multiple comparisons determine if a significant difference between elementary and middle, elementary and high school, and high school and middle school exists.

The design of the survey included six reverse scored items to increase the validity. Research Question 2, items one (teachers are responsible for maintaining their own technology including hardware and software) and nine (teachers do not provide their own technical support for hardware and software issues) from domain three (Staffing and Technology Support) each had 244 responses. The mean of item one was 3.59 and the standard deviation was .94 . The mean of item nine was 2.79 and the standard deviation was .987 . Item one had $55.3 \%$ disagree responses and item nine had $40.6 \%$ agree responses. This demonstrates consistency between the two questions 
and a valid response when reversing the terminology. There is congruency between the positive scale and the reverse scale.

Research Question 3, items one (technology is not integrated into the curriculum and is a stand-alone learning environment) and four (technology use is integrated into the curriculum) from domain seven (Teacher and Student Perceived Obstacles) had 239 and 236 responses. The mean of item one was 4.03 and the standard deviation was .914. The mean of item four was 1.84 and the standard deviation was .712. Item one had 54.4\% disagree responses and item four had $60.2 \%$ agree responses. This demonstrates consistency between the two questions and a valid response when reversing the terminology.

Research Question 4, items one (teacher attitude toward technology is poor) and six (teacher attitude toward technology is positive) from domain seven (Teacher and Student Perceived Obstacles) had 236 and 234 responses. The mean of item one was 4.00 and the standard deviation was .804. The mean of item six was 1.93 and the standard deviation was .763. Item one had $60.2 \%$ disagree response and item six had 63.2\% agree response. This again demonstrates consistency between the two questions and a valid response when reversing the terminology.

\section{Presentation of Descriptive Characteristics of Respondents.}

West Virginia principals completed the survey using Survey Monkey. The survey was emailed to 658 principals. Of the 658 email addresses compiled for this study, 23 were returned as non-deliverable or had previously opted out of participation through Survey Monkey. The total number of successful emails sent included 408 elementary, 123 middle school, and 104 high school $(\mathrm{N}=635)$. Elementary principals responding to the survey totaled 140 . This created a response rate of $34 \%$. Middle school principals responding totaled 61 creating a $49.6 \%$ response rate. The 43 
high school principals responding created a $41 \%$ response rate. The total responses were $\mathrm{N}=244$.

The overall response rate from all three categories is $38.4 \%$. See Table 3 .

Table 3: Survey Response by Group

\begin{tabular}{lcccc}
\hline West Virginia School Principal Survey & Total \% of & Response & Emails per Group & \% of Responses \\
Level & Responses & Count & Sent & by Group \\
& $56.5 \%$ & 140 & 408 & $34 \%$ \\
Elementary Principal & $24.6 \%$ & 61 & 123 & $50 \%$ \\
Middle School Principal & $17.3 \%$ & 43 & 104 & $41 \%$ \\
High School Principal & & 244 & $\mathrm{~N}=635$ & \\
Total: $38.4 \%$ & &
\end{tabular}

In addition, $100 \%$ of the $55 \mathrm{West}$ Virginia counties are represented in this study. There are 241 principals that selected their home county from the demographics section of the survey, see Table 4. This means that 3 principals left the demographic question pertaining to their county blank during completion of the survey.

Table 4: Representation of West Virginia Counties

\begin{tabular}{lclclc}
\hline County & \# of Responses & County & \# of Responses & County & \# of Responses \\
Barbour & 1 & Lewis & 5 & Raleigh & 8 \\
Berkeley & 10 & Lincoln & 4 & Randolph & 6 \\
Boone & 4 & Logan & 8 & Ritchie & 4 \\
Braxton & 3 & Marion & 6 & Roane & 2 \\
Brooke & 3 & Marshall & 5 & Summers & 2 \\
Cabell & 12 & Mason & 3 & Taylor & 1 \\
Calhoun & 1 & McDowell & 4 & Tucker & 1 \\
Clay & 1 & Mercer & 4 & Tyler & 2 \\
Doddridge & 2 & Mineral & 7 & Upshur & 3 \\
Fayette & 7 & Mingo & 5 & Wayne & 5 \\
Gilmer & 1 & Monongalia & 8 & Webster & 2 \\
Grant & 2 & Monroe & 1 & Wetzel & 4 \\
Greenbrier & 3 & Morgan & 2 & Wirt & 3 \\
Hampshire & 2 & Nicholas & 7 & Wood & 13 \\
Hancock & 2 & Ohio & 5 & Wyoming & 4 \\
Hardy & 4 & Pendleton & 2 & & \\
Harrison & 7 & Pleasants & 3 & & $\mathrm{~N}=241$ \\
Jackson & 5 & Pocahontas & 3 & & 3 blank \\
Jefferson & 2 & Preston & 6 & & \\
Kanawha & 13 & Putnam & 8 & & \\
\hline
\end{tabular}


The demographics section demonstrates several characteristics of West Virginia principals. One characteristic of West Virginia principals according to the survey demonstrates that $76.2 \%$ of the 248 respondents have less than 15 years experience as acting principal as described in Table 5 . The total number of respondents differs in each area due to principals skipping questions throughout the survey.

Table 5: West Virginia Principals’ Experience

West Virginia School Principal Survey

Years Experience as a Principal

Answer Options

\begin{tabular}{cc} 
Response & Response Count \\
Percent & \\
$76.2 \%$ & 189 \\
$23.8 \%$ & 59 \\
& \\
\hline
\end{tabular}

The demographics section of the survey also suggests that principals have had a variety of technology training. Of the 247 responses, one individual skipped this question, $95.1 \%$ have had some type of technology training in the last five years, see Table 6.

Table 6: West Virginia Principals’ Technology Training

\begin{tabular}{lcc}
\hline West Virginia School Principal Survey & \\
Have You Completed Any Technology Training in the Last Five Years \\
Through a College or University, WVDE, or Your County? \\
Answer Options & Response & Response Count \\
\multicolumn{4}{l}{ Percent } & 235 \\
Yes & $95.1 \%$ & 12 \\
No & $4.9 \%$ & \\
answered question & 247 & \\
skipped question & 1 & \\
\hline
\end{tabular}

Table 7 represents the variety of training West Virginia principals have received. This demonstrates that the largest percent of principals have had training on implementing technology into the curriculum, $82.2 \%$. The second area West Virginia principals are trained is data driven 
decision-making, $72.5 \%$, which also supports the curriculum and how successfully it is being implemented. The data shows that a large number of principals have had a variety of training in the area of technology integration and much fewer have been trained in the area of social impact of technology and how to provide technical support.

Table 7: Types of Training

\begin{tabular}{|c|c|c|c|}
\hline \multicolumn{4}{|c|}{ West Virginia School Principal Survey } \\
\hline \multicolumn{4}{|c|}{ Topic/Topics of Training: } \\
\hline \multicolumn{2}{|l|}{ Answer Options } & $\begin{array}{c}\text { Response } \\
\text { Percent }\end{array}$ & $\begin{array}{c}\text { Response } \\
\text { Count }\end{array}$ \\
\hline \multicolumn{2}{|c|}{ General Technology Introductory Course } & $37.7 \%$ & 89 \\
\hline \multicolumn{2}{|c|}{ Social Impact of Technology } & $19.1 \%$ & 45 \\
\hline \multicolumn{2}{|c|}{ Technical, Such as Hardware and Software Issues } & $42.8 \%$ & 101 \\
\hline \multicolumn{2}{|c|}{ How to Integrate Technology Into the Curriculum } & $82.2 \%$ & 194 \\
\hline \multicolumn{2}{|c|}{ How to Increase Effective Use of Technology } & $67.4 \%$ & 159 \\
\hline \multicolumn{2}{|c|}{ Data Driven Decision Making } & $72.5 \%$ & 171 \\
\hline \multicolumn{2}{|l|}{ Other } & $14.0 \%$ & 33 \\
\hline answered question & 236 & & \\
\hline skipped question & 12 & & \\
\hline
\end{tabular}

\section{Analysis of Data}

Research Question 1: What technology support do West Virginia principals provide to teachers? Designed to determine if administrative motivation plays a role in technology support from administrators is domain seven. This domain, administrative motivation, is defined as the principals‘ perception and actions pertaining to implementing, improving, and maintaining all aspects of technology while inspiring others to meet technology challenges with a positive attitude. Question 9, item 5, the principal provides time in the master schedule for classroom use of the computer lab" generated a mean of 1.46 and a standard deviation of 0.693 through a Multivariate Analysis of Variance (MANOVA) test from 244 responses.

\section{MANOVA}

$$
\text { Elementary Mean }=1.37, \mathrm{SD}=0.604
$$


Middle School Mean $=1.56, \mathrm{SD}=0.807$

High School Mean $=1.63, \mathrm{SD}=0.757$

Item Composite $(\mathrm{N}=244)$ Mean $=1.46, \mathrm{SD} 0.693$

The overall MANOVA yielded a significant finding, $\mathrm{F}=2.307, \mathrm{df}=(15,217)$, and $\mathrm{p}=.005$ utilizing the Roy‘s Largest Root test. Because the MANOVA yielded an overall significant value, the 15 component ANOVAs were computed. Only one item from the 15 component ANOVAs yielded a significant value of $p<.05$. Fourteen of the fifteen items did not yield a significant difference for research question one. The item yielding a significant difference was from Domain 6, item 12, -th甲rincipal provides time in the master schedule for classroom use of the computer lab."

Continuing with Analysis of Variance (ANOVA) to determine if there is a significant difference between the mean scores of two or more groups, the three levels of principals, a significant difference of .049 exists. The ANOVA produced an F value of 3.057 and $\mathrm{df}=(2,241)$, see Table 8.

ANOVA

Domain 6, Item 12 from Appendix K Figure 1: Research Question 1, Data Analysis Survey Question 9

Item 5 from Survey

Sig. Diff. $=.049$

Table 8: Research Question 1, Survey Question 9, Item 5

\begin{tabular}{lccccc}
\hline & Sum of Squares & df & Mean Squares & F & Sig. \\
\hline Between Groups & 2.887 & 2 & 1.443 & 3.057 & .049 \\
Within Groups & 113.781 & 241 & .472 & & \\
Total & 116.668 & 243 & & & \\
\hline
\end{tabular}


Continuing with a Tukey Honestly Significant Difference test to determine if there is a significant difference between group means does not produce any significant evidence between groups, elementary verses middle, elementary verses high school, and middle verses high school. The total number of responses are 140 elementary, 61 middle school, and 43 high school. TUKEY

Elementary to Middle $=.184$

Elementary to $\mathrm{HS}=.084$

Middle to $\mathrm{HS}=.864$

Sig. Diff. $=.089$

$\mathrm{N}=$ Elem. 140, MS 61, HS 43

Tukey post-hoc comparisons of the three groups indicate that there is not a statistically significant difference between any comparisons of the three levels of principals.

Research Question 2: Who do West Virginia principals rely on to provide technology support when unable to do so themselves? Domain three, staffing and technology support, including individuals that provide direct technology support to classroom teachers, question 10 , item 5 is designed to determine if there is a full time Technology Integration Specialist (TIS) in your school". This question generated a mean of 3.89 and standard deviation of 1.426 through a MANOVA test from 241 responses.

MANOVA

Elementary Mean $=4.22, \mathrm{SD}=1.159$

Middle School Mean $=3.45, \mathrm{SD}=1.712$

High School Mean $=3.42, \mathrm{SD}=1.5$

Item Composite $(\mathrm{N}=241)$ Mean $=3.89, \mathrm{SD} 1.426$ 
The overall MANOVA yielded a significant finding, $\mathrm{F}=3.867$, $\mathrm{df}=(10,217)$, and $\mathrm{p}=$ .000 utilizing Roy‘s Largest Root test. Pillai‘s Trace, Wilks‘ Lambda, and Hotelling‘s Trace also all three yielded a significant finding of $p<.05$. Because the MANOVA yielded an overall significant value, the 10 component ANOVAs were computed. Three of the ten items from the 10 component ANOVAs yielded a significant value of $\mathrm{p}<.05$. The first item yielding a significant difference was from Domain 3, Item 5, there is a full time Technology Integration Specialist (TIS) in your school".

Continuing with an ANOVA test to determine if there is a significant difference between the mean scores of two or more groups, the three levels of principals, a significant difference of .000 exists. The ANOVA produced an F value of 9.656 and $\mathrm{df}=(2,238)$, see Table 9.

ANOVA

Domain 3, Item 5 from Appendix K Figure 2: Research Question 2, Data Analysis

Survey Question 10

Item 5 from Survey

Sig. Diff. $=.000$

Table 9: Research Question 2, Survey Question 10, Item 5

\begin{tabular}{lccccc}
\hline & Sum of Squares & df & Mean Squares & F & Sig. \\
\hline Between Groups & 36.624 & 2 & 18.312 & 9.656 & .000 \\
Within Groups & 451.351 & 238 & 1.896 & & \\
Total & 487.975 & 240 & & & \\
\hline
\end{tabular}

A Tukey HSD demonstrated a .001 significant difference between elementary verses middle school and a .003 significant difference between elementary verses high school. There was no significant difference between middle school verses high school at .993 . A total of $25.4 \%$ of elementary principals responded with disagree and 57.2\% strongly disagree for a total of 114 of the 138 responses, approximately $82 \%$ of the schools do not have a TIS. A total of $15 \%$ of middle 
school principals responded with disagree and 45\% strongly disagree for 36 of the 60 responses, approximately $60 \%$. Only $37.2 \%$ of high school principals responded with disagree and $27.9 \%$ strongly disagree for 28 of the 43 responses, approximately $65 \%$.

TUKEY

Elementary to Middle $=.001$

Elementary to $\mathrm{HS}=.003$

Middle to $\mathrm{HS}=.993$

Sig. Diff. $=(1) .991,(2) 1.000$

$\mathrm{N}=$ Elem. 138, MS 60, HS 43

Tukey post-hoc comparisons of the three groups indicate elementary principals $(\mathrm{M}=4.22$, 95\% CI $[4.03,4.42])$ compared to middle school principals $(\mathrm{M}=3.45,95 \% \mathrm{CI}[3.01,3.89])$ has a significant difference of $p=.001$. CI is the abbreviation for confidence interval and df is the abbreviation for degree of freedom. Also comparing the elementary $(\mathrm{M}=4.22,95 \% \mathrm{CI}[4.03$, 4.42]) to high school principals $(\mathrm{M}=3.42,95 \% \mathrm{CI}[2.96,3.88])$ demonstrates a significant difference of $p=.003$.

Research Question 2: Who do West Virginia principals rely on to provide technology support when unable to do so themselves? Domain three, staffing and technology support, including individuals that provide direct technology support to classroom teachers, question 10, item 8 is designed to determine if students are utilized to provide technical assistance." This question generated a mean of 3.05 and standard deviation of 1.168 through a MANOVA test from 242 responses.

MANOVA

Elementary Mean $=3.22, \mathrm{SD}=1.232$ 
Middle School Mean $=2.82, \mathrm{SD}=1.073$

High School Mean $=2.79, \mathrm{SD}=0.989$

Item Composite $(\mathrm{N}=242)$ Mean $=3.05, \mathrm{SD} 1.168$

Continuing with an ANOVA determines if there is a significant difference between the mean scores of two or more groups, the three levels of principals, a significant difference of .022 exists. This is the second item from research question two generating a significant value from the ANOVA test.

A one-way ANOVA was used to test for differences between the three levels of principals. Responses from the principals differed significantly across the three groups, $\mathrm{F}=3.880, \mathrm{df}=(2$, 239), and $\mathrm{p}=.022$, see Table 10 .

\section{ANOVA}

Domain 3, Item 8 from Appendix K Figure 2: Research Question 2, Data Analysis Survey Question 10

Item 8 from Survey

Sig. Diff. $=.022$

Table 10: Research Question 2, Survey Question 10, Item 8

\begin{tabular}{lccccc}
\hline & Sum of Squares & df & Mean Squares & F & Sig. \\
\hline Between Groups & 10.331 & 2 & 5.166 & 3.880 & .022 \\
Within Groups & 318.169 & 239 & 1.331 & & \\
Total & 328.500 & 241 & & & \\
\hline
\end{tabular}

Continuing with a TUKEY HSD demonstrated there were no significant differences between elementary and middle school principals, elementary to high school principals, and middle school to high school principals.

\section{TUKEY}

Elementary to Middle $=.060$ 
Elementary to $\mathrm{HS}=.082$

Middle to HS $=.991$

Sig. Diff. $=.087$

$\mathrm{N}=$ Elem. 138, MS 61, HS 43

Tukey post-hoc comparisons of the three groups indicate that there is not a statistically significant difference between any comparisons of the three levels of principals.

Research Question 2: Who do West Virginia principals rely on to provide technology support when unable to do so themselves? Domain three, staffing and technology support, including individuals that provide direct technology support to classroom teachers, question 10, item 10 is designed to determine if lack of additional staff to assist school-wide with technology is an obstacle." This question generated a mean of 1.95 and standard deviation of 1.064 through a MANOVA test from 244 responses.

MANOVA

Elementary Mean $=1.85, \mathrm{SD}=0.967$

Middle School Mean $=2.05, \mathrm{SD}=1.102$

High School Mean $=2.3, \mathrm{SD}=1.245$

Item Composite $(\mathrm{N}=244)$ Mean $=1.95, \mathrm{SD} 1.064$

Continuing with an ANOVA determines if there is a significant difference between the mean scores of two or more groups, the three levels of principals, a significant difference of .042 exists. This is the third item from research question two generating a significant value from the ANOVA test. 
A one-way ANOVA was used to test for differences between the three levels of principals.

Responses from the principals differed significantly across the three groups, $\mathrm{F}=3.206, \mathrm{df}=(2$, 241) and $\mathrm{p}=.042$, see Table 11.

\section{ANOVA}

Domain 3, Item 10 from Appendix K Figure 2: Research Question 2, Data Analysis

Survey Question 10

Item 10 from Survey

Sig. Diff. $=.042$

Table 11: Research Question 2, Survey Question 10, Item 10

\begin{tabular}{lccccc}
\hline & Sum of Squares & df & Mean Squares & F & Sig. \\
\hline Between Groups & 7.125 & 2 & 3.563 & 3.206 & .042 \\
Within Groups & 267.772 & 241 & 1.111 & & \\
Total & 274.898 & 243 & & & \\
\hline
\end{tabular}

A Tukey HSD demonstrated a .039 significant difference between elementary verses high school. A total of $42.9 \%$ of elementary principals responded with strongly agree and $40 \%$ agree for 116 of the 140 responses, approximately $82.857 \%$. A total of $36.1 \%$ of middle school principals responded with strongly agree and $41 \%$ agree for 47 of the 61 responses, approximately $77.1 \%$. Only $27.9 \%$ of high school principals responded with strongly agree and $41.9 \%$ agree for a total of 30 of the 43 responses, approximately $69.8 \%$.

TUKEY

Elementary to Middle $=.436$

Elementary to $\mathrm{HS}=.039$

Middle to $\mathrm{HS}=.451$

Sig. Diff. $=(1) .534,(2) .364$

$\mathrm{N}=$ Elem. 140, MS 61, HS 43 
Tukey post-hoc comparisons of the three groups indicate elementary compared to middle school principals has no significant difference, $\mathrm{p}=.436$. Comparing the elementary $(\mathrm{M}=1.85$, $95 \%$ CI $[1.69,2.01])$ to high school principals $(\mathrm{M}=2.30,95 \% \mathrm{CI}[1.92,2.69])$ demonstrates a significant difference $\mathrm{p}=.039$. There is no significant difference between middle school and high school principals, $\mathrm{p}=.451$.

Research Question 3: What facilitates principals' implementation of technology in West Virginia public schools? Designed to determine teacher and student perceived obstacles is domain seven. This domain is defined as attitude toward technology and technology use. Question 16, item 3, -students are aware of the value of technology, and encourage teachers to use technology" generated a mean of 2.08 and a standard deviation of 0.771 through a MANOVA test on 239 responses.

MANOVA

Elementary Mean $=2.23, \mathrm{SD}=0.825$

Middle School Mean $=1.88, \mathrm{SD}=0.64$

High School Mean $=1.88, \mathrm{SD}=0.662$

Item Composite $(\mathrm{N}=239)$ Mean $=2.08, \mathrm{SD} 0.771$

The overall MANOVA yielded a significant finding, $\mathrm{F}=1.705, \mathrm{df}=(20,187)$, and $\mathrm{p}=.036$ utilizing Roy‘s Largest Root test. Because the MANOVA yielded an overall significant value, the 20 component ANOVAs were computed. There are 21 items; however, one item was yes/no and not computed in the ANOVA test. Only one item from the 20 component ANOVAs yielded a significant value of $p<.05$. Nineteen of the twenty items did not yield a significant difference for research question three. The item yielding a significant difference was from Domain 7 , Item 15 , -students are aware of the value of technology, and encourage teachers to use technology." 
Continuing with ANOVA testing to determine if there is a significant difference between the mean scores of two or more groups, the three levels of principals, a significant difference of .003 does exist. The ANOVA produced an $\mathrm{F}$ value of 6.099 and $\mathrm{df}=(2,236)$, see Table 12 . ANOVA

Domain 7, Item 15 from Appendix K Figure 3: Research Question 3, Data Analysis Survey Question 16

Item 3 from Survey

Sig. Diff. $=.003$

Table 12: Research Question 3, Survey Question 16, Item 3

\begin{tabular}{lccccc}
\hline & Sum of Squares & df & Mean Squares & F & Sig. \\
\hline Between Groups & 6.954 & 2 & 3.477 & 6.099 & .003 \\
Within Groups & 134.536 & 236 & .570 & & \\
Total & 141.490 & 238 & & & \\
\hline
\end{tabular}

A Tukey HSD demonstrated a .010 significant difference between elementary verses middle school. A total of $14 \%$ of elementary principals responded with strongly agree and $59.6 \%$ agree for 100 of the 136 responses, approximately $73.6 \%$. A total of $25 \%$ of middle school principals responded with strongly agree and $63.3 \%$ agree for 53 of the 60 responses, approximately $88.3 \%$. A total of $25.6 \%$ of high school principals responded with strongly agree and $62.8 \%$ agree for 38 of the 43 responses, approximately $88.4 \%$. Just over $88 \%$ of middle school and high school principals either agreed or strongly agreed with this statement for a level of significance between the two groups of 1.000 .

\section{TUKEY}

Elementary to Middle $=.010$

Elementary to $\mathrm{HS}=.026$

Middle to $\mathrm{HS}=1.000$ 
Sig. Diff. $=(1) 1.000,(2) 1.000$

\section{$\mathrm{N}=$ Elem. 136, MS 60, HS 43}

Tukey post-hoc comparisons of the three groups indicate elementary principals $(\mathrm{M}=2.23$, $95 \% \mathrm{CI}[2.09,2.37])$ compared to middle school principals $(\mathrm{M}=1.88,95 \% \mathrm{CI}[1.72,2.05])$ demonstrates a significant difference of $\mathrm{p}=.010$. Also comparing the elementary principals $(\mathrm{M}=$ $2.23,95 \% \mathrm{CI}[2.09,2.37])$ to high school principals $(\mathrm{M}=1.88,95 \% \mathrm{CI}[1.68,2.09])$ demonstrates a significant difference of $p=.026$. There is not a significant difference between middle school and high school principals, $\mathrm{p}=1.000$.

Research Question 4: What impedes principals‘ implementation of technology in West Virginia public schools? Designed to determine obstacles related to technology is domain one. Question 18, obstacles related to infrastructure includes building structure, hardware, software, and funding. Item 9, -software is too expensive" generated a mean of 2.62 and standard deviation of 1.04 through a MANOVA test on 235 responses.

\section{MANOVA}

Elementary Mean $=2.72, \mathrm{SD}=1.052$

Middle School Mean $=2.31, \mathrm{SD}=1.012$

High School Mean $=2.73, \mathrm{SD}=0.975$

Item Composite $(\mathrm{N}=235)$ Mean $=2.62, \mathrm{SD} 1.04$

The overall MANOVA yielded a significant finding, $\mathrm{F}=1.894, \mathrm{df}=(24,189)$, and $\mathrm{p}=.010$ utilizing Roy‘s Largest Root test. The other three tests within the MANOVA, Pilai`s Trace, Wilks‘ Lambda, and Hotelling's Trace also demonstrated a significant difference of $p<.05$. Because the MANOVA yielded an overall significant value, the 24 component ANOVAs were computed. Four items from the 24 items yielded a significant value of $p<.05$. Twenty of the 24 items did not yield 
a significant difference for research question four. The first item yielding a significant difference was from Domain 1, Item 12, - safvare is too expensive."

Continuing with an ANOVA to determine if there is a significant difference between the mean scores of two or more groups, the three levels of principals, a significant difference of .031 exists. The ANOVA produced an $\mathrm{F}=3.515$, and $\mathrm{df}=(2,232)$, see Table 13 .

ANOVA

Domain 1, Item 9 from Appendix K Figure 4: Research Question 4, Data Analysis

Survey Question 18

Item 9 from Survey

Sig. Diff. $=.031$

Table 13: Research Question 4, Survey Question 18, Item 9

\begin{tabular}{lccccc}
\hline & Sum of Squares & df & Mean Squares & F & Sig. \\
\hline Between Groups & 7.449 & 2 & 3.724 & 3.515 & 0.031 \\
Within Groups & 245.845 & 232 & 1.060 & & \\
Total & 253.294 & 234 & & & \\
\hline
\end{tabular}

A Tukey HSD demonstrated a .031 significant difference between elementary verses middle school. A total of $9.6 \%$ of elementary principals responded with strongly agree and $40.4 \%$ agree for 68 of the 136 responses, approximately $50 \%$. A total of $22.4 \%$ of middle school principals responded with strongly agree and $39.7 \%$ agree for 36 of the 58 responses, approximately $62.1 \%$. A total of $7.3 \%$ of high school principals responded with strongly agree and $36.6 \%$ agree for 18 of the 41 responses, approximately 43.9\%. Fifteen responses also were recorded in the neutral category of high school principals for $36.6 \%$.

\section{TUKEY}

Elementary to Middle $=.031$

Elementary to $\mathrm{HS}=.998$ 
Middle to $\mathrm{HS}=.113$

Sig. Diff. $=.063$

$\mathrm{N}=$ Elem. 136, MS 58, HS 41

Tukey post-hoc comparisons of the three groups indicate elementary principals $(\mathrm{M}=2.72$, $95 \%$ CI $[2.54,2.90])$ compared to middle school principals $(\mathrm{M}=2.31,95 \% \mathrm{CI}[2.04,2.58])$ have a significant difference of $\mathrm{p}=.031$. Comparing the elementary to high school principals demonstrates no significant difference, $\mathrm{p}=.998$. There is no significant difference between middle school and high school principals, $\mathrm{p}=.113$.

Research Question 4: What impedes principals‘ implementation of technology in West Virginia public schools? Designed to determine obstacles related to technology is domain one. Question 18, obstacles related to infrastructure includes building structure, hardware, software, and funding. Item 11, -software is not designed to track student data" generated a mean of 3.27 and standard deviation of 1.019 through a MANOVA test on 234 responses.

\section{MANOVA}

Elementary Mean $=3.38, \mathrm{SD}=0.987$

Middle School Mean $=2.98, \mathrm{SD}=1.106$

High School Mean $=3.32, \mathrm{SD}=0.934$

Item Composite $(\mathrm{N}=234)$ Mean $=3.27, \mathrm{SD} 1.019$

Continuing with an ANOVA to determine if there is a significant difference between the mean scores of two or more groups, the three levels of principals, a significant difference of .041 exists. This is the second item from research question four generating a significant value from the ANOVA test. 
A one-way ANOVA was used to test for differences between the three levels of principals.

Responses from the principals differed significantly across the three groups, $\mathrm{F}=3.232$, and $\mathrm{df}=(2$, 231), see Table 14.

ANOVA

Domain 1, Item 11 from Appendix K Figure 4: Research Question 4, Data Analysis

Survey Question 18

Item 11 from Survey

Sig. Diff. $=.041$

Table 14: Research Question 4, Survey Question 18, Item 11

\begin{tabular}{lccccc}
\hline & Sum of Squares & df & Mean Squares & F & Sig. \\
\hline Between Groups & 6.588 & 2 & 3.294 & 3.232 & .041 \\
Within Groups & 235.451 & 231 & 1.019 & & \\
Total & 242.038 & 233 & & & \\
\hline
\end{tabular}

A Tukey HSD demonstrated a .033 significant difference between elementary verses middle school. A total of $7.5 \%$ of elementary principals responded with strongly disagree and $47.8 \%$ disagree for 74 of the 134 responses, approximately $55.3 \%$. A total of $5.1 \%$ of middle school principals responded with strongly disagree and $33.9 \%$ disagree for 23 of the 59 responses, approximately $39 \%$. A total of $7.3 \%$ of high school principals responded with strongly disagree and $39 \%$ disagree for a total of 19 of the 41 responses, approximately $46.3 \%$.

TUKEY

Elementary to Middle $=.033$

Elementary to $\mathrm{HS}=.934$

Middle to $\mathrm{HS}=.236$

Sig. Diff. $=.076$

$\mathrm{N}=$ Elem. 134, MS 59, HS 41 
Tukey post-hoc comparisons of the three groups indicate elementary principals $(\mathrm{M}=3.38$, 95\% CI $[3.21,3.55])$ compared to middle school principals $(\mathrm{M}=2.98,95 \% \mathrm{CI}[2.69,3.27])$ demonstrates a significant difference, $p=.033$. There is no significant difference demonstrated between elementary principals and high school principals, $p=.934$. There is no significant difference between middle school principals and high school principals, $\mathrm{p}=.236$.

Research Question 4: What impedes principals‘ implementation of technology in West Virginia public schools? Domain 2 is designed to determine obstacles related to social issues. Question 19 addresses social issues as an obstacle. Item 2, -equal access to technology for everyone is an issue in your school" generated a mean of 3.34 and standard deviation of 1.216 through a MANOVA test on 234 responses.

\section{MANOVA}

Elementary Mean $=3.52, \mathrm{SD}=1.139$

Middle School Mean $=3, \mathrm{SD}=1.352$

High School Mean $=3.23, \mathrm{SD}=1.165$

Item Composite $(\mathrm{N}=234)$ Mean $=3.34, \mathrm{SD} 1.216$

Continuing with an ANOVA to determine if there is a significant difference between the mean scores of two or more groups, the three levels of principals, a significant difference of .019 exists. This is the third item from research question four generating a significant value from the ANOVA test.

A one-way ANOVA was used to test for differences between the three levels of principals. Responses from the principals differed significantly across the three groups, $F=4.045$, and $\mathrm{df}=(2$, 231), see Table 15. 


\section{ANOVA}

Domain 2, Item 18 from Appendix K Figure 4: Research Question 4, Data Analysis Survey Question 19

Item 2 from Survey

Sig. Diff. $=.019$

Table 15: Research Question 4, Survey Question 19, Item 2

\begin{tabular}{lccccc}
\hline & Sum of Squares & df & Mean Squares & F & Sig. \\
\hline Between Groups & 11.650 & 2 & 5.825 & 4.045 & .019 \\
Within Groups & 332.679 & 231 & 1.440 & & \\
Total & 344.329 & 233 & & & \\
\hline
\end{tabular}

A Tukey HSD demonstrated a .017 significant difference between elementary verses middle school. A total of $15.6 \%$ of elementary principals responded with strongly disagree and $51.1 \%$ disagree for 90 of the 135 responses, approximately $66.7 \%$. A total of $13.6 \%$ of middle school principals responded with strongly agree and $33.9 \%$ agree for 28 of the 59 responses, approximately $47.5 \%$. A total of $10 \%$ of high school principals responded with strongly disagree and $42.5 \%$ disagree for 21 of the 40 responses, approximately $52.5 \%$.

TUKEY

Elementary to Middle $=.017$

Elementary to $\mathrm{HS}=.364$

Middle to $\mathrm{HS}=.631$

Sig. Diff. $=(1) .556,(2) .370$

$\mathrm{N}=$ Elem. 135, MS 59, HS 40

Tukey post-hoc comparisons of the three groups indicate elementary principals $(\mathrm{M}=3.52$, $95 \%$ CI $[3.32,3.71])$ compared to middle school principals $(\mathrm{M}=3.00,95 \%$ CI $[2.65,3.35]) \mathrm{a}$ significant difference, $\mathrm{p}=.017$. There is no significant difference demonstrated between 
elementary principals and high school principals, $\mathrm{p}=.364$. There is no significant difference between middle school principals and high school principals, $\mathrm{p}=.631$.

Research Question 4: What impedes principals' implementation of technology in West Virginia public schools? Domain seven is designed to determine teacher and student perceived obstacles. Question 20 addresses teacher and student perceived obstacles defined as attitude toward technology and technology use. Item 5, tack of time to teach technology to students is an obstacle" generated a mean of 2.51 and standard deviation of 1.12 through a MANOVA test on 236 responses.

\section{MANOVA}

Elementary Mean $=2.34, \mathrm{SD}=1.056$

Middle School Mean $=2.64, \mathrm{SD}=1.156$

High School Mean $=2.9, \mathrm{SD}=1.179$

Item Composite $(\mathrm{N}=236)$ Mean $=2.51, \mathrm{SD} 1.12$

Continuing with an ANOVA to determine if there is a significant difference between the mean scores of two or more groups, the three levels of principals, a significant difference of .010 exists. This is the fourth item from research question four generating a significant value from the ANOVA test.

A one-way ANOVA was used to test for differences between the three levels of principals. Responses from the principals differed significantly across the three groups, $F=4.677$, and $\mathrm{df}=(2$, 233), see Table 16.

ANOVA

Domain 7, Item 23 from Appendix K Figure 4: Research Question 4, Data Analysis Survey Question 20 
Item 5 from Survey

Sig. Diff. $=.010$

Table 16: Research Question 4, Survey Question 20, Item 5

\begin{tabular}{lccccc}
\hline & Sum of Squares & df & Mean Squares & F & Sig. \\
\hline Between Groups & 11.386 & 2 & 5.693 & 4.677 & .010 \\
Within Groups & 283.576 & 233 & 1.217 & & \\
Total & 294.962 & 235 & & & \\
\hline
\end{tabular}

A Tukey HSD demonstrated a .012 significant difference between elementary verses high school. A total of $19.9 \%$ of elementary principals responded with strongly agree and $48.5 \%$ agree for 93 of the 136 responses, approximately $68.4 \%$. A total of $18.6 \%$ of middle school principals responded with strongly agree and $33.9 \%$ agree for 31 of the 59 responses, approximately $52.5 \%$. Another $35.6 \%$ of middle school principals responded with disagree, 21 principals. A total of $9.8 \%$ of high school principals responded with strongly agree and $39 \%$ agree for 20 of the 41 responses, approximately 48.8\%. High school principals also responded with disagree, 39\%, 16 responses, creating an equal amount of agree and disagree choices.

\section{TUKEY}

Elementary to Middle $=.179$

Elementary to $\mathrm{HS}=.012$

Middle to $\mathrm{HS}=.483$

Sig. Diff. $=(1) .275,(2) .397$

\section{$\mathrm{N}=$ Elem. 136, MS 59, HS 41}

Tukey post-hoc comparisons of the three groups indicate elementary principals compared with middle school principals have no significant difference, $p=.179$. Comparing the elementary $(\mathrm{M}=2.34,95 \% \mathrm{CI}[2.16,2.52])$ to high school principals $(\mathrm{M}=2.90,95 \% \mathrm{CI}[2.53,3.27])$ 
demonstrates a significant difference, $p=.012$. There is no significant difference between middle school principals and high school principals, $\mathrm{p}=.483$.

\section{Summary}

The demographic characteristics collected through Survey Monkey focus on elementary, middle school, and high school principals in the fifty-five counties of West Virginia. The information collected for the demographics determines the years experience and technology training of West Virginia principals. A MANOVA test on the data pertaining to each research question demonstrated a significant difference of $\mathrm{p}<.05$ and provided significant data for the researcher to continue with the ANOVA on each component. A total of nine, $12.8 \%$, of the seventy items from the survey demonstrated significant differences through ANOVA computations. Continuing with Tukey tests eliminated one item as being significant from RQ-1, principals provide time in the master schedule for classroom use of the computer lab," and one item from RQ2, -students are utilized to provide technical support." The other seven items, $10 \%$, supporting RQ2, RQ-3, and RQ-4 continued to demonstrate significant differences between the three levels of principals and chapter five explains each in detail supporting the research of this study.

Pages 146-148, Summary at a Quick Glance, include five additional tables (Table 17-Table 21) that summarize the demographics of this study, the key points from the survey results, and the key points from the analysis of data. 


\section{Chapter Five: Conclusions}

\section{Introduction}

Chapter five describes the data collected and the implications the findings may have on West Virginia principals implementing technology in West Virginia public schools. The summary of the study briefly reviews the entire process and restates the four research questions.

Next, the researcher interprets and discusses the data from the statistical analyses in chapter four and the findings will provide pathways for West Virginia principals to follow while leading their schools into the 21 st century world of technology. Presented next is a discussion based on the findings and suggestions on how to move West Virginia principals forward in the Global21 initiative. Recommendations from this study for West Virginia principals may enhance the implementation process and use of technology in West Virginia public schools. Also included are additional research suggestions that may assist other researchers with ideas to extend this particular project.

West Virginia Department of Education has a large initiative to move students into the 21 st century with a tremendous focus on technology. This 21 st century learning plan has a catchy title, Global21: Students deserve it. The world demands it" (WVDE, n.d.). This includes revolutionary changes in technology addressing research tools, email, word processing, Internet, and presentation software. These components must be a successful part of a pedagogical approach for the 21 st century learner as a new generation of students that have never known a world without the Internet, without computers, and without cell phones (WVDE, n.d.). Every student that enters the doors of West Virginia public schools is a digital native.

This study provides information pertinent to the state superintendent, West Virginia Department of Education, West Virginia Department of Technology, and principals as the 
Global21 initiative attempts to provide all West Virginia students a bridge of technology to cross the digital divide. Obstacles discussed in this chapter are relevant to West Virginia principals by providing information that has a direct impact on technology use as it relates to the national context found in the literature review.

\section{Summary of the Study}

The purpose of this study was to determine if obstacles implementing technology nationally according to the literature are consistent with West Virginia obstacles based on the perception of West Virginia principals. Little is known about obstacles West Virginia principals face during the technology implementation process compared to the obstacles nationally as described in the literature review. This study provides information about West Virginia obstacles and how they fit into the national context.

This research examined the role of the principal in providing technological leadership and other providers of technological support at the three levels, elementary, middle school, and high school. The research also examines what impedes and facilitates the implementation of technology according to the principals' perceptions. The data provides comparisons between the three groups, elementary to middle school, elementary to high school, and middle school to high school. According to Friedman (2005), the playing field has become level, creating a worldwide competition for those students in public education having access to 21 st century technology. West Virginia principals are meeting this challenge by providing technology rich environments for our students.

The literature reviewed for this study reveals many obstacles to successfully implementing technology nationally and this research provides data supporting that many of the same obstacles for West Virginia principals exist. Reviewing the history of technology from the early 1980s in 
West Virginia public schools provides evidence of a strong push from the West Virginia Department of Education to keep West Virginia at the top for enhancing students ${ }^{\text {` }} 21$ st century skills through the use of technology. The Global21 initiative is also a strong indicator of West Virginia's path down the technology highway to provide students 21 st century skills to compete in the world around them.

This study involved data collection through an online survey requesting information from West Virginia principals pertaining to eight domains and seventy items to answer four research questions. The four questions are:

1) What technology support do West Virginia principals provide to teachers?

2) Who do West Virginia principals rely on to provide technology support when unable to do so themselves?

3) What facilitates principals` implementation of technology in West Virginia public schools?

4) What impedes principals' implementation of technology in West Virginia public schools?

Originally included in this study were 658 West Virginia principals divided into three groups, elementary, middle school, and high school. There were 23 email addresses returned as non-deliverable or had opted out of receiving emails through Survey Monkey. Successful emails sent to elementary principals totaled 408, middle school totaled 123, and high school totaled 104. A total of 140 elementary principals, 61 middle school principals, and 43 high school principals responded to the survey. The response rate for elementary principals was $34 \%$, middle school principals $50 \%$, and high school principals $41 \%$. Elementary principals made up $56.5 \%$ of the total responses, middle school 24.6\%, and high school 17.3\%. Representation from all fifty-five West Virginia counties occurred. 


\section{Discussion and Recommendations}

Years Experience. The demographics collected from the three levels of West Virginia principals demonstrates that $76.3 \%$ have less than fifteen years experience as a principal. This demographic can be used to support that West Virginia principals have the knowledge to be technology leaders. The principal as a technology leader, noted as one of the most important factors affecting the effective integration of educational technology (Byrom \& Bignham, 2001). If colleges and universities are providing principals with course work in the area of technological expertise, then this population of principals should possess the skills needed to become a successful technology leader.

According to the literature review, the active role of the principal is extremely important for the successful implementation of technology in public schools. The data collected for this study also strongly support the importance of a strong technological principal to enhance the technology experience in public schools. An area that could possibly enhance the skills of new principals would be to review the graduate requirements of colleges and universities to determine if technology course work supports the needs of public school principals in the field of technology. Colleges and universities must remain directly involved with the public education system to meet the ever changing demands of future principals especially in the field of technology.

Training. The next question from the demographics section of the survey provides data supporting that $95.2 \%$ of West Virginia principals have been involved in some type of technology training. The largest numbers of principals have been trained in the area of integrating technology. According to this research, principals perceive the West Virginia Department of Education, individuals in technology positions at the county level, RESA, and building level technology savvy individuals as good providers of training in the area of technological skills. 
As West Virginia continues to focus on the area of integrating technology into the curriculum, the data supports this process as being successful for principals. Schools that are not being successful in this area may be attempting to provide technology as a separate entity and time to teach technology is sparse. Technology is a tool to enhance each curricular area. Computer labs must also be part of the classroom curriculum and not a location that provides time for the teacher to catch up on other items while students play.

Principals adjusting schedules to provide everyone computer lab time is extremely important for the implementation process of technology in West Virginia public schools. Technology savvy teachers must also have time built into their schedules by the principal if they are to provide technical support to other classroom teachers. Individuals that sacrifice their own time or even time with their students quickly become frustrated with attempting to provide everyone technical support.

West Virginia principals offer high levels of experience integrating technology into the curriculum and providing support with data driven decisions. The data also demonstrates there is a need to increase principals ' awareness in the area technical abilities to repair general software and hardware issues, and the impact technology has on our society. Course work through universities and colleges could address this issue with additional technology courses. Local RESAs could provide additional training through the West Virginia Department of Education. However, the training must address the immediate needs of the principals and determining this through surveys would be one method. Providing more technological training for principals also creates the concern of finding more time in the daily routine for principals to provide additional technical support without sacrificing other responsibilities. 
The second largest number of principals received training in the area of data driven decision-making. This also supports that the WVDE is successful in moving information from the top down as the emphasis on data collection continues to grow. According to this study, elementary principals feel software is designed to track student progress and it is utilized successfully. However, middle and high school principals do not support this. Technology tools such as Palms are utilized at the elementary level for reading assessments and providing a tracking device for the student work. This type of tool assists teachers with pinpointing areas students may have concerns. Software at the middle school and high school level tends to be more expensive and different methods are used such as maintaining student work on file servers for evaluation of the product not necessarily utilized to track student progress.

As schools become more data driven, software that is capable of tracking student progress becomes more important. The availability of this type of software often is an obstacle. However, according to the literature review, companies are becoming more aware of educational needs and are attempting to provide additional software packages that can track student data. Competition among vendors may assist with driving software costs down.

The final demographic in the area of training provides data supporting only $43 \%$ of the principals have received actual training in the area technical support for hardware and software. At this point, the training seems to be limited in this area. This is an area that some self-taught technology savvy principals can become a huge asset for their school. However, providing technology support can easily consume a principal's day and other responsibilities may become issues if not addressed. An important component of a 21 st century principal then becomes time management. 
This creates an opportunity for the WVDE to collect additional data from West Virginia principals to determine specific areas of technology support they are lacking. RESA and county technology coordinators could collect this information and provide a more robust support to relieve principals' responsibilities of technical support in these areas of need. If this direction is not heeded, these technology savvy principals will sacrifice more of their own time and take away from their role as an instructional leader. They will not be able to enhance overall student achievement.

Technical Support. The data compiled from all three levels of principals supports the administrator being responsible for maintaining technology within their building, $56.7 \%$ agree or strongly agree. This provides evidence that West Virginia principals are expected to provide this technical support, but often lack the expertise to do so. Lack of immediate technical support is a major obstacle for hardware, $70.4 \%$ agree or strongly agree, and also software according to $66.1 \%$ of the principals. Whether providing it themselves or depending upon others, this is a major obstacle according to the perception of West Virginia principals.

Sixty percent of the principals consider the technical support they receive in their building is preventive maintenance. Only $46.4 \%$ of the principals attempt to adjust scheduling to provide technological experts in their building time to assist others. This means that individuals that can assist with technology support must do so on their own time or sacrifice time with their students.

The data from the responses of all three levels of principals support that teachers are not responsible for maintaining their own technology. The data also demonstrates that approximately $48.4 \%$ of the schools do not have a media specialist to assist with technology support. County technicians other than RESA technicians are responsible for support of technology according to $79.1 \%$ of the responses. RESA technicians provide technological support according to $48.8 \%$ of the responses. Only $20.8 \%$ of the principals have access to a Technology Integration Specialist 
(TIS) to manage technology in their schools. Elementary principals responded with $82 \%$ stating they do not have a TIS in their school. Middle school principals responded at $60 \%$ and high school principals at $65 \%$.

Even though West Virginia Department of Technology has set high standards for the TIS positions, and provides extensive training opportunities for these individuals, the data shows there are still not enough TIS positions to provide support to a large number of schools. The TIS is responsible for providing teachers with assistance integrating technology, providing support to students, and assisting with technological issues is their last priority. However, from personal experience it is extremely difficult to utilize technology if there are technical concerns.

This demonstrates inconsistency among the three levels of principals. Non-flexible schedules and limited staffing in the elementary schools do not provide those principals with an opportunity to move staff around to free up time for technical assistance or a position for a TIS. Middle schools and high schools tend to have a little more flexibility with this and even may have the opportunity to provide a teaching position for a TIS on staff by eliminating another position. However, evidence indicates that computer usage by students in schools with a TIS shows only modest increase (Williams, 2000). This again could be related to the TIS focusing their attention on providing technical support instead of focusing on student and teacher technology goals due to lack of technical support being offered to the schools.

The data collected from all three levels of principals demonstrates the need for additional technological training for teachers. Teachers are not responsible for maintaining technology in their building beyond simple fixes such as paper jams and restarting the computers. The research shows nearly $50 \%$ of the schools do not have media specialists to assist with technology support. Almost $80 \%$ of the responses demonstrate that county level technicians maintain technology but are 
overwhelmed and unable to provide much support beyond preventive maintenance. The literature review provides positive feedback on the Technology Integration Specialist positions. The WVDE utilizes a vigorous program to educate and prepare teachers to become a TIS but funding to support these positions in individual schools is usually an obstacle.

Perhaps the WVDE should re-evaluate this position and focus more directly on providing individuals for technical support. This research demonstrates that West Virginia has been very successful with integrating technology into the curriculum. However, there could be two sides to this as West Virginia may be successful in the area of technology integration due to the TIS position providing opportunities to teachers and students to be successful with technology. One model WVDE would like to see implemented with the TIS position is schools with 20 or fewer teachers have at least a half time TIS and schools with more than 20 teachers have a full time TIS on staff (WVDE, 2008, p. 1).

Other individuals are also available to provide limited technology support. Data compiled from all three levels of principals supports that teachers are capable of handling minor technical glitches such as frozen screens and jammed printers in their own classrooms. The data also provides evidence that principals utilize students to assist with technical assistance, supported by nearly $43 \%$ of the principals. Surprisingly there was not much variance between elementary, middle school, and high school principals. This could be contributed to the technological exposure elementary students have in the 21 st century world before they even enter school.

Utilizing students in the classroom is an alternative to providing staffed technical support. Kanawha County Schools utilized Area Technology Teachers (ATT) from 1996-2003 for technical support and training teachers in the area of technology. Each high school had one ATT position and this ATT was responsible for the feeder schools in the immediate area. As an ATT, I utilized 
students and paid them small stipends through Kanawha County Department of Technology. Increasing the number of programs to provide students with community service hours or small stipends could benefit schools with hardware and software issues. Middle schools could develop technology courses that focus on technical support and when these students reach high school, they could become part of a technology support program and utilized throughout the feeder schools.

Staff Development. According to the data, nearly half of the principals are responsible for the provision of school based staff development in the area of technology. When principals receive staff development in the area of technology, they are sharing this knowledge with their classroom teachers. Principals continue to focus on how to integrate technology into the curriculum as an instructional leader and not on technical issues. Integrating technology has been a key area of focus by the WVDE and data supports they have done an excellent job with this.

Seventy-two percent of the principals stated teachers in the building provide technology staff development. Additionally, $82.8 \%$ of the principals stated that county level personnel provide staff development in the area of technology. Only $38.9 \%$ of the schools utilize video conferencing for staff development. This is a disappointing statistic demonstrating the lack of use of distance learning labs. These labs could also provide the opportunity for one instructor to teach to multiple classrooms across the state if utilized to their fullest potential. Just over $61 \%$ of the principals responding stated they utilize professional learning communities to enhance technology. Anyone providing technology staff development from within the building can facilitate technology use and provide enhanced opportunities.

The data collected demonstrates that the lack of staff development in the area of technology is not an obstacle. However, it pinpoints the area of staff development in the area of technical support as a concern. The combined responses from all three levels of principals support the 
principal as an active leader in technology and they are providing whatever expertise they can provide to make their school a 21 st century learning environment.

Funding. According to the data, principals perceive lack of equal funding for each county as an obstacle to implementing technology. Inequality of funds creates an obstacle more difficult for some counties to overcome due to smaller populations and a smaller tax base. Nearly $50 \%$ of public education is funded through property taxes. Federal, state, and local funds are not equally distributed to schools according to the research. Even the distribution of funds within states to individual counties may differ. The data from this research suggests that even middle school principals consider equal access to technology as an obstacle to implementing technology successfully compared to elementary and high school principals. This would be an area to perform additional research at the federal and state level. Perhaps the review and changes in policy at the federal, state, and county levels would be the only method to address this obstacle.

Many of the categories discussed revolve around lack of funding. Sixty-seven percent of the principals stated lack of funding for hardware as being an obstacle. The biggest obstacle according to this survey is the lack of funding for technical support demonstrated by $76.4 \%$ of the principals. This is an ongoing issue in public education in general. Lack of adequate funding for new buildings, staff, technology, transportation, maintenance, and many other issues create many obstacles counties and states have difficulty addressing. This issue is not an easy one to resolve but the expense to maintain technology at a competitive level is tremendous.

Attitude. The data from this study strongly supports principals‘ perception of positive building culture toward technology is high with $93.6 \%$ agreeing or strongly agreeing. The literature review provides support that the attitude of the principals has a positive impact on technology within the building. Attitude in West Virginia public schools is definitely not an 
obstacle according to the research. This may be attributed to the positive roll the WVDE and West Virginia Department of Technology have taken beginning in the early 1980s supporting, enhancing, and leading the way for technology. This occurs under the direct supervision of the state superintendents and their focus on technology to keep West Virginia among the leading states for technology implementation. The superintendents have provided a strong technology plan and vision to support technology statewide. Teacher and student perceived obstacles according to the principals responding to this study also demonstrate that teacher and student attitude it positive toward technology and is not an obstacle.

Policy. Over $96 \%$ of the principals are aware of a comprehensive technology plan in accordance to WVDE Policy 2470 that is reviewed annually. This policy requires a comprehensive technology plan to provide a roadmap of implementing technology through time. One hundred percent of the principals responding stated their students and staff are aware of an Acceptable Use Policy. Nearly $91 \%$ of the principals have a comprehensive technology plan in addition to the county plan.

In addition to policy, a technology committee is present in $79.6 \%$ of the schools represented in this study. This evidence strongly supports the WVDE as a strong facilitator of technology policy. Principals have been extremely successful disseminating information received from the WVDE to staff, students, and parents involved in their school. Planning and creating policy to support technology has become a routine part of the successful implementation process in West Virginia.

Facilities. Lack of adequate electricity is supported by $54.1 \%$ of the principals as an obstacle that impedes the implementation of technology. According to the data, poor Internet access is not an obstacle in most areas. The data does not support older facilities as a barrier to 
implementing technology, which is contradictory of the information in the literature review. However, lack of adequate electricity could be contributed to the age of West Virginia public school buildings. There is no real solution to this obstacle other than when new schools are constructed; a technology committee should be involved to assist with determining the technology needs of today and for the future. Other information to review would be the cost of upgrading in old facilities compared to initial expenses during new constructions. There is documentation providing the amounts schools have spent specifically on facility issues during the technology implementation process.

Hardware/Software. Hardware purchases predetermined by the state are listed by $57.3 \%$ of the principals as an obstacle. This sometimes creates an issue with schools wanting to purchase items outside of the state contract at a discounted price. Although the initial price may be cheaper, keeping hardware consistent throughout the building is extremely important when providing technical support. A variety of hardware may also create a variety of technical issues that could be costly. By purchasing from the state contracts, equipment remains consistent and the warranty work usually is provided without additional costs to the school. Contracts now are more flexible to accommodate the every changing technology. As equipment becomes cheaper or updated, contracts can be adjusted to provide the best equipment to the students at the best price.

Expensive software according to all three levels of West Virginia principals is also an obstacle to implementing technology. Again, purchasing through state contracts has assisted with this issue allowing for bulk rate purchases and consistency in software also decreases technical issues.

Time. Another concern that may negatively impact technology according to individual group responses suggest that elementary school principals consider lack of time to teach 
technology to students as an obstacle to implementing technology successfully. This same data from the middle school principals supports that lack of time to teach technology to students is not an obstacle. High school principals are split nearly equally on lack of time to teach technology as being an obstacle. This may relate to scheduling issues such as flexibility, lack of staff to support technology, and lack of staff to teach technology. Additional research could look at specific amounts of time each level of student utilizes technology each day and possibly see if the outcome academically is enhanced by the number of minutes of technology use. This type of study may produce evidence supporting that more time is needed for technology in public schools. Principals provided with this type of data may reconsider scheduling and alternative methods to providing technology support within their building if it is truly enhancing student performance.

Access. Taking this one-step further, the data from this study also shows $74.2 \%$ of the principals concerned that students do not have access to 21 st century technology outside of the public school. As schools attempt to enhance their own technological environment, society may be increasing the gap between our students that have access and those that do not. Additional responsibility then falls upon the public schools to provide technology to these students as not to increase the social gap possibly created by the driving force of technology. Social impact of technology on students would be an entirely new direction to advance this study.

Additional Research Questions. Many obstacles to implementing technology exist according to the literature and many of these obstacles are similar for West Virginia public school principals. The data from this study answers four research questions pertaining to the role of the principal implementing technology in West Virginia public schools. Also offered are some suggestions that may assist principals in the technology implementation process and perhaps provide solutions that may prevent these items from becoming obstacles. 
An additional study to extend this study would be to compare schools of excellence in West Virginia to the same number of schools not recognized as schools of excellence and the expertise of the principal in the field of technology. This could provide data supporting schools with strong technological leaders enhance the academics of their students through the use of technology. Utilizing a survey to expand this study to the teachers and their expertise in the area of technology may also provide very pertinent data. An extension of this would be to review the goals and objectives of the WVDE Global21 initiative and look at schools that are aligning their technology goals with this initiative compared to those that are not. This could be determined through a survey of the principal and staff to gain an understanding of their knowledge base of this initiative.

Questions have emerged during this study generating topics for additional research. Is there a relationship between technology utilization and student performance? The tremendous amount of funding allocated yearly for technology should positively affect student performance as schools move into the 21 st century completely equipped with all realms of technology. What is the impact of technology (specifically computer and Internet use) on the way teachers teach and students learn? Teachers may be saving time in areas of specific curriculum due to the use of technology but are students reaching a higher depth of knowledge and graduating with skills to compete worldwide? Does the investment in technology compare to other educational initiatives in terms of costs verses benefits? The cost of maintaining the ever-changing technology in schools is tremendous. What other initiatives could be more successful if they were funded as technology is today in public schools? 
Summary at a Quick Glance

Table 17: Years Experience as a Principal-Less than 15 Years

$\begin{array}{cccc}\text { Experience } & \text { Elementary } & \text { Middle } & \text { High } \\ \mathrm{N}=249 & 74.1 \% & 85.2 \% & 71.1 \%\end{array}$

Table 18: Percent of Principals with Technology Training

\begin{tabular}{cccc}
\hline Training & Elementary & Middle & High \\
$\mathrm{N}=248$ & $93 \%$ & $98.4 \%$ & $97.8 \%$ \\
\hline
\end{tabular}

Table 19: Types of Training

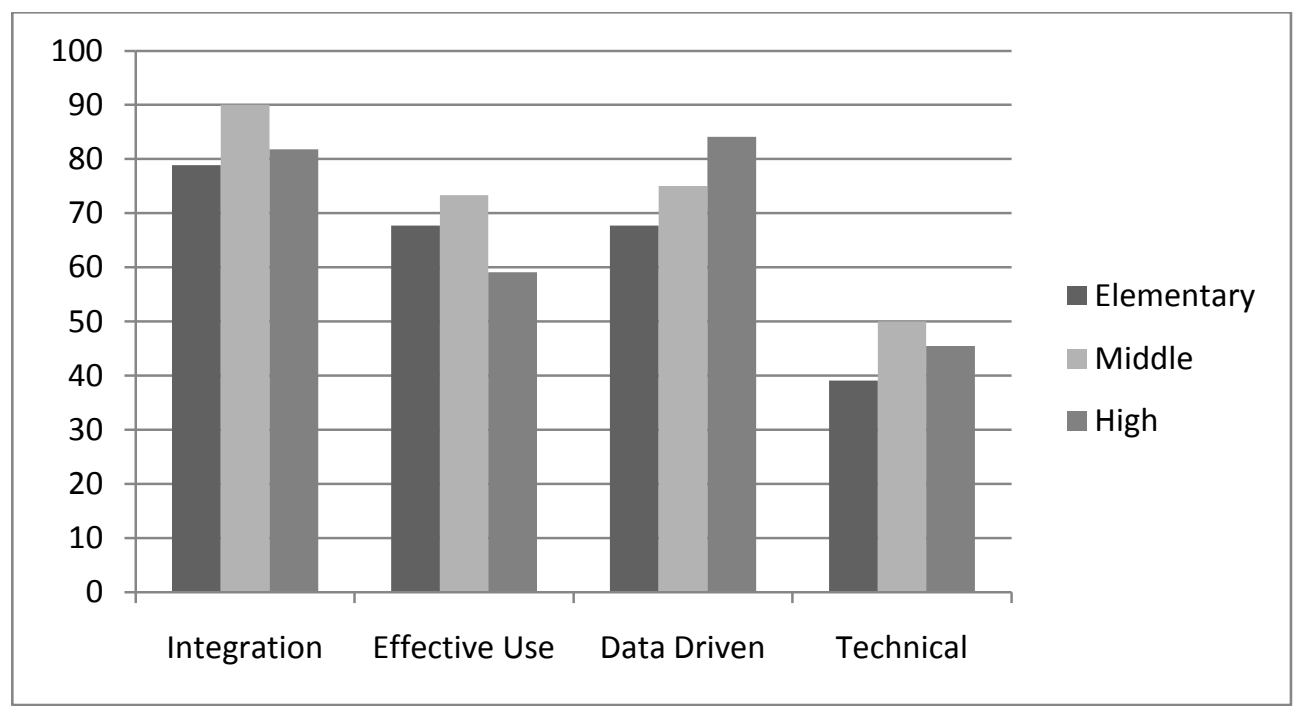

Table 20: Summary of Responses with at Least One Group at 70\% or Higher (Strongly Disagree and Disagree)

\begin{tabular}{lcccc}
\hline Survey Item & $\begin{array}{c}\text { Research } \\
\text { Question }\end{array}$ & $\begin{array}{c}\text { Elementary } \\
\text { School }\end{array}$ & $\begin{array}{c}\text { Middle } \\
\text { School }\end{array}$ & $\begin{array}{c}\text { High } \\
\text { School }\end{array}$ \\
\hline $\begin{array}{l}\text { Technology is not integrated into the curriculum and is a stand- } \\
\text { alone learning environment }\end{array}$ & 3 & $84.4 \%$ & $91.4 \%$ & $83.3 \%$ \\
Teacher attitude toward technology is poor & 4 & $83.1 \%$ & $81.3 \%$ & $90.3 \%$ \\
Student attitude toward technology is poor & 4 & $94.1 \%$ & $96.7 \%$ & $100 \%$ \\
\hline
\end{tabular}


Table 21: Summary of Responses with at Least One Group at 70\% or Higher (Strongly Agree and Agree)

\begin{tabular}{|c|c|c|c|c|}
\hline Survey Item & $\begin{array}{l}\text { Research } \\
\text { Question }\end{array}$ & $\begin{array}{l}\text { Elementary } \\
\text { School }\end{array}$ & $\begin{array}{l}\text { Middle } \\
\text { School }\end{array}$ & $\begin{array}{l}\text { High } \\
\text { School }\end{array}$ \\
\hline $\begin{array}{l}\text { Lack of immediate technical support for hardware is an } \\
\text { obstacle }\end{array}$ & 1 & $69.8 \%$ & $78.7 \%$ & $60.5 \%$ \\
\hline $\begin{array}{l}\text { Lack of immediate technical support for software is an } \\
\text { obstacle }\end{array}$ & 1 & $66.2 \%$ & $70.5 \%$ & $60.6 \%$ \\
\hline $\begin{array}{l}\text { The school administrator provides recognition to staff } \\
\text { members providing technology training }\end{array}$ & 1 & $85.8 \%$ & $94.9 \%$ & $100 \%$ \\
\hline $\begin{array}{l}\text { The principal allocates funding for technology as a } \\
\text { priority }\end{array}$ & 1 & $79.3 \%$ & $80.3 \%$ & $83.3 \%$ \\
\hline $\begin{array}{l}\text { The principal demonstrates positive technology use to } \\
\text { teachers and students }\end{array}$ & 1 & $95 \%$ & $93.4 \%$ & $97.6 \%$ \\
\hline $\begin{array}{l}\text { The principal supports teachers and students and the use } \\
\text { of technology }\end{array}$ & 1 & $99.3 \%$ & $100 \%$ & $100 \%$ \\
\hline $\begin{array}{l}\text { The principal's attitude influences the success of } \\
\text { technology in the building }\end{array}$ & 1 & $95 \%$ & $96.7 \%$ & $95.3 \%$ \\
\hline $\begin{array}{l}\text { The principal provides time in the master schedule for } \\
\text { classroom use of the computer lab }\end{array}$ & 1 & $97 \%$ & $91.8 \%$ & $88.4 \%$ \\
\hline $\begin{array}{l}\text { The principal provides time in the master schedule for } \\
\text { technology literate staff to assist other staff }\end{array}$ & 1 & $60.7 \%$ & $70 \%$ & $60.4 \%$ \\
\hline $\begin{array}{l}\text { A county level technician other than RESA is responsible } \\
\text { for maintaining technology in the school }\end{array}$ & 2 & $77.1 \%$ & $83.6 \%$ & $79.1 \%$ \\
\hline $\begin{array}{l}\text { Lack of additional staff to assist school-wide with } \\
\text { technology is an obstacle }\end{array}$ & 2 & $82.9 \%$ & $77.1 \%$ & $70.8 \%$ \\
\hline Your building culture is positive toward technology & 3 & $91.8 \%$ & $96.6 \%$ & $95.4 \%$ \\
\hline $\begin{array}{l}\text { School based technology staff development is provided } \\
\text { by teachers in the building }\end{array}$ & 3 & $65.6 \%$ & $80 \%$ & $74.5 \%$ \\
\hline $\begin{array}{l}\text { School based technology staff development is provided } \\
\text { by county level personnel }\end{array}$ & 3 & $81.7 \%$ & $83.1 \%$ & $86 \%$ \\
\hline $\begin{array}{l}\text { School based technology staff development is provided } \\
\text { by other staff within the building such as a media } \\
\text { specialist or TIS }\end{array}$ & 3 & $66.9 \%$ & $70 \%$ & $74.4 \%$ \\
\hline $\begin{array}{l}\text { Training goes beyond the technology component and } \\
\text { addresses the specific area of integrating technology into } \\
\text { the curriculum }\end{array}$ & 3 & $75.5 \%$ & $69.3 \%$ & $67.4 \%$ \\
\hline $\begin{array}{l}\text { School based staff development provides technology skill } \\
\text { enhancements for teachers }\end{array}$ & 3 & $84.4 \%$ & $91.4 \%$ & $83.3 \%$ \\
\hline $\begin{array}{l}\text { Students are aware of the value of technology and } \\
\text { encourage teachers to use technology }\end{array}$ & 3 & $73.6 \%$ & $88.3 \%$ & $88.4 \%$ \\
\hline Technology use is integrated into the curriculum & 3 & $89.6 \%$ & $90 \%$ & $90.3 \%$ \\
\hline $\begin{array}{l}\text { Lack of funding to maintain the fast pace of technological } \\
\text { advances in hardware }\end{array}$ & 4 & $63.9 \%$ & $72.9 \%$ & $70.7 \%$ \\
\hline Lack of funding for technical support personnel & 4 & $76.9 \%$ & $81 \%$ & $68.3 \%$ \\
\hline $\begin{array}{l}\text { Lack of access to technology for students outside of } \\
\text { school is a concern for homework assignments }\end{array}$ & 4 & $73.5 \%$ & $78 \%$ & $70.7 \%$ \\
\hline Teacher attitude toward technology is positive & 4 & $88.9 \%$ & $87.9 \%$ & $87.8 \%$ \\
\hline
\end{tabular}




\section{Important Findings from the Study}

- Lack of immediate technical support is an obstacle according to all three levels of principals

- West Virginia principals are expected to provide technical support

- $60 \%$ of the principals consider the technical support they receive as preventive maintenance

- Teachers are not responsible for their own technical support

- Nearly $80 \%$ of principals rely on county technicians other than RESA for technical support

- Only $20.8 \%$ of West Virginia principals have access to a Technology Integration Specialist (TIS)

- Scheduling computer labs for additional technology use is more difficult at the elementary level

- $50 \%$ of the schools do not have a media specialist to assist with technical support

- Teachers are capable of handling minor technical issues

- Nearly $50 \%$ of principals provide staff development in the area of technology

- $72 \%$ of the principals stated that teachers within their building provide technology staff development

- Nearly $83 \%$ of the principals stated that county level personnel provide technology staff development

- Video conferencing is utilized by less than $40 \%$ of the principals for technology staff development

- Just over $61 \%$ of the principals stated they do use PLCs for staff development in the area of technology

- Principals do not perceive the lack of staff development in the area of technology an obstacle, however, in the area of technical support staff development is lacking

- Lack of equal funding for technology is an obstacle

- $67 \%$ of the principals stated lack of funding for hardware is an obstacle

- Lack of funding was the biggest obstacle for technical support, 76.4\% principals

- Nearly $94 \%$ of the principals agree or strongly agree that the culture in their building is very positive toward technology

- Over $96 \%$ of the principals are aware of a comprehensive technology plan that is reviewed annually, WVDE Policy 2470

- $100 \%$ of the principals stated their staff and students are aware of an Acceptable Use Policy

- Nearly $91 \%$ of the principals have a comprehensive technology plan in addition to the county plan

- Nearly $80 \%$ of the principals have a technology committee in their building

- Lack of adequate electricity is an obstacle that impedes the implementation of technology

- $57 \%$ of the principals perceive predetermined contracts by the state for hardware purchases as an obstacle

- Expensive software is also an obstacle according to all three levels of principals

- According to the elementary principals, lack of time to teach technology is an obstacle

- Nearly $75 \%$ of the principals are concerned about lack of student access to 21 st century technology outside of the school 


\section{References}

Apple Classrooms of Tomorrow, ACOT. (1995). Changing the conversation about teaching, learning, and technology. Retrieved from http://www.apple.com/education/k12/leadership.acot/library.html

Anderson, R. E., \& Dexter, S. (2005). School technology leadership: An empirical investigation of prevalence and impact. Educational Administration Quarterly, 41, 49-82.

Anderson, R. E., \& Dexter, S. (2000). School technology leadership: incidence and impact. Center for Research on Information Technology and Organizations, University of California, Irvine and University of Minnesota. Retrieved from http://www.crito.uci.edu/tlc/html/findings.html

Asher, G. (2002). Inadequate infrastructure, a common barrier to the infusion of technology into K-12 education, especially in rural schools. Technology Instructor, St. Cloud University (pp. 46-48).

Baker, T.L. (1994). Doing social research (2 ${ }^{\text {nd }}$ ed.), New York: McGraw-Hill Inc.

Bakia, M., \& Mitchell, K., \& Yang, E. (2007). State strategies and practices for educational technology: Volume i-examining the enhancing education through technology program. U.S. Department of Education Office of Planning, Evaluation, and Policy Development. Washington, DC.

Barnett, H. (2001). Successful k-12 technology planning: Ten essential elements. Eric Digest ED457858. Retrieved from http://www.ericdigest.org/2002-2/ten.htm

Bausell, C.V., \& Klemick, E. (2007). Tracking U.S. trends. Education Week 26 (30), $42-44$.

Becker, H. (2001). How are teachers using computers in instruction? Retrieved from http:www.crito.uci.edu/tlc/findings/conferences-pdf/how_are_teachers_using.pdf 
Bell Atlantic Corporation (n.d.). Bell Atlantic world school program puts West Virginia students in a cyber class of their own; James Earl Jones presents "graduation address". Retrieved from http://prnwire.com/cgibin/stories.pl?ACCT=104\&STORY=/www/story/132640\&EDATE=

Bennett, F. (n.d.). Technology and world education. Retrieved from http://www.cris.com/ faben1/worlded.html

Birinci, G., \& Kabakei, I. (2007). School principals' views about their roles in technology planning: A case in Eskisehir. Anadolu University.

Bozeman, W.C., \& Spuck, D.W. (1991). Technological competence: Training educational leaders. Journal of Research on Computing in Education. 23 (4), 31-46.

Byrom, E., \& Bingham, M. (2001). Factors influencing the effective use of technology in teaching and learning. Retrieved from http://www.eric.ed.gov/ERICDocs/data/ericdocs2sq1/content_storage_01/0000019b/80/1a/9 a/6d.pdf

Chiero, R.T. (1997). Teachers' perspectives on factors that affect computer use. Journal of Research on Computing, 30(2), 133-144.

Chin, B., \& Horton, J. (1993). Teachers' perceptions of instructional technology and staff development. Journal of Education Technology Systems, 22(2), 83-98.

Cisco Networking Academy (2008). Program overview Cisco networking academy. Retrieved from http://www.cisco.com/web/learning/netacad/academy/index.html

Coghlan, B. F. (2004). Addressing the barriers to technology integration: A case study of a rural school. (Doctoral dissertation, Mississippi State University). 
Costello, R. (1997). The leadership role in making the technology connection. THE Journal (Technology Horizons in Education), Vol. 25, 1997.

Cummings, L.E. (1995). Educational Technology-A faculty resistance view, Part 1:Iincentives and understandings. Educational Technology Review (4) pp.13-18.

Davis, G. (2008). The development and field test of the education technology leadership assessment survey. Dissertation Abstracts International, 69, 04A.

DeBell, W., \& Chapman, C. (2006). Computer and Internet use by students in 2003: Statistical analysis report. Washington, DC: National Center for Education Statistics, U.S. Dept. of Education, Institute of Education Sciences.

Earle, R., S. (2002). The integration of instructional technology into public schools: promises and challenges. Educational Technology Magazine. Vol. 42, No. 1, January-February, 2002, p. 5-13.

Editorial Projects in Education Research Center (2007). Technology counts: 2007. A digital decade. Retrieved from http://www.edweek.org/rc

Editorial Projects in Education Research Center (2008). Technology counts 2008. The push to improve science, technology, engineering, and mathematics. Retrieved from http:/www.edweek.org/ew/toc/2008/03/27/index.html

Edtech (2009). Retrieved from http://edtech.com

Federal Communications Commission (n.d.). E-Rate. Retrieved from http://www.fcc.gov/learnnet Friedman, T.H. (2005). The world is flat. New York: Farrar, Straus and Giroux.

Fullan, M. (2001). Leading in a culture of change. San Francisco, CA: Jossey-Bass.

Hasselbring, T. (1991). Improving education through technology: barriers and recommendations. Preventing School Failure, Vol. 35, n 3, pp. 33-37. 
Hofer, M., Chamberlin, B., \& Scot, T. (2004). Fulfilling the need for a technology integration specialist. The Journal, October 2004. Retrieved from http://www.thejournal.com/?id=16981

Hoffman, B. (1997). Integrating technology into schools. Education Digest, 62(5), 51-55.

Hopkins, G., (2002, June 18). Technology standards for school leaders released. Education World, Retrieved from http://www.educationworld.com/a_admin/admin/admin247.shtml

Horne, E., Coffman, T., Campbell, A., Heller, E., \& Slater, L., (2010). The new literacy crisis: immigrants teaching natives in the digital age. Presented at the CRSTE 2010 Cyber Conference. Retrieved from http://crste.org/c3handouts.html

Hurst, M., (2005). Technology counts: 2005, schools eye future costs. Vol. 24, Issue 35, Pages 3436, 39. Retrieved from http://www.edweek.org/ew/articles/2005/05/05/35costs.h24.html?rale=KQE5d7nM\%2F

Institute for the Transfer of Technology Education. (1995). Technology's impact on learning. Retrieved from http://www.nsba.org/sbot/toolkit/tiol.html\#Enhanced

Kearsley, G., \& Lynch, W. (1992, Fal192). Educational leadership in the age of technology: The new skills. Journal of Research on Computing in Education, 25(1), 50. Retrieved from Academic Search Premier database.

Kimble, C. (1999). The impact of technology on learning: Making sense of the research. Aurora, CO: Mid-Continent Regional Educational Lab. (ERIC Document Reproduction Service No. ED450723).

Kincaid, T., \& Feldner, L. (2002). Leadership for technology integration: the role of principals and mentors. Educational Technology and Society 5 (1) 2002. Retrieved from http://www.ifets.info/journals/5_1/kincaid.html 
Kulik, J. (1994). Meta-analytic studies of findings on computer-based instruction. In Baker, E.L. and O`Neil, H.F. Jr. (Eds.), Technology assessment in education and training. (pp. 9-33) Hillsdale, NJ: Lawrence Erlbaum.

MacNeil, A. J., \& Delafield, D. P. (1998). Principal leadership for successful school technology implementation. Society for Information Technology and Teacher Education International Conference $\left(9^{\text {th }}\right.$, Washington, DC).

MacNeil, A. J., Spuck, D., \& Ceyanes, J. (1998). Developing trust between principal and teachers. Retrieved from http//:ceyanes.com/UCEA.pdf

Mann, D. (1999). Documenting the effects of instructional technology; a fly-over of policy questions. Retrieved from http://www.ed.gov/rschstat/eval/tech/techconf99/whitepapers/paper6.html

Mann, D., Ph.D., Shakeshaft, C., Ph.D., Becker, J., Ph.D., Kottkamp, R., Ph.D. (n.d.). West Virginia Story: Achievement gains from a statewide comprehensive instructional technology program. Retrieved November from http://www.mff.org/pubs/ME155.pdf

McKinzie, J. (2002). Leading by example: The high touch high tech principal. The Educational Technology Journal Volume 11, no. 10.

Milken Exchange on Educational Technology (1999). Educational technology policies of the 50 states: Facts and figures. Santa Monica, CA: Milken Family Foundation. Retrieved from http://www.mff.org/edtech/publication.taf?_function=detail\&Content_uid1=268

Monk, D., Pijanowski, J., \& Hussain S. (1997). Financing schools: the future of children. Vol. 7 , No. 3. Retrieved from http://www.futureofchildren.org/usr_doc/vol7no3ART4.pdf

Nagel, D. (2008). Education technology spending to top $\$ 56$ billion by 2012. T.H.E. Journal. Retrieved from http://www.thejournal.com/articles/23299 
National Center for Education Statistics (2000). Teachers' tools for the 21 st century: A report on teachers' use of technology. Jessup, MD: US Department of Education.

National Education Association (2008). Access, adequacy, and equity in education technology. Retrieved from http://sc08.sc-education.org/conference/k12/.../08gainsandgapsedtech.pdf

National School Boards Association (2001). Roles I systematic change. Retrieved fro http://nsba.org/sbot/toolkit/risc.html

New York State Education Department (1998). Guidelines and standards for technology infrastructure of 21 st century educational facilities. ERIC ED460577. Retrieved from http://www.eric.ed.gov/ERICDocs/data/ericdocs2sql/content_storage_01/0000019b/80/19 /ad/12.pdf

O‘Dwyer, L., Russell, M., \& Bebell, D. (2003). Elementary teachers` use of technology: characteristics of teachers, schools, districts associated with technology use. Retrieved from http://www.intasc.org.

Paine, S. (n.d.). West Virginia Virtual School. Welcome from the state superintendent of schools. Retrieved from http://virutalschool.k12.wv.us/vschool/index.html

Peat, J., Mellis, C., Williams, K., \& Xuan W. (2002). Health science research: A handbook of quantitative methods. London: Sage.

Prensky, M. (2006). Listen to the natives. Educational Leadership/The Best of Educational Leadership 2005-2006. Alexandria, VA: ASCD. 20-23.

Reeves, T. (1998). The impact of media and technology in schools. A research report prepared for The Bertelsmann Foundation. Retrieved from http://www.athensacademy.org/instruct/media_tech/reeves0.html 
Regional Educational Service Agency (RESA) Website. Retrieved from http://resa1.k12.wv.us/about.asp

Ronnkvist, A., Dexter, S., Anderson, R. (2000). Technology support: Its depth, breadth, and impact in America's schools. Teaching and Learning, and Computing: 1998 National Survey Report \#5. ERIC ED445658.

Rowand, C. (2000). Teacher use of computers and the Internet in public schools. State in brief. National Center for Education Statistics, Washington, D.C.

Sandholtz, J. H., Ringstaff, C., \& Dwyer, D.C. (1997). Teaching with technology: Creating student-centered classrooms. New York: Columbia University.

Sawtelle, S. (2008). Does this really work? Learning and Leading with Technology, 13-15. Retrieved from http://www.iste.org

Schoeny, Z. G., Heaton, L.A., \& Washington, L. A. (1999). Perceptions and educational technology needs of school administrators. Society for Information Technology and Teacher Education International Conference (10 ${ }^{\text {th }}$, San Antonio, TX).

School Technology Report to Congressional Requesters (1998). Five school districts experiences in funding technology programs. (ERIC Document Reproduction Service No. ED416848). SearchDataCenter.com (2009). Tech Target Data Center Media. Retrieved from http://searchdatacenter.techtarget.com/

Simmons, E., \& Wilmot, A. (n.d.). Incentive payments on social surveys. Retrieved from http://www.ons.gov.uk/about/who-we-are/our-services/data-collectionmethodology/reports-and-publications/incentive-payments-on-social-surveys.pdf 
Slowinski, J. (2000a). The gap between preparation and reality in training teachers to use technology. The Technology Source Archives. University of North Carolina, September/October 2000, p 1-6.

Slowinski, J. (2000b). Becoming a technologically savvy administrator. ERIC Digest Number 135, ED438593.

Solomon, D. J. (2001). Conducting web-based surveys. Eric Digest ED458291. Retrieved from http://www.ericdigests.org/2002-2/surveys.htm

Stansbury, M. (January 9, 2008). Schools need help with tech support. eSchool News. Retrieved from http://www.eschoolnews.com/news/top-news/index.cfm?print\&i=51522

Starr, L. (2009, September 23). The Administrator's role in technology integration. Education World, Retrieved from http://www.educationworld.com/a_tech/tech087.shtml

Stegall, P. (1998). The principal-Key to technology implementation. National Catholic Education Association (95 ${ }^{\text {th }}$, Los Angeles, CA).

Suskie, L. A. (1996). Questionnaire survey research: What works (2 ${ }^{\text {nd }}$ Edition). Tallahassee, Florida: Association for Institutional Research.

Survey Monkey (n.d.). Wikipedia. Retrieved from http://en.wikipedia.org/wiki/SurveyMonkey Tapscott, D. (1998). The net generation and the school. The Milken Exchange on Education and Technology. Retrieved from http://www.milkenexchange.org/feature/tapscott_full.html Taylor, R., \& Landin, D. (1999). A reinventing education project. West Virginia International Conference on Mathematics. Science Education and Technology 1999 (p. 442). Retrieved from: http://www.editlib.org/?fuseaction=Reader.ChooseCitationFormat\&paper_id=7148\&citatio nformat $=$ BibTex\&save_format $=$ true $\% 0$ Conference Proceedings 
Technology Standards for School Administrators Collaborative. (November, 2001). Technology Standards for School Administrators Collaborative: Author. Retrieved from http://www.ncrtec.org/pd/tssa/

The CEO Forum, Year 4 Star Report (June 2001). School technology and readiness report. Key building blocks for student achievement in the 21st century. Retrieved from http://www.ceoforum.org

United States Department of Education (1999a). Administrator's edtech goals. Washington, D.C. Retrieved from http://www.ed.gov/Technology/goals.html

United States Department of Education (1999c). Teacher quality: A report on the preparation and qualifications of public school teachers. Washington, D.C. Retrieved from http://www.ed.gov

United States Department of Education (1993). Using technology to support education reform. Washington, DC. Retrieved from http://www.ed.gov/pubs/EdReforStudies/TechReform Van Teijlingen, E., \& Hundley, V. (2001). Social Research Update, The Importance of Pilot Studies. Issue 35, Sociology at Surrey.

Vogt, P. W. (2005). Dictionary of statistics \& methodology: a nontechnical guide for the social sciences. Thousand Oaks: Sage Publications, Inc.

Vogt, W. P. (1993). Dictionary of statistics and methodology: a nontechnical guide for the social sciences. Newbury Park, California: Sage Publications, Inc.

Warhaftig, A. (2005). Educational technology in the "real world". Retrieved from http://www.edtechnot.com/Notarticle1101.html 
Weinreich, N. (1996). Integrating quantitative and qualitative methods in social marketing research. Social Marketing Quarter. Retrieved from http://www.socialmarketing.com/research.html

West Virginia Department of Education (2001, June 15). Twenty-eight counties receive technology grants totaling $\$ 4$ million. Retrieved from http://wvde.state.wv.us/news/337

West Virginia Department of Education (2002, July 25). First annual Caperton educational technology winner announced. Retrieved from http://wvde.sate.wv.us/news/481

West Virginia Department of Education (2003, July 23). Fifteen counties awarded enhancing education through technology grants. Retrieved from http://wvde.state.wv.us/news/637

West Virginia Department of Education (2003, September 25). West Virginia's virtual school to be highlighted in national virtual town hall meeting. Retrieved from http://wvde.state.wv.us/news/667

West Virginia Department of Education (2003, September 26). WVDE's reinventing education program to be presented on Capitol Hill. Retrieved from http://wvde.state.wv.us/news/668 West Virginia Department of Education (2004, August 06). Technology conference capped off with awards luncheon. Retrieved from http://wvde.state.wv.us/news/814

West Virginia Department of Education. (2005). West Virginia educational technology plan. WVDE, March 2005. 1-84. p.84.

West Virginia Department of Education (2006, August 10). Twelve counties receive $\$ 1.8$ million in technology grants. Retrieved from http://wvde.state.wv.us/news/1252

West Virginia Department of Education (2008, August 6). Eighteen counties awarded enhancing education through technology grants. Retrieved from http://wvde.state.wv.us/news/815 
West Virginia Department of Education (2008). West Virginia educational technology plan. WVDE, June 2007. 1-54. 54 p. Retrieved from http://access.k12.wv.us/techplan/WV\%20State\%20Tech\%20Plan.pdf

West Virginia Department of Education. (2008, March 27). West Virginia's use of school technology at the top of the class. Retrieved from http://wvde.state.wv.us/news/1641/flash

West Virginia Department of Education. (2008, June 27). About 100 educators become technology integration specialists. Retrieved from http://wvde.state.wv.us/news/1697/flash

West Virginia Department of Education (2008, November 17). Verizon renews support of free online resources for teachers with $\$ 73,000$ grant. Retrieved from http://wvde.state.wv.us/news/1794

West Virginia Department of Education (2009, August 9). Seventeen counties awarded enhancing education through technology grants. Retrieved from http://wvde.state.wv.us/news/1035

West Virginia Department of Education (n.d.). Policy 2450. Retrieved from WVDE Web site: http://www.k12.wv.us/policies/index.htm

West Virginia Department of Education (n.d.). Policy 2460. Retrieved from WVDE Web site: http://www.k12.wv.us/policies/index.htm

West Virginia Department of Education (n.d.). Policy 2470. Retrieved from WVDE Web site: http://www.k12.wv.us/policies/index.htm.

West Virginia Department of Education (n.d.). Policy 2520. Retrieved from WVDE Web site: http://www.k12.wv.us/policies/index.htm

West Virginia Department of Education (n.d.). Policy 5100. Retrieved from WVDE Web site: http://www.k12.wv.us/policies/index.htm 
West Virginia Department of Education (n.d.). Policy 5310. Retrieved from WVDE Web site: http://www.k12.wv.us/policies/index.htm

West Virginia Department of Education (n.d.). West Virginia basic skills/computer education overview, Retrieved from http://access.k12.wv.us/bsce/overview.htm

West Virginia Department of Education (n.d.). Long-range strategic educational technology plan: West Virginia educational plan. Retrieved from WVDE Web site: http://access.k12.wv.us/techplan.stateplan.htm

West Virginia Department of Education (n.d.). 21st century skills in West Virginia. Retrieved from http://www.21stcenturyskills.org/documents/p21_wv2008.pdf

West Virginia Department of Education (n.d.). Global21. Retrieved from http://wvde.state.wv.us/global21/overview.html

West Virginia Governor‘s Advisory Council for Technology in Education (2005). Retrieved from http://wvgovedact.org

West Virginia Education Information System (n.d.). Retrieved from WVEIS Web site: http://resa6.k12.wv.us/page10.html

West Virginia Virtual School (n.d.). About the West Virginia virtual school. Retrieved from http://virtualschool.k12.wv.us/vschool/about.html

Wilburg, J. (1991). Cognitive apprenticeships: An instructional design review of successful systems. In D. Carey, R. Carey, D.A Willis, \& J. Wills (Eds.), Technology and teacher education 1991 annual (pp. 238-243). Charlottesville, VA: Association for the Advancement of Computers in Education. 
Williams, C. (2000). Internet access in U.S. public schools and classrooms: 1994-1999, (NCES 2000-086). Washington, D.C.: U.S. Department of Education, National Center for Education Statistics.

Word IQ (2009). Retrieved from http://www.wordiq.com 
Appendix A

Sample Technology Integration Specialist Job Description (p. 1)

\section{Sample Technology Integration Specialist Job Description}

School district seeks Technology Integration Specialists to assist teachers in elementary, middle and high schools enhance learning through improved integration of technology. The primary focus of the Technology Integration Specialist is to enrich and support teaching and learning while strengthening the technology skills of students, teachers and staff. Ideal candidates should work well with others, be skilled in team management, have a background in instructional design, and have clear goals and strategies for integrating technology into instruction. Teaching experience is also required.

This is a 12-month position and reports directly to the principal. The position has some administrative responsibilities in coordinating teams, consulting on technology budgets, supervising training activities, establishing technology policies, and proposing learning objectives for staff as they relate to technology. Successful candidates will not be responsible for maintaining the school or district Web site, monitoring and troubleshooting computer labs, maintaining computer networks, or providing technical support to schools or districts.

Responsibilities Include:

- Collaborate with teachers to support their use of technology in delivery of curricula through a variety of instructional methods. In partnership, the Technology Integration Specialist and the teacher will work toward integrating the use of hardware, software and Internet resources in support of student learning and assisting teachers in meeting state and national standards for subject-area and technology-learning objectives. 


\title{
Appendix A
}

\author{
Sample Technology Integration Specialist Job Description (p. 2)
}

- Create learning resources for teachers, staff and students. These may include Web sites, tutorials, interactive programs and databases that support teachers in integrating technology. Ideally, teachers will be guided and encouraged to develop their own resources, while the Technology Integration Specialist will support these efforts by providing additional support as needed.

- Structure the technology education of teachers. Though the Technology Integration Specialist may not directly conduct all training, lab work or classes regarding computer use, he or she will coordinate instruction to meet technology proficiency goals.

Additional instruction of parents or community members may also strengthen students ${ }^{6}$ technology skills.

- Consult on the technology budget for computer resources, including hardware, software, learning resources and training needs.

- Recommend and, in some cases, purchase hardware, software and related resources.

- Identify trends in software, curriculum, teaching strategies and other educational areas.

- Assess technology skill levels of students, teachers and staff.

- Create, maintain and oversee integration of the school's technology plan with a technology committee.

\section{Required Skills}

In addition to experience in related responsibilities, the applicant should have:

- Teaching experience.

- An understanding of key learning theories and methods of instruction, and their relation to technology integration.

- Familiarity with methods for integrating technology into the curriculum such as WebQuests, online resources, digital portfolios and other forms of assessment.

- Experience with effective technology teaching strategies in teaching software and hardware skills.

- Technology skills in up-to-date computer software, including word processing, database, spreadsheet, Web page development, presentation, digital video and audio editing, image processing, and graphics applications.

Taken from the online article Fulfilling the Need for a Technology Integration Specialist" by Mark Hofer, Barbara Chamberlin, \& Tammy Scott. The Journal, (2004). http://thejournal.com 


\section{Appendix B}

Sample Job Posting for Nicholas County in West Virginia

\section{Sample Job Posting for Nicholas County in West Virginia}

POSITION: Technology Integration Specialist Supported with Title I Schools Improvement Funds

QUALIFICATIONS: 1. West Virginia Teacher Certification CERTIFICATIONS 2. West Virginia Technology Integration Specialist Certification or Temporary

Authorization or willing to pursue TIS credential

ASSIGNMENT/ RESPONSIBILITIES: Cherry River Elementary

PERFORMANCE

RESPONSIBILITIES: See Job Description

SALARY: Per Nicholas County Scale

TERM OF EMPLOYMENT: Standard 200 Day Contract

POSTED DATE: August 25, 2008

DEADLINE: August 29, 2008 
Appendix C

Job Description: EETT Grant Technology Integration Specialist (p. 1)

\section{EETT GRANT Appendix D - TECHNOLOGY INTEGRATION SPECIALIST JOB DESCRIPTION}

CERTIFICATION: WV Teacher Licensure + WV Technology Integration Specialist Credential or Temporary Authorization

REPORTS TO: Principal and Central Office Technology Supervisor

PURPOSE: This individual provides training and support to the staff on technology integration, the new West Virginia Learning Skills and Technology Tools Content Standards and Objectives (Policy 2520.14), educator technology standards as reflected in West Virginia Policy 5310 Performance Evaluation of School Personnel and various statewide technology resources as well as county/school software applications. This individual also assists in the implementation of the county and school technology plans.

\section{DUTIES AND RESPONSIBILITIES}

1. MAJOR FUNCTION: Planning and Facilitating Teaching and Learning

- Leads in the school's use of instructional technology to enhance learning

- Models the integration of technology in all curriculum areas

- Assesses learning and information needs of students and staff

- Collaborates with teachers and other instructional staff to develop curriculum materials and specific lesson plans that integrate technology

- Plans and works collaboratively with teachers

- Facilitates school participation in technology programs and activities

- Conducts staff development in the areas of technology integration, the new West Virginia Learning Skills and Technology Tools Content Standards and Objectives (Policy 2520.14), educator technology standards as reflected in West Virginia Policy 5310 Performance Evaluation of School Personnel and various statewide technology resources as well as county/school software applications

- Instructs students and staff in the effective use of ideas and information

- Incorporates information literacy into day-to-day instruction

- Follows a plan for professional development and actively seeks out opportunities to grow professionally

- Upgrades professional knowledge and skills on a continual basis 


\section{Appendix C}

Job Description: EETT Grant Technology Integration Specialist (p. 2)

2. MAJOR FUNCTION: Planning and Facilitating Information Access and Delivery

- Implements best practices related to technology use in the school program based on research, pilot programs, and state/national standards

- Works with the principal and school leadership team to provide access to technology resources and services at point of need

- Works with teachers and technology staff in the selection of resources that are compatible with the school technology infrastructure

- Assists with planning the design of the technology infrastructure so that information resources are continually available to the school community

- Promotes family, business, and community partnerships that support the academic success, career readiness, and general well-being of all children

- Adheres to and communicates copyright as well as other laws and guidelines pertaining to the distribution and ethical use of all resources

3. MAJOR FUNCTION: Planning and Facilitating Program Administration

- Provides leadership and collaborates with the School Technology Team to develop, implement, and update a school instructional technology plan aligned with the countylevel technology plan

- Collaborates with teachers, media and technology staff, and students to evaluate and select resources addressing curricular needs and learning goals

- Plays a role in the school's budgetary process to ensure funding for the instructional technology program to support school-wide goals

- Leads in the ongoing evaluation of the effectiveness of the instructional technology program

- Prepares and submits accurate reports as required

- Carries out non-instructional duties as assigned and/or as needed to ensure student safety

\section{KNOWLEDGE, SKILLS, AND ABILITIES}

- Possesses effective communication and interpersonal skills

- Demonstrates ability to operate technology equipment and use standard software

- Possesses organizational skills

- Exhibits classroom management skills

- Communicates effectively with all levels of technology 
Appendix D

Principal Survey: Directions for Panel of Experts

Purpose: The purpose of a survey review by the Panel of Experts is to increase validity of the survey instrument. Validity is defined as the degree to which a test measures what it is intended to measure (i.e., how items relate to the topic, mutually exclusive questions/statements).

\section{Study Research Questions:}

1) Who do principals rely on to provide technology support when unable to do so themselves?

2) What technology support do elementary principals and support personnel provide to teachers?

3) What facilitates principals' implementation of technology in West Virginia public schools?

4) What impedes principals' implementation of technology in West Virginia public schools?

Directions: Review the entire Survey of West Virginia K-12 Public School Principals provided and record feedback pertaining to each corresponding item. Relate each survey question or statement to the following three questions based upon information collected from the Web Center for Social Research (2006):

1) Does the question adequately address the four research questions guided by a comprehensive review of the literature?

2) Do the questions contain sufficient information to enable an adequate response by the respondent based on their current position as principal?

3) Is each question designed to eliminate bias and designed not to force the respondent to answer with a particular response?

Thank you for taking your time to review this survey instrument and your input is greatly appreciated and will be considered for enhancing this survey.

Sincerely,

David W. Agnew

Principal, Sissonville Elementary School

Doctoral Student

dagnew@access.k12.wv.us
Paul E. Chapman, Principal Investigator

Interim Associate Dean

(304) 293-2174

Paul.Chapman@mail.wvu.edu 
Appendix E

Directions for Pilot Study Participants

Purpose: The purpose of a survey review by the Pilot Study participants is to check for survey consistency, clearly defined directions, easy to follow format, and reliability.

Directions: Complete the entire Survey of West Virginia K-12 Public School Principals provided online through Survey Monkey. Relate each survey question or statement to the following three questions based upon information collected from the Web Center for Social Research (2006):

1) Does the question adequately address the four research questions guided by a comprehensive review of the literature?

2) Do the questions contain sufficient information to enable an adequate response by the respondent based on their current position as principal?

3) Is each question designed to eliminate bias and designed not to force the respondent to answer with a particular response?

One Pilot Study participant will discuss the survey after completion with the researcher to see if there are any concerns about reliability that may need reviewed.

Thank you for taking your time to review this survey instrument and your input is greatly appreciated and will be considered for enhancing this survey.

Sincerely,

David W. Agnew

Principal, Sissonville Elementary School

Doctoral Student

dagnew@access.k12.wv.us
Paul E. Chapman, Principal Investigator

Interim Associate Dean

(304) 293-2174

Paul.Chapman@mail.wvu.edu 
Appendix F

Letter Requesting Support

David W. Agnew

41 Demra Drive

Charleston, WV 25320

April 18, 2010

Dr. Steven L. Paine

West Virginia State Superintendent of Schools

WVDE

Dear Dr. Paine,

My name is David Agnew and I am currently working with Dr. Paul Chapman through West Virginia University to complete my doctorate in Educational Leadership. I am currently an elementary principal at Sissonville Elementary School in Kanawha County.

The title of my dissertation is Administrative Obstacles to Technology Use in West Virginia Public Schools: A Survey of West Virginia Principals." I am in the process of finalizing a survey that I plan to email a random sample of West Virginia principals. The data will be collected and divided by three categories, elementary, middle, and high school results.

I am requesting a letter of support from you and your permission to send a copy of that letter to each county superintendent and principal accompanying a letter or email from me introducing my project. The survey will be conducted online and contacts with each randomly selected principal will be made through email and Survey Monkey.

I appreciate your consideration for this request.

Sincerely,

David W. Agnew

Cc Dr. Paul Chapman 


\title{
Appendix G
}

\section{Letter of Support}

\section{West Virginia Deparment of

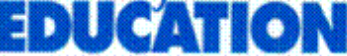

\author{
Dr. Steven L. Paine, State Sinperintendent of Schools \\ 1900 Kanawba Bowlevard, East, Building o \\ Charlestow, wV 25305.0330 \\ Phomet 304.558-268 \\ Fax: 304.558.0048
}

butp://worde.state, wo ws

May 14,2010

Dear Superintendents and Principals:

Mr. David Agnew, principal at Sissonville Elementary School in Kanawha County, is working toward the completion of a doctorate in Educational Leadership from West Virginia University. The title of his dissertation is "Administrative Obstacles

to Technology Use in West Virginia Public Schools: A Survey of West Virginia

Principals." David is in the process of finalizing his survey that will be distributed

to all county superintendents and a random sample of West Virginia principals.

Understanding the demanding nature of administrators ' work and schedules, $\mathrm{Mr}$. Agnew's survey is concise but thorough; I encourage you to devote a few minutes of your time to contribute to his research.

My best wishes to David on the completion of his doctorate and my thanks to each of you for your leadership.

Sincerely,

Removed Signature for Security

Steven L. Paine

State Superintendent of Schools

SLP:BJJ/gkb

Control \# 10-519E 


\title{
Appendix $\mathrm{H}$
}

\author{
Superintendent Survey Introduction Letter
}

May, 2010

Dear Superintendent,

My name is David Agnew and I am currently involved with the Leadership Doctoral Cohort at West Virginia University. I am sending this letter to inform you that a random sample of your principals will soon be invited to participate in a research study designed specifically for West Virginia Public school principals. The purpose of the study is to establish the principals' perceptions of obstacles to implementing technology in West Virginia public schools. The information collected will be compiled into three categories; elementary, middle, and high school principals. A random sample of principals will be sent a letter requesting their assistance in completing an electronic survey. They will receive an email after the letter with information pertaining to the study and a hypertext link for the principals to follow providing them a survey to complete online. The data collected is a critical component of my doctoral dissertation, which will be conducted under the supervision of Dr. Paul Chapman, Interim Associate Dean at West Virginia University.

The following assurances, as required by West Virginia University, will be respected: participation in the study is voluntary, information will be kept confidential, and the participant may refuse to participate, quit at any time, or skip any questions with no negative effect in employment status.

To ensure all procedures are followed the West Virginia University Institutional Review Board has acknowledgment of this study on file. I will serve as the Principal Investigator under the direct supervision of Dr. Paul Chapman from WVU. Dr. Chapman may be contacted at (304) 293-2174 (Office) or email at Paul.Chapman@mail.wvv.edu.

If you have any questions about this project, please contact me at my work number (304)-3481961 or email at dagnew@access.k12.wv.us. In addition, upon completion of this project, I will send you a copy of the results per your request.

Sincerely,

David W. Agnew

Principal, Sissonville Elementary School

Doctoral Student

dagnew@access.k12.wv.us
Paul E. Chapman, Principal Investigator

Interim Associate Dean

(304) 293-2174

Paul.Chapman@mail.wvu.edu 
Appendix I

Email to Principals

June, 2010

Elementary, Middle, and High School Principals of West Virginia Public Schools

Dear Sir or Madam:

My name is David Agnew and I am requesting your assistance. I am currently involved with the Leadership Doctoral Cohort at West Virginia University and in the final stages of obtaining my Doctor in Education Leadership.

I am conducting research to establish the principal's perceptions of obstacles to implementing technology in West Virginia public schools. The information collected will assist with compiling this information into three categories; elementary, middle, and high school principals. Your responses will remain confidential.

You will receive an additional email in approximately three days containing a link to an online survey. This survey will take approximately ten minutes to complete. A short demographics section is included. Your responses will be recorded through the use of a Likert Scale. This scale will consist of five responses: Strongly Agree, Agree, Neutral, Disagree, and Strongly Disagree. The other questions in the survey will be answered as Yes or No.

I appreciate your timely response to complete this survey. There will not be any penalty for those choosing not to participate. Please answer all questions the best to your ability.

To ensure all procedures are followed the West Virginia University Institutional Review Board has acknowledgment of this study on file. I will serve as the Principal Investigator under the direct supervision of Dr. Paul Chapman from WVU. Dr. Chapman may be contacted at (304) 293-2174 (Office) or email at Paul.Chapman@mail.wvv.edu.

Dr. Paine, State Superintendent of Schools, has approved this project.

If you have any questions about this project, please contact me at my work number (304)-3481961. In addition, upon completion of this project, I will send you a copy of the results per your request.

Sincerely,

David W. Agnew

Principal, Sissonville Elementary School

Paul E. Chapman, Principal Investigator

Doctoral Student Interim Associate Dean

dagnew@access.k12.wv.us (304) 293-2174

Paul.Chapman@mail.wvu.edu 
Appendix I (2)

Email Sent to All West Virginia Principals

June, 2010

Elementary, Middle, and High School Principals of West Virginia Public Schools

Dear Sir or Madam:

A few days ago you received an email introducing myself and my study that I am conducting with West Virginia Principals for completion of my Doctorate through West Virginia University. You have been selected to participate in this survey described in the previous email.

I am conducting research to establish the principal's perceptions of obstacles to implementing technology in West Virginia public schools. The information collected will assist with compiling this information into three categories; elementary, middle, and high school principals. Your responses will remain confidential.

Please follow this link http://SURVEYMONKEY (link inserted here). This survey will take approximately ten minutes to complete. A short demographics section is included. Your responses will be recorded through the use of a Likert Scale. This scale will consist of five responses: Strongly Agree, Agree, Neutral, Disagree, and Strongly Disagree. The other questions in the survey will be answered as Yes or No.

I appreciate your timely response to complete this survey. There will not be any penalty for those choosing not to participate. Please answer all questions the best to your ability.

The first fifty principals to complete and submit the survey will be entered in a drawing for a $\$ 100$ gift card. The next fifty respondents plus the first fifty minus the first winner will be eligible for a $\$ 50$ gift card drawing and all but the first two winners will be eligible for a drawing to win one of four $\$ 25$ gift cards. You will be selected for this drawing by your email address but it will not be linked to your responses to the survey itself. You will be contacted via email once the survey is complete. The approximate date for completion is October 01, 2010.

To ensure all procedures are followed the West Virginia University Institutional Review Board has acknowledgment of this study on file. I will serve as the Principal Investigator under the direct supervision of Dr. Paul Chapman from WVU. Dr. Chapman may be contacted at (304) 293-2174 (Office) or email at Paul.Chapman@mail.wvv.edu.

Dr. Paine, State Superintendent of Schools, has approved this project.

If you have any questions about this project, please contact me at my work number (304)-348-1961. In addition, upon completion of this project, I will send you a copy of the results per your request.

Sincerely,

David W. Agnew

Principal, Sissonville Elementary School

Doctoral Student

dagnew@access.k12.wv.us
Paul E. Chapman, Principal Investigator

Interim Associate Dean

(304) 293-2174

Paul.Chapman@mail.wvu.edu 
Appendix I (3)

Follow-up Email Sent to Non-Respondents

August, 2010

Dear Sir or Madam:

In June, 2010 your received an email introducing myself and my study that I am conducting with West Virginia Principals for completion of my Doctorate through West Virginia University. Following that email you received a second email with a link to the survey located online through Survey Monkey. This is a follow-up email to request that you complete the online survey so the results will represent a large number of principals in West Virginia.

I am conducting research to establish the principal's perceptions of obstacles to implementing technology in West Virginia public schools. The information collected will assist with compiling this information into three categories; elementary, middle, and high school principals. Your responses will remain confidential.

Please follow this link [SurveyLink] to complete the survey. This survey will take approximately ten minutes to complete. A short demographics section is included. Your responses will be recorded through the use of a Likert Scale. This scale will consist of five responses: Strongly Agree, Agree, Neutral, Disagree, and Strongly Disagree. The other questions in the survey will be answered as Yes or No.

I appreciate your timely response to complete this survey. Please answer all questions to the best of your ability. There will not be any penalty for those choosing not to participate. You may opt-out by following this link [RemoveLink].

To ensure all procedures are followed the West Virginia University Institutional Review Board has acknowledgment of this study on file. I will serve as the Principal Investigator under the direct supervision of Dr. Paul Chapman from WVU. Dr. Chapman may be contacted at (304) 293-2174 (Office) or email atPaul.Chapman@mail.wvv.edu.

If you complete the survey, you will be eligible for a drawing to win one of four $\$ 25$ gift cards. You will be selected for this drawing by your email address but it will not be linked to your responses to the survey itself. You will be contacted via email once the survey is complete. The approximate date for completion is October 01, 2010.

Dr. Paine, State Superintendent of Schools, has approved this project.

If you have any questions about this project, please contact me at my work number (304)-348-1961. In addition, upon completion of this project, I will send you a copy of the results per your request.

Sincerely,

David W. Agnew

Principal, Sissonville Elementary School

Doctoral Student

dagnew@access.k12.wv.us
Paul E. Chapman

Interim Associate Dean

(304) 293-2174

Paul.Chapman@mail.wvu.edu 
Appendix I (4)

Final Email Request to Non-Respondents

August 23, 2010

Principals:

This is my final request for you to complete my online survey designed to collect data looking at the perception of principals and technology use in their building. I have emailed two requests previously and I understand this is an extremely busy time of the year. However, this survey should take ten minutes or less to conduct.

Here is a link to the survey:

[SurveyLink]

This survey link will become inactive in the next 10-14 days so please complete at your earliest convenience. This link is uniquely tied to this survey and your email address. Please do not forward this message.

Please note: If you do not wish to receive further emails from me, please click the link below, and you will be automatically removed from my mailing list.

[RemoveLink]

To ensure all procedures are followed the West Virginia University Institutional Review Board has acknowledgment of this study on file. I will serve as the Principal Investigator under the direct supervision of Dr. Paul Chapman from WVU. Dr. Chapman may be contacted at (304) 293-2174 (Office) or email at Paul.Chapman@mail.wvv.edu.

If you complete the survey, you will be eligible for a drawing to win one of four $\$ 25$ gift cards. You will be selected for this drawing by your email address but it will not be linked to your responses to the survey itself. You will be contacted via email once the survey is complete. The approximate date for completion is October 01, 2010.

Dr. Paine, State Superintendent of Schools, has approved this project.

If you have any questions about this project, please contact me at my work number (304)-348-1961. In addition, upon completion of this project, I will send you a copy of the results per your request.

Sincerely,

David W. Agnew

Principal, Sissonville Elementary School

Doctoral Student

dagnew@access.k12.wv.us
Paul E. Chapman

Interim Associate Dean

(304) 293-2174

Paul.Chapman@mail.wvu.edu 
Appendix J

Principal Perception Survey (p. 1)

School Principal Survey Technology Use in West Virginia Public Schools: A Survey of West Virginia Principals 2010

Please Mark One: Elementary Principal 1
Middle School Principal

2
High School Principal 3

Years Experience as a Principal:

Less than Fifteen Years

1

Fifteen Years or More

2

Have You Completed Any Technology Training in the Last Five Years Through a College or University, WVDE, or Your County?

Yes

No

If Yes to Previous Question, Select Topics of Courses:

1. General Technology Introductory Courses

2. Social Impact of Technology

3. Technical, Such as Hardware and Software Issues

4. How to Integrate Technology into the Curriculum

5. How to Increase Effective Use of Technology

6. Data Driven Decision Making

7. Other

Please Fill in the Blank With Your County: 
Appendix $\mathbf{J}$

Principal Perception Survey (p.2)

$\underline{\mathrm{RO1}}$

Please mark if you Strongly Agree, Agree, Neutral, Disagree, or Strongly Disagree. Staffing and Technology Support include individuals that provide direct technology support to classroom teachers.

\begin{tabular}{|c|c|c|c|c|c|}
\hline $\begin{array}{c}\text { Staffing and Technology Support } \\
\text { (3) }\end{array}$ & $\begin{array}{l}\text { Strongly } \\
\text { Agree }\end{array}$ & Agree & Neutral & Disagree & $\begin{array}{l}\text { Strongly } \\
\text { Disagree }\end{array}$ \\
\hline $\begin{array}{l}\text { the administrator is responsible for } \\
\text { maintaining technology in the school }\end{array}$ & & & & & \\
\hline $\begin{array}{l}\text { lack of immediate technical support for } \\
\text { hardware is an obstacle }\end{array}$ & & & & & \\
\hline $\begin{array}{l}\text { lack of immediate technical support for } \\
\text { software is an obstacle }\end{array}$ & & & & & \\
\hline
\end{tabular}

Please mark if you Strongly Agree, Agree, Neutral, Disagree, or Strongly Disagree. Staff Development is defined as part of a process utilized to enhance teaching skills.

\begin{tabular}{|c|c|c|c|c|c|}
\hline $\begin{array}{l}\text { Provision of Staff Development } \\
\text { (4) }\end{array}$ & $\begin{array}{l}\text { Strongly } \\
\text { Agree }\end{array}$ & Agree & Neutral & Disagree & $\begin{array}{l}\text { Strongly } \\
\text { Disagree }\end{array}$ \\
\hline $\begin{array}{l}\text { school based technology staff } \\
\text { development is provided by the building } \\
\text { administrator }\end{array}$ & & & & & \\
\hline
\end{tabular}

Please mark if you Strongly Agree, Agree, Neutral, Disagree, or Strongly Disagree.

\begin{tabular}{|c|c|c|c|c|c|}
\hline $\begin{array}{l}\text { Staff Development Concerns } \\
\text { (5) }\end{array}$ & $\begin{array}{l}\text { Strongly } \\
\text { Agree }\end{array}$ & Agree & Neutral & Disagree & $\begin{array}{l}\text { Strongly } \\
\text { Disagree }\end{array}$ \\
\hline \multicolumn{6}{|l|}{$\begin{array}{l}\text { the school administrator provides } \\
\text { recognition to staff members providing } \\
\text { technology training }\end{array}$} \\
\hline \multicolumn{6}{|l|}{$\begin{array}{l}\text { lack of staff development in the area of } \\
\text { technology is an obstacle }\end{array}$} \\
\hline $\begin{array}{l}\text { lack of training for principals in } \\
\text { technology is an obstacle }\end{array}$ & & & & & \\
\hline
\end{tabular}




\section{Appendix J}

\section{Principal Perception Survey (p. 3)}

\begin{tabular}{|c|c|c|c|c|c|}
\hline $\begin{array}{c}\text { Administrative Motivation } \\
\text { (6) }\end{array}$ & $\begin{array}{l}\text { Strongly } \\
\text { Agree }\end{array}$ & Agree & Neutral & Disagree & $\begin{array}{l}\text { Strongly } \\
\text { Disagree }\end{array}$ \\
\hline \multicolumn{6}{|l|}{$\begin{array}{l}\text { the principal allocates funding for } \\
\text { technology as a priority }\end{array}$} \\
\hline \multicolumn{6}{|l|}{$\begin{array}{l}\text { the principal demonstrates positive } \\
\text { technology use to teachers and students }\end{array}$} \\
\hline \multicolumn{6}{|l|}{$\begin{array}{l}\text { the principal supports teachers and } \\
\text { students and the use of technology }\end{array}$} \\
\hline \multicolumn{6}{|l|}{$\begin{array}{l}\text { the principal's attitude influences the } \\
\text { success of technology in the building }\end{array}$} \\
\hline \multicolumn{6}{|l|}{$\begin{array}{l}\text { the principal provides time in the master } \\
\text { schedule for classroom use of the } \\
\text { computer lab }\end{array}$} \\
\hline \multicolumn{6}{|l|}{$\begin{array}{l}\text { the principal provides time in the master } \\
\text { schedule for technology literate staff to } \\
\text { assist other staff }\end{array}$} \\
\hline \multicolumn{6}{|l|}{$\begin{array}{l}\text { technology integration is not a school } \\
\text { priority }\end{array}$} \\
\hline $\begin{array}{l}\text { technology integration is not a county } \\
\text { priority }\end{array}$ & & & & & \\
\hline
\end{tabular}




\section{Appendix $\mathbf{J}$}

\section{Principal Perception Survey (p. 4)}

\section{$\underline{\mathrm{RO} 2}$}

Please mark if you Strongly Agree, Agree, Neutral, Disagree, or Strongly Disagree. Staffing and Technology Support include individuals that provide direct technology support to classroom teachers.

\begin{tabular}{|c|c|c|c|c|c|}
\hline $\begin{array}{l}\text { Staffing and Technology Support } \\
\text { (3) }\end{array}$ & $\begin{array}{l}\text { Strongly } \\
\text { Agree }\end{array}$ & Agree & Neutral & Disagree & $\begin{array}{l}\text { Strongly } \\
\text { Disagree }\end{array}$ \\
\hline \multicolumn{6}{|l|}{$\begin{array}{l}\text { teachers are responsible for maintaining } \\
\text { their own technology including hardware } \\
\text { and software }(* 3)\end{array}$} \\
\hline \multicolumn{6}{|l|}{$\begin{array}{l}\text { the school media specialist is responsible } \\
\text { for maintaining technology }\end{array}$} \\
\hline \multicolumn{6}{|l|}{$\begin{array}{l}\text { a county level technician other than } \\
\text { RESA is responsible for maintaining } \\
\text { technology in the school }\end{array}$} \\
\hline \multicolumn{6}{|l|}{$\begin{array}{l}\text { RESA technicians are responsible for } \\
\text { maintaining technology in the school }\end{array}$} \\
\hline \multicolumn{6}{|l|}{$\begin{array}{l}\text { there is a full time Technology Integration } \\
\text { Specialist (TIS) in your school }\end{array}$} \\
\hline \multicolumn{6}{|l|}{$\begin{array}{l}\text { there is a part time Technology } \\
\text { Integration Specialist (TIS) in your school }\end{array}$} \\
\hline \multicolumn{6}{|l|}{$\begin{array}{l}\text { teachers have achieved autonomy in } \\
\text { handing common technical problems in } \\
\text { their own classrooms (e.g., frozen screens, } \\
\text { jammed printers, software updates) }\end{array}$} \\
\hline \multicolumn{6}{|l|}{$\begin{array}{l}\text { students are utilized to provide technical } \\
\text { assistance }\end{array}$} \\
\hline \multicolumn{6}{|l|}{$\begin{array}{l}\text { teachers do not provide their own } \\
\text { technical support for hardware and } \\
\text { software issues }\left({ }^{*} 3\right) \text {. }\end{array}$} \\
\hline $\begin{array}{l}\text { lack of additional staff to assist school- } \\
\text { wide with technology is an obstacle }\end{array}$ & & & & & \\
\hline
\end{tabular}




\section{Appendix $\mathbf{J}$}

\section{Principal Perception Survey (p.5)}

\section{$\underline{\mathrm{RO} 3}$}

Please Mark One Answer per Statement

Infrastructure includes Building Structure, Hardware, Software, and Funding. Please mark if you Strongly Agree, Agree, Neutral, Disagree, or Strongly Disagree the item is an obstacle in your building for implementing technology.

\begin{tabular}{|c|c|c|c|c|c|}
\hline $\begin{array}{l}\text { Obstacles Related to } \\
\text { Infrastructure } \\
\text { (1) }\end{array}$ & $\begin{array}{c}\text { Strongly } \\
\text { Agree }\end{array}$ & Agree & Neutral & Disagree & $\begin{array}{l}\text { Strongly } \\
\text { Disagree }\end{array}$ \\
\hline $\begin{array}{l}\text { counties in WV are funded equally for } \\
\text { technology }\end{array}$ & & & & & \\
\hline $\begin{array}{l}\text { investments in technology are supported } \\
\text { by adequate budgets to maintain existing } \\
\text { equipment }\end{array}$ & & & & & \\
\hline
\end{tabular}

Please mark if you Strongly Agree, Agree, Neutral, Disagree, or Strongly Disagree.

Social Issues.

\begin{tabular}{|c|c|c|c|c|c|}
\hline $\begin{array}{l}\text { Social Issues } \\
\text { (2) }\end{array}$ & $\begin{array}{l}\text { Strongly } \\
\text { Agree }\end{array}$ & Agree & Neutral & Disagree & $\begin{array}{l}\text { Strongly } \\
\text { Disagree }\end{array}$ \\
\hline $\begin{array}{l}\text { your building culture is positive toward } \\
\text { technology }\end{array}$ & & & & & \\
\hline
\end{tabular}

Please mark if you Strongly Agree, Agree, Neutral, Disagree, or Strongly Disagree.

Staffing and Technology Support include individuals that provide direct technology support to classroom teachers.

\begin{tabular}{|c|c|c|c|c|c|}
\hline $\begin{array}{l}\text { Staffing and Technology Support } \\
\text { (3) }\end{array}$ & $\begin{array}{l}\text { Strongly } \\
\text { Agree }\end{array}$ & Agree & Neutral & Disagree & $\begin{array}{l}\text { Strongly } \\
\text { Disagree }\end{array}$ \\
\hline \multicolumn{6}{|l|}{$\begin{array}{l}\text { technical support is provided for } \\
\text { preventive maintenance }\end{array}$} \\
\hline $\begin{array}{l}\text { scheduling is configured so the } \\
\text { technological experts within the building } \\
\text { can provide technology support without } \\
\text { compromising their own instructional } \\
\text { responsibilities }\end{array}$ & & & & & \\
\hline
\end{tabular}




\section{Appendix J}

\section{Principal Perception Survey (p.6)}

\begin{tabular}{|c|c|c|c|c|c|}
\hline $\begin{array}{l}\text { Provision of Staff Development } \\
\text { (4) }\end{array}$ & $\begin{array}{l}\text { Strongly } \\
\text { Agree }\end{array}$ & Agree & Neutral & Disagree & $\begin{array}{l}\text { Strongly } \\
\text { Disagree }\end{array}$ \\
\hline \multicolumn{6}{|l|}{$\begin{array}{l}\text { school based technology staff } \\
\text { development is provided by teachers in } \\
\text { the building }\end{array}$} \\
\hline \multicolumn{6}{|l|}{$\begin{array}{l}\text { school based technology staff } \\
\text { development is provided by county level } \\
\text { personnel }\end{array}$} \\
\hline \multicolumn{6}{|l|}{$\begin{array}{l}\text { school based technology staff } \\
\text { development is provided by other staff } \\
\text { within the building such as a media } \\
\text { specialist or Technology Integration } \\
\text { Specialist (TIS) }\end{array}$} \\
\hline \multicolumn{6}{|l|}{$\begin{array}{l}\text { school based technology staff } \\
\text { development is provided online with } \\
\text { video conferencing }\end{array}$} \\
\hline \multicolumn{6}{|l|}{$\begin{array}{l}\text { professional learning communities (PLCs) } \\
\text { are utilized in your school to enhance } \\
\text { technology }\end{array}$} \\
\hline $\begin{array}{l}\text { Staff Development Concerns } \\
\text { (5) }\end{array}$ & $\begin{array}{l}\text { Strongly } \\
\text { Agree }\end{array}$ & Agree & Neutral & Disagree & $\begin{array}{l}\text { Strongly } \\
\text { Disagree }\end{array}$ \\
\hline \multicolumn{6}{|l|}{$\begin{array}{l}\text { training goes beyond the technology } \\
\text { component and addresses the specific area } \\
\text { of integrating technology into the } \\
\text { curriculum }\end{array}$} \\
\hline $\begin{array}{l}\text { school based staff development provides } \\
\text { technology skill enhancements for } \\
\text { teachers }\end{array}$ & & & & & \\
\hline
\end{tabular}




\section{Appendix J}

\section{Principal Perception Survey (p.7)}

\begin{tabular}{|c|c|c|c|c|c|}
\hline $\begin{array}{l}\text { Teacher and Student Perceived } \\
\text { Obstacles } \\
\text { (7) }\end{array}$ & $\begin{array}{l}\text { Strongly } \\
\text { Agree }\end{array}$ & Agree & Neutral & Disagree & $\begin{array}{l}\text { Strongly } \\
\text { Disagree }\end{array}$ \\
\hline \multicolumn{6}{|l|}{$\begin{array}{l}\text { technology is not integrated into the } \\
\text { curriculum and is a stand-alone learning } \\
\text { environment }(* 1)\end{array}$} \\
\hline \multicolumn{6}{|l|}{$\begin{array}{l}\text { teachers are comfortable utilizing students } \\
\text { for technical support }\end{array}$} \\
\hline \multicolumn{6}{|l|}{$\begin{array}{l}\text { students are aware of the value of } \\
\text { technology and encourage teachers to use } \\
\text { technology }\end{array}$} \\
\hline $\begin{array}{l}\text { technology use is integrated into the } \\
\text { curriculum }\left({ }^{*} 1\right)\end{array}$ & & & & & \\
\hline
\end{tabular}

Please Mark One Answer per Statement

Technology Policy is defined as a plan of action to reach specific outcomes or a guide to assist with reaching those outcomes. This policy pertains to the field of technology.

\begin{tabular}{l}
\multicolumn{1}{c|}{\begin{tabular}{l|}
\multicolumn{1}{c|}{ Policy } \\
(8)
\end{tabular}} \\
\hline your county has a comprehensive \\
technology plan in accordance to WVDE \\
Policy 2470 that you review annually \\
\hline your students and staff are aware of an \\
Acceptable Use Policy establishing \\
criteria for acceptable and safe use of the \\
Internet \\
your school has a comprehensive \\
technology plan in addition to the county \\
plan \\
you have a school based technology \\
committee that examines the technology \\
implementation process annually \\
you are aware of The Council of School \\
Attorneys and Technology Leadership \\
Network (CSATLN) to assist principals \\
with legal issues involving technology
\end{tabular}




\section{Appendix $\mathbf{J}$}

\section{Principal Perception Survey (p. 8)}

\section{$\underline{\text { R04 }}$}

Please Mark One Answer per Statement

Infrastructure includes Building Structure, Hardware, Software, and Funding. Please mark if you Strongly Agree, Agree, Neutral, Disagree, or Strongly Disagree the item is an obstacle in your building for implementing technology.

\begin{tabular}{|c|c|c|c|c|c|}
\hline $\begin{array}{l}\text { Obstacles Related to } \\
\text { Infrastructure } \\
\text { (1) }\end{array}$ & $\begin{array}{l}\text { Strongly } \\
\text { Agree }\end{array}$ & Agree & Neutral & Disagree & $\begin{array}{l}\text { Strongly } \\
\text { Disagree }\end{array}$ \\
\hline \multicolumn{6}{|l|}{$\begin{array}{l}\text { lack of adequate electricity/location of } \\
\text { power outlets }\end{array}$} \\
\hline \multicolumn{6}{|l|}{ poor Internet access speed } \\
\hline \multicolumn{6}{|l|}{$\begin{array}{l}\text { internet speeds are too slow to access } \\
\text { online software packages }\end{array}$} \\
\hline \multicolumn{6}{|l|}{$\begin{array}{l}\text { old facilities prevent upgrading to house } \\
\text { new technology (asbestos, lighting, } \\
\text { electricity, etc.) }\end{array}$} \\
\hline \multicolumn{6}{|l|}{ computer hardware is outdated } \\
\hline \multicolumn{6}{|l|}{$\begin{array}{l}\text { hardware purchases are predetermined by } \\
\text { state contracts }\end{array}$} \\
\hline \multicolumn{6}{|l|}{ insufficient amount of hardware } \\
\hline \multicolumn{6}{|l|}{ hardware purchased is not user friendly } \\
\hline \multicolumn{6}{|l|}{ software is too expensive } \\
\hline \multicolumn{6}{|l|}{ software titles are limited } \\
\hline \multicolumn{6}{|l|}{$\begin{array}{l}\text { software is not designed to track student } \\
\text { data }\end{array}$} \\
\hline \multicolumn{6}{|l|}{$\begin{array}{l}\text { newly purchased software will not } \\
\text { function correctly on current hardware } \\
\text { configurations }\end{array}$} \\
\hline \multicolumn{6}{|l|}{$\begin{array}{l}\text { technology grant requirements are too } \\
\text { difficult }\end{array}$} \\
\hline \multicolumn{6}{|l|}{$\begin{array}{l}\text { lack of funding to maintain the fast pace } \\
\text { of technological advances in hardware }\end{array}$} \\
\hline \multicolumn{6}{|l|}{$\begin{array}{l}\text { lack of funding for technical support } \\
\text { personnel }\end{array}$} \\
\hline lack of funding to upgrade Internet access & & & & & \\
\hline
\end{tabular}




\section{Appendix J}

Principal Perception Survey (p. 9)

Please mark if you Strongly Agree, Agree, Neutral, Disagree, or Strongly Disagree. Social Issues.

\begin{tabular}{|c|c|c|c|c|c|}
\hline $\begin{array}{l}\text { Social Issues } \\
\text { (2) }\end{array}$ & $\begin{array}{l}\text { Strongly } \\
\text { Agree }\end{array}$ & Agree & Neutral & Disagree & $\begin{array}{l}\text { Strongly } \\
\text { Disagree }\end{array}$ \\
\hline $\begin{array}{l}\text { technology causes great anxiety issues in } \\
\text { your building }\end{array}$ & & & & & \\
\hline $\begin{array}{l}\text { equal access to technology for everyone is } \\
\text { an issue in your school }\end{array}$ & & & & & \\
\hline
\end{tabular}

Please mark if you Strongly Agree, Agree, Neutral, Disagree, or Strongly Disagree.

Teacher and Student perceptions are defined as attitude toward technology and technology use.

\begin{tabular}{|c|c|c|c|c|c|}
\hline $\begin{array}{c}\text { Teacher and Student Perceived } \\
\text { Obstacles } \\
\text { (7) }\end{array}$ & $\begin{array}{l}\text { Strongly } \\
\text { Agree }\end{array}$ & Agree & Neutral & Disagree & $\begin{array}{l}\text { Strongly } \\
\text { Disagree }\end{array}$ \\
\hline \multicolumn{6}{|l|}{$\begin{array}{l}\text { teacher attitude toward technology is poor } \\
(* 2)\end{array}$} \\
\hline \multicolumn{6}{|l|}{ student attitude toward technology is poor } \\
\hline \multicolumn{6}{|l|}{$\begin{array}{l}\text { lack of access to technology for students } \\
\text { outside of school is a concern for } \\
\text { homework assignments }\end{array}$} \\
\hline \multicolumn{6}{|l|}{$\begin{array}{l}\text { lack of access to technology for teachers } \\
\text { outside of school inhibits productivity }\end{array}$} \\
\hline \multicolumn{6}{|l|}{$\begin{array}{l}\text { lack of time to teach technology to } \\
\text { students is an obstacle }\end{array}$} \\
\hline $\begin{array}{l}\text { teachers' attitude toward technology is } \\
\text { positive }\left({ }^{*} 2\right)\end{array}$ & & & & & \\
\hline
\end{tabular}

\begin{tabular}{llc} 
RQ & Domains & Items \\
\hline RQ1 & $3,4,5,6$ & 15 \\
RQ2 & 3 & 10 \\
RQ3 & $1,2,3,4,5,7,8$ & 21 \\
RQ4 & $1,2,7$ & 24 \\
Total & & 70
\end{tabular}


Appendix K (p. 1)

Figure 1: Research Question One, Data Analysis

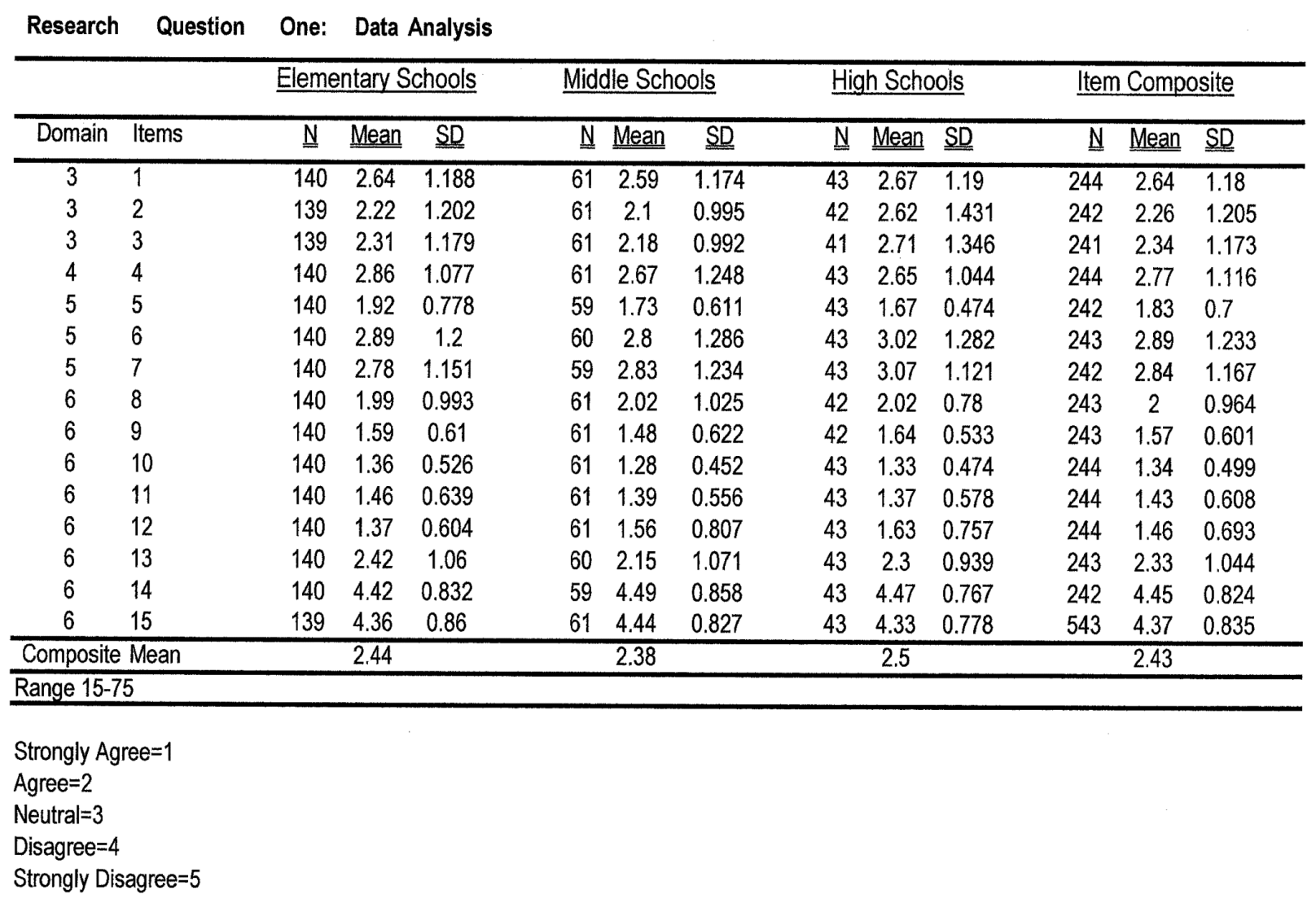

Figure 1. Research Question One: Data Analysis

This figure represents the mean and standard for each item of the domains listed. The four domains in this figure $(3,4,5$, and 6$)$ contain data to address research question one.

Elementary, middle, and high school level principals divide the figure. Also included is the composite of all three levels of principals for each item. $\mathrm{N}$ represents the total number of responses for each item. 
Appendix K (p. 2)

Figure 2: Research Question Two, Data Analysis

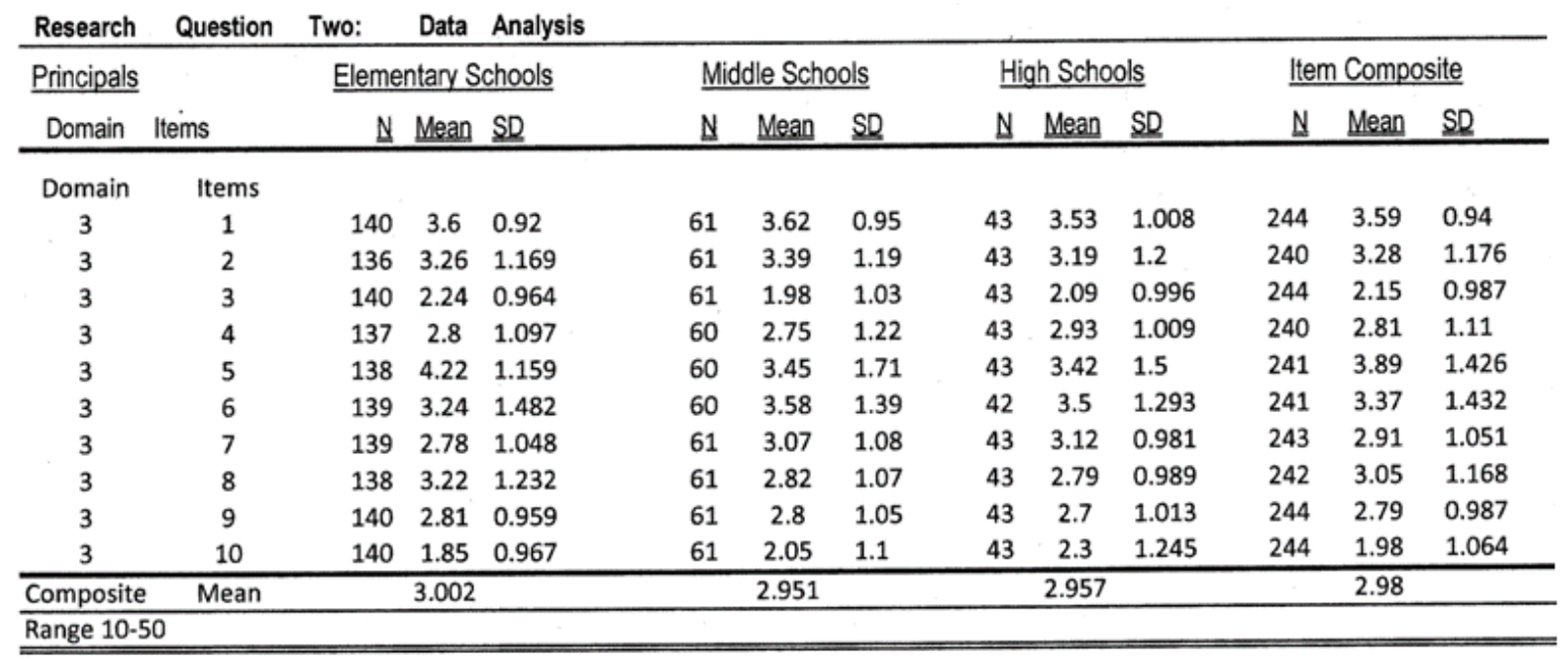

Figure 2. Research Question Two: Data Analysis

This figure represents the mean and standard for each item of the domain listed. The domain in this figure (3) contains data to address research question two. Elementary, middle, and high school level principals divide the figure. Also included is the composite of all three levels of principals for each item. $\mathrm{N}$ represents the total number of responses for each item. 


\section{Appendix K (p. 3)}

Figure 3: Research Question Three, Data Analysis

\begin{tabular}{|c|c|c|c|c|c|c|c|c|c|c|c|c|c|}
\hline \multirow{2}{*}{$\begin{array}{l}\text { Research } \\
\text { Principals }\end{array}$} & \multirow[t]{2}{*}{ Question } & \multirow[t]{2}{*}{ Three: } & \multirow{2}{*}{\multicolumn{2}{|c|}{$\begin{array}{c}\text { Data Analysis } \\
\text { Elementary Schools }\end{array}$}} & \multirow{2}{*}{\multicolumn{3}{|c|}{ Middle Schools }} & \multirow{2}{*}{\multicolumn{3}{|c|}{ High Schools }} & \multirow{2}{*}{\multicolumn{3}{|c|}{ Item Composite }} \\
\hline & & & & & & & & & & & & & \\
\hline Domain & Items & $\underline{\underline{N}}$ & Mean & $\underline{\mathrm{SD}}$ & $\underline{\underline{N}}$ & Mean & $\underline{\mathrm{SD}}$ & $\underline{\underline{N}}$ & Mean & $\underline{S D}$ & $\underline{\underline{N}}$ & Mean & $\underline{\underline{S D}}$ \\
\hline 1 & $\overline{1}$ & 135 & 3.56 & 0.967 & 55 & 3.69 & 1.034 & 40 & 3.75 & 0.84 & 230 & 3.62 & 0.962 \\
\hline 1 & 2 & 137 & 3.28 & 1.124 & 59 & 3.51 & 1.18 & 42 & 3.31 & 1.137 & 238 & 3.34 & 1.14 \\
\hline 2 & 3 & 134 & 1.7 & 0.614 & 60 & 1.65 & 0.547 & 43 & 1.72 & 0.549 & 237 & 1.69 & 0.584 \\
\hline 3 & 4 & 137 & 2.71 & 1.03 & 60 & 2.52 & 0.93 & 43 & 2.35 & 1.11 & 240 & 2.6 & 1.026 \\
\hline 3 & 5 & 136 & 2.99 & 1.202 & 59 & 2.78 & 1.084 & 42 & 2.52 & 1.11 & 237 & 2.86 & 1.166 \\
\hline 4 & 6 & 136 & 2.47 & 0.981 & 60 & 2.22 & 0.922 & 43 & 2.14 & 0.915 & 239 & 2.35 & 0.962 \\
\hline 4 & 7 & 136 & 2.19 & 0.83 & 59 & 2.14 & 0.819 & 43 & 2.02 & 0.831 & 238 & 2.15 & 0.826 \\
\hline 4 & 8 & 136 & 2.54 & 1.135 & 60 & 2.45 & 1.213 & 43 & 2.12 & 0.956 & 239 & 2.44 & 1.132 \\
\hline 4 & 9 & 136 & 3.24 & 1.124 & 60 & 3.23 & 1.031 & 43 & 3.05 & 1.174 & 239 & 3.2 & 1.108 \\
\hline 4 & 10 & 136 & 2.43 & 1.066 & 60 & 2.7 & 1.03 & 42 & 2.24 & 1.1 & 238 & 2.46 & 1.07 \\
\hline 5 & 11 & 135 & 2.22 & 0.861 & 58 & 2.19 & 0.888 & 43 & 2.23 & 0.922 & 236 & 2.22 & 0.875 \\
\hline 5 & 12 & 135 & 2.07 & 0.788 & 58 & 1.98 & 0.761 & 42 & 2 & 0.826 & 235 & 2.04 & 0.786 \\
\hline 7 & 13 & 136 & 4.03 & 0.877 & 60 & 3.97 & 1.057 & 43 & 4.12 & 0.823 & 239 & 4.03 & 0.914 \\
\hline 7 & 14 & 136 & 2.97 & 1.04 & 60 & 2.7 & 0.908 & 43 & 2.77 & 0.922 & 239 & 2.87 & 0.991 \\
\hline 7 & 15 & 136 & 2.23 & 0.825 & 60 & 1.88 & 0.64 & 43 & 1.88 & 0.662 & 239 & 2.08 & 0.771 \\
\hline 7 & 16 & 135 & 1.86 & 0.755 & 60 & 1.8 & 0.605 & 41 & 1.85 & 0.727 & 236 & 1.84 & 0.712 \\
\hline 8 & 17 & 137 & 2.06 & 0.338 & 60 & 2.1 & 0.44 & 43 & 2.09 & 0.426 & 240 & 2.08 & 0.381 \\
\hline 8 & 18 & 137 & 2 & 0 & 60 & 2 & 0 & 43 & 2 & 0 & 240 & 2 & 0 \\
\hline 8 & 19 & 137 & 2.22 & 0.627 & 60 & 2.13 & 0.503 & 43 & 2.14 & 0.516 & 240 & 2.18 & 0.578 \\
\hline 8 & 20 & 137 & 2.48 & 0.858 & 60 & 2.33 & 0.752 & 43 & 2.28 & 0.701 & 240 & 2.41 & 0.808 \\
\hline 8 & 21 & 136 & 3.47 & 0.886 & 60 & 3.7 & 0.72 & 43 & 3.58 & 0.823 & 239 & 3.55 & 0.838 \\
\hline Composite & Mean & & 2.6 & & & 2.55 & & & 2.48 & & & 2.57 & \\
\hline
\end{tabular}

Figure 3. Research Question Three, Data Analysis

This figure represents the mean and standard for each item of the domains listed. The seven domains in this figure $(1,2,3,4,5,7$, and 8$)$ contain data to address research question three. Elementary, middle, and high school level principals divide the figure. Also included is the composite of all three levels of principals for each item. N represents the total number of responses for each item. 
Appendix K (p.4)

Figure 4: Research Question Four, Data Analysis

\begin{tabular}{|c|c|c|c|c|c|c|c|c|c|c|c|c|c|}
\hline Research & Question & Four: & Data & Analysis & & & & & & & & & \\
\hline \multirow{2}{*}{$\frac{\text { Principals }}{\text { Domain }}$} & \multirow[b]{2}{*}{ Items } & \multicolumn{3}{|c|}{ Elementary Schools } & \multicolumn{3}{|c|}{ Middle Schools } & \multicolumn{3}{|c|}{ High Schools } & \multicolumn{3}{|c|}{$\underline{\text { Item Composite }}$} \\
\hline & & $\underline{\underline{N}}$ & Mean & $\underline{\mathrm{SD}}$ & $\underline{N}$ & Mean & $\underline{\underline{S D}}$ & $\underline{\underline{N}}$ & Mean & $\underline{\underline{\mathrm{SD}}}$ & $\underline{\underline{N}}$ & Mean & $\underline{\underline{S D}}$ \\
\hline 1 & 1 & 134 & 2.62 & 1.261 & 58 & 2.74 & 1.319 & 41 & 3.12 & 1.364 & 233 & 2.74 & 1.302 \\
\hline 1 & 2 & 136 & 3.05 & 1.243 & 59 & 2.83 & 1.341 & 41 & 3.02 & 1.255 & 236 & 2.99 & 1.268 \\
\hline 1 & 3 & 135 & 3.21 & 1.174 & 59 & 2.85 & 1.35 & 41 & 3.29 & 1.23 & 235 & 3.14 & 1.236 \\
\hline 1 & 4 & 135 & 2.94 & 1.303 & 59 & 3.03 & 1.313 & 41 & 3.39 & 1.358 & 235 & 3.04 & 1.32 \\
\hline 1 & 5 & 136 & 3.38 & 1.068 & 59 & 3.12 & 1.084 & $41^{\prime}$ & 3.24 & 1.261 & 236 & 3.29 & 1.109 \\
\hline 1 & 6 & 136 & 2.61 & 1.117 & 58 & 2.47 & 1.012 & 40 & 2.55 & 1.108 & 234 & 2.56 & 1.087 \\
\hline 1 & 7 & 136 & 3.19 & 1.139 & 58 & 2.83 & 1.172 & 41 & 2.88 & 1.208 & 235 & 3.05 & 1.167 \\
\hline 1 & 8 & 136 & 3.52 & 0.966 & 59 & 3.44 & 0.933 & 41 & 3.41 & 1.072 & 236 & 3.48 & 0.974 \\
\hline 1 & 9 & 136 & 2.72 & 1.052 & 58 & 2.31 & 1.012 & 41 & 2.73 & 0.975 & 235 & 2.62 & 1.04 \\
\hline 1 & 10 & 136 & 3.18 & 0.983 & 58 & 2.83 & 0.958 & 41 & 3.12 & 1.1 & 235 & 3.09 & 1.005 \\
\hline 1 & 11 & 134 & 3.38 & 0.987 & 59 & 2.98 & 1.106 & 41 & 3.32 & 0.934 & 234 & 3.27 & 1.019 \\
\hline 1 & 12 & 135 & 3.28 & 1.012 & 59 & 3 & 1.017 & 41 & 3.2 & 1.167 & 235 & 3.2 & 1.044 \\
\hline 1 & 13 & 135 & 2.68 & 1.034 & 58 & 2.45 & 0.976 & 41 & 2.66 & 0.965 & 234 & 2.62 & 1.009 \\
\hline 1 & 14 & 136 & 2.29 & 1.06 & 59 & 2.12 & 1.068 & 41 & 2.22 & 1.084 & 236 & 2.23 & 1.064 \\
\hline 1 & 15 & 134 & 1.98 & 1.051 & 58 & 1.9 & 1.038 & 41 & 2.15 & 1.195 & 233 & 1.99 & 1.073 \\
\hline 1 & 16 & 135 & 2.76 & 1.16 & 59 & 2.54 & 1.291 & 41 & 2.71 & 1.123 & 235 & 2.7 & 1.187 \\
\hline 2 & 17 & 135 & 3.28 & 1.083 & 59 & 3.15 & 1.172 & 41 & 3.41 & 1.072 & 235 & 3.27 & 1.103 \\
\hline 2 & 18 & 135 & 3.52 & 1.139 & 59 & 3 & 1.352 & 40 & 3.23 & 1.165 & 234 & 3.34 & 1.216 \\
\hline 7 & 19 & 136 & 4 & 0.826 & 59 & 3.98 & 0.841 & 41 & 4.02 & 0.689 & 236 & 4 & 0.804 \\
\hline 7 & 20 & 136 & 4.35 & 0.694 & 59 & 4.46 & 0.567 & 41 & 4.37 & 0.488 & 236 & 4.38 & 0.631 \\
\hline 7 & 21 & 136 & 2.24 & 0.962 & 59 & 2.24 & 0.916 & 41 & 2.32 & 1.011 & 236 & 2.25 & 0.956 \\
\hline 7 & 22 & 136 & 3.35 & 1.085 & 59 & 3.37 & 1.065 & 41 & 3.34 & 1.175 & 236 & 3.36 & 1.092 \\
\hline 7 & 23 & 136 & 2.34 & 1.056 & 59 & 2.64 & 1.156 & 41 & 2.9 & 1.179 & 236 & 2.51 & 1.12 \\
\hline 7 & 24 & 135 & 1.9 & 0.715 & 58 & 1.9 & 0.852 & 41 & 2.07 & 0.787 & 234 & 1.93 & 0.763 \\
\hline Composite & & & 2.99 & & & 2.84 & & & 3.0279 & & & 2.96 & \\
\hline
\end{tabular}

Figure 4: Research Question Four, Data Analysis

This figure represents the mean and standard for each item of the domains listed. The three domains in this figure $(1,2$, and 7$)$ contain data to address research question four. Elementary, middle, and high school level principals divide the figure. Also included is the composite of all three levels of principals for each item. $\mathrm{N}$ represents the total number of responses for each item. 


\section{Author Note}

David W. Agnew, College of Human Resources and Education, West Virginia University. Correspondence concerning this paper should be addressed to David W. Agnew, College of Human Resources and Education, West Virginia University, Allen Hall, P.O. Box 6122, Morgantown, WV 26506-6122. E-mail: Dagnew1@frontier.com 